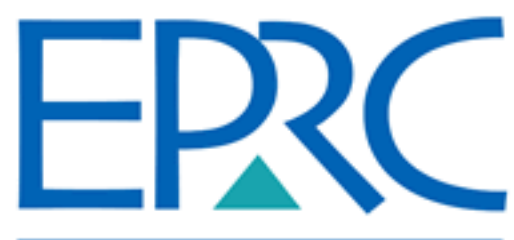

EUROPEAN POLICIES

RESEARCH CENTRE

\title{
The Micro-efficiency of EU Cohesion Policy
}

\section{Peter Wostner}

\author{
J une 2008 \\ European Policy Research Paper \\ Number 64
}

Published by:

European Policies Research Centre

University of Strathclyde

40 George Street

Glasgow G1 1QE

United Kingdom

ISBN: $1-871130-70-0$ 


\section{University of
Strathclyde Glasgow}

\section{European Policies Research Centre \\ University of Strathclyde \\ 40 George Street \\ Glasgow G1 1QE}

Tel: +44 1415483339

Fax: +44 1415484898

Author email:

peter.wostner@gov.si 


\title{
The Micro-efficiency of EU Cohesion Policy ${ }^{1}$ Peter Wostner ${ }^{2}$
}

\begin{abstract}
Cohesion policy micro-efficiency is determined by the institutional or absorption capacity of recipient regions and Member States. This, in turn, co-determines the policy's macro-economic impact. The analysis shows that Cohesion policy is not perceived as an "EU receipts maximising instrument", but instead that it is understood as a means to the set objectives, i.e. that it is about the genuine impact. At the same time, however, the analysis also shows that proper change to implementation systems is needed. The paper puts forward four proposals for improvements. The most radical of them, the 'coordinated full decentralisation' option, conceives Cohesion policy as a bulk transfer of investment-conditioned financial resources, where full responsibility for the legality, regularity, efficiency and effectiveness would be entirely transferred to the Member States/regional level while, at the same time, preserving Cohesion policy as a genuine European policy. The analysis reveals that the subsidiarity principle is still not taken into account to a satisfactory degree, that experience and political context have significant influence on the (optimal) design of implementation systems and finally that, on average, there seems to be merit in concentration both with regard to the number of operational programmes (less so for their thematic focus) as well as to the number of institutions involved in the implementation systems, horizontally and especially vertically.

Keywords: EU, Cohesion policy, Regional policy, Absorption capacity, Implementation systems
\end{abstract}

J EL Classification codes: D73, D78, E61, R58, 023, H77

\footnotetext{
${ }^{1}$ The paper represents part of the PhD thesis on the 'The rationale and effectiveness of EU Cohesion policy', which the author is preparing at the Faculty of Economics, University of Ljubljana. Comments and suggestions are very welcome and should be sent to peter.wostner@gov.si

${ }^{2}$ Works at the Government Office for Local Self-Government and Regional Policy (GOSP), Republic of Slovenia, Kotnikova 28, $1000 \mathrm{Lj}$ ubljana. Views expressed in the paper are exclusively those of the author and do not necessarily correspond to those of the GOSP.
} 


\section{TABLE OF CONTENTS}

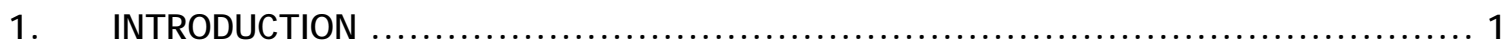

2. THEORETICAL AND EMPIRICAL CONSIDERATIONS $\ldots \ldots \ldots \ldots \ldots \ldots \ldots \ldots \ldots \ldots \ldots \ldots \ldots \ldots$

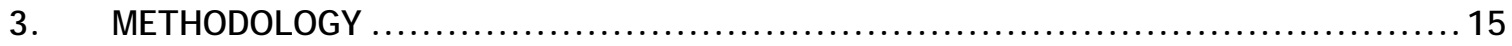

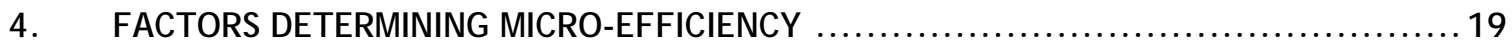

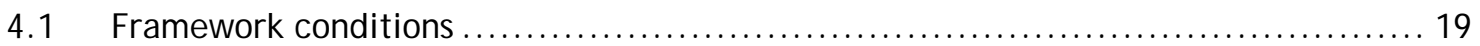

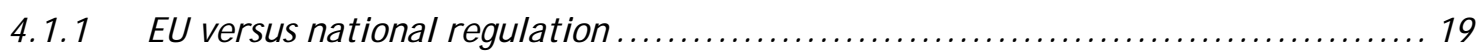

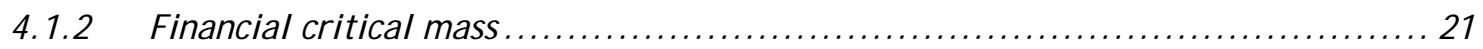

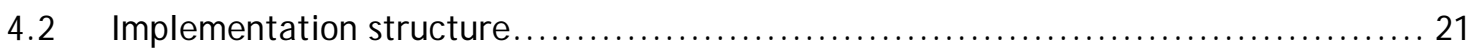

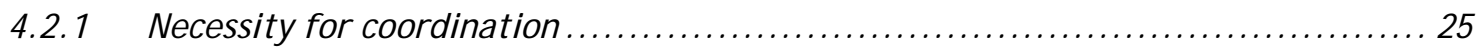

4.2.2 How many institutions should be involved? .................................. 27

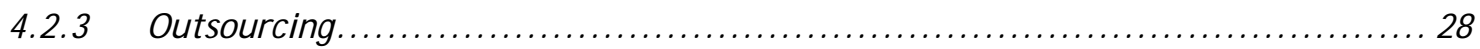

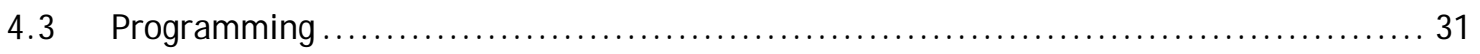

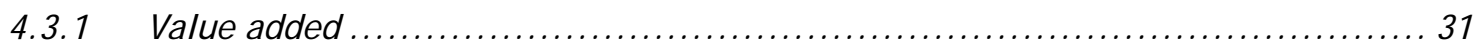

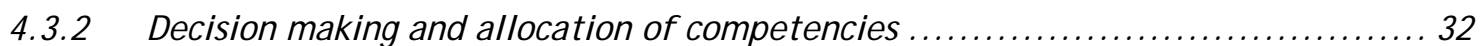

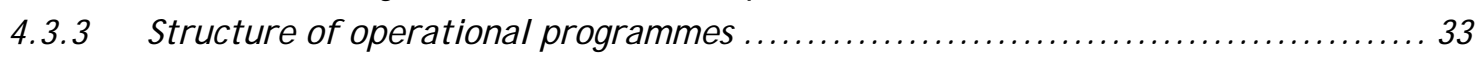

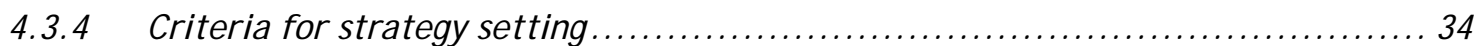

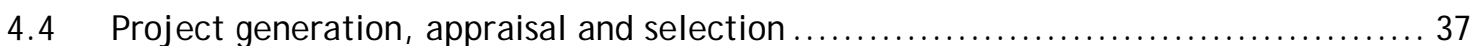

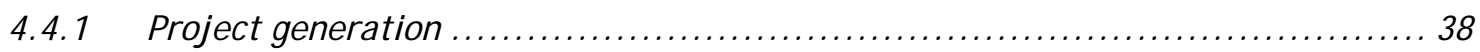

4.4.2 Allocating money to intermediaries......................................... 40

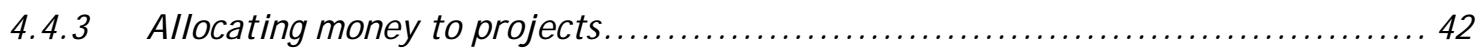

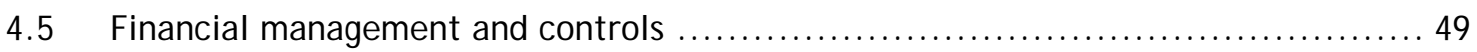

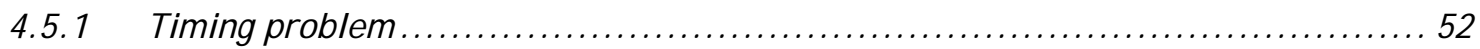

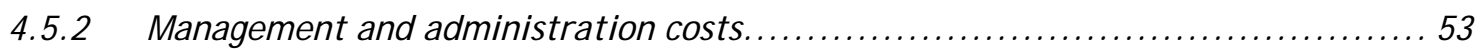

4.5.3 Legality \& regularity vs. efficiency $\&$ effectiveness: the right balance $\ldots \ldots \ldots \ldots . \ldots 5$

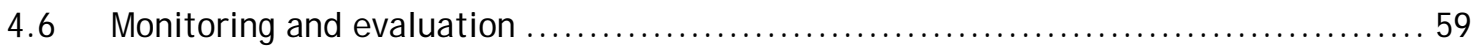

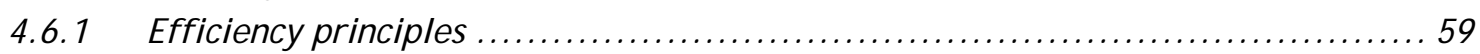

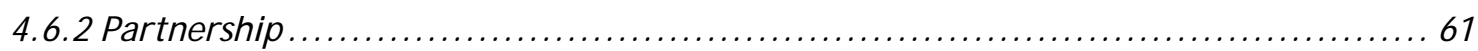

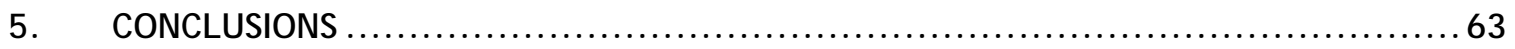

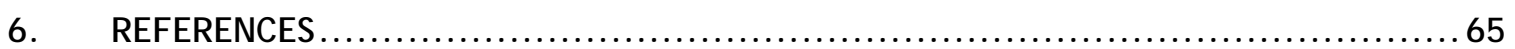

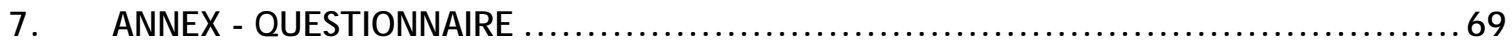




\section{LIST OF TABLES}

Table 1: Factors and implementation mechanisms as identified in ÖIR study $\ldots \ldots \ldots \ldots \ldots \ldots \ldots . \ldots$

Table 2: Key indicators for Candidate Countries to effectively manage the Structural Funds ...... 9

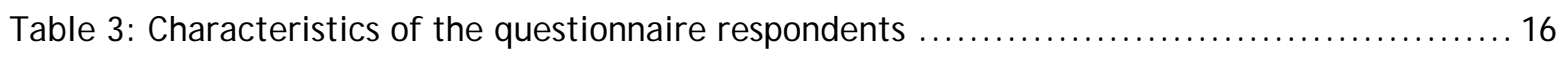

Table 4: Advantages and disadvantages of differentiated and subsumed systems $\ldots \ldots \ldots \ldots \ldots 23$

Table 5: Advantages and disadvantages of project selection $\ldots \ldots \ldots \ldots \ldots \ldots \ldots \ldots \ldots \ldots \ldots, 42$

Table 6: Advantages and disadvantages of financial management and control systems .......... 51

\section{ABBREVIATIONS}

$\begin{array}{ll}\text { ERDF } & \begin{array}{l}\text { European Regional Development Fund } \\ \text { ESF }\end{array} \\ \text { EU } & \text { European Social Fund } \\ \text { General regulation } & \begin{array}{l}\text { Council Regulation (EC) No } 1083 / 2006 \text { of } 11 \text { J uly } 2006 \text { laying down } \\ \text { general provisions on the European Regional Development Fund, the } \\ \text { European Social Fund and the Cohesion Fund and repealing Regulation } \\ \text { (EC) No 1260/ 1999 }\end{array} \\ \text { IB } & \begin{array}{l}\text { Intermediate Body } \\ \text { MA }\end{array} \\ \text { OP } & \text { Managing Authority } \\ \text { SF } & \text { Structural Funds }\end{array}$




\section{EXECUTIVE SUMMARY}

There is a growing body of literature reviewing the macro-effectiveness of Cohesion policy, whose, admittedly mixed conclusions, nevertheless give a strong signal that Cohesion policy impact is conditional on good management practices or, more generally, on the institutional or absorption capacity of the recipient regions and Member States. Absorption capacity thus seems to determine what we call the micro-efficiency of the policy. This is the focus of this paper, with the ambition systematically to identify those institutional arrangements at every step of the policy cycle which contribute to an efficient and effective Cohesion policy implementation system. Ultimately, the findings could possibly be used both to improve the implementation systems, as well as for the reform of the regulatory framework in which Cohesion policy operates.

The systematic analysis of the paper makes use of existing evaluations and complements them with the conclusions from an extended EU-wide questionnaire, which was prepared specifically as a basis for this paper. The questionnaire has been structured around the standard phases of the policy cycle and, for each phase a critical assessment has been made of present practices. This often required preparation of relevant typologies, due to different practices in different systems. On this basis, it has been possible to survey respondents' views on how implementation systems could be made more efficient and effective. The questionnaire has been completed only by people who have direct experience of Cohesion policy management. Research undertaken has also benefited from the author's first-hand experience of Cohesion policy management, as he was directly responsible for the Structural and Cohesion Funds implementation in the Slovenian Managing Authority.

The results on the criteria that need to be taken into account when devising a strategy for the use of Cohesion policy resources, indicate that this policy is not perceived as an "EU receipts maximising instrument", but instead that Cohesion policy is understood as a means for delivering set objectives, i.e. about the genuine impact which the operational programmes have been devised to bring. However, the implementation systems, according to the respondents, not only need simplification, but proper change. The reasons for such a conclusion are not based only on the findings by the European Court of Auditors, which has reported control failures in all of the audited programmes, but also on the following arguments: (a) the time needed from project idea to project start in a modern, globalized world is unacceptably long; in fact, time management in general represents a fundamental weakness of Cohesion policy implementation systems; (b) there is universal agreement that the system is over-controlled, which holds true both at the national as well as EU levels; and (c) the management costs on the side of administration and project holders were estimated to be as high as $15 \%$ of total costs, which would translate to a soaring $€ 61$ billion over the period of the financial perspective and potential savings of $€ 4$ billion for every percentage point reduction in administration costs. Before looking at the possible improvements put forward in the paper, it is worth mentioning that the respondents attribute $55 \%$ of all administrative procedures to the EU legislation and requirements. Thus, even though the recipient Member 
States and regions clearly bear major responsibility for designing the administrative procedures which are streamlined, straightforward and adapted to the needs of beneficiaries, reform is clearly needed also at the EU level.

The possible improvements are presented in the order of the extent to which they could improve the system. However, this is simultaneously inversely correlated with the ease with which reforms could be introduced.

- Among the milder improvements to the system is a significantly more extended use of the proportionality principle. It has been demonstrated that smaller projects tend to be more demanding in terms of management requirements and are thus associated with a greater administrative burden per monetary unit spent. In turn, this translates into staffing costs not being dependent on funding levels, but on the number of projects instead. This principle has already been introduced in the Regulations (Art. 13 of the Regulation No. 1083/2006), but it is still rather unclear how extensively it will be used or rather how extensively the control and audit institutions will allow it to be implemented.

- The second possible change is an 'augmented strategy based on administrative costs'. Taking into account that the administrative costs of (for example) ESF type operations are, on average, almost twice as high as Cohesion Fund operations, that the EU instruments are significantly more administratively-demanding than national ones, and that Cohesion policy resources only represent a limited share of total public capital expenditures, the Cohesion policy impact could be improved by re-focusing the EU resources on operations which are cheaper to implement, while the rest would be financed through national policies only. Such commitment could be contract-based or established on the basis of the open method of coordination approach.

- Third, 'overcontrol' and rigid interpretations of the regulations are also the result of the manner in which controls and audits are performed - i.e. increasingly risk-averse practices, combined with uncoordinated institutions, tend to give rise to practices that put more focus on procedures rather than on content. Thus, new agreement is needed among all the stakeholders on how Cohesion policy will be implemented; the institution of 'contracts of confidence' could (amongst others) be used for such a change. At the same time, it is possible that contracts of confidence could, in practice, make national control and audit institutions even more, not less, rigid. As a result this instrument could also work to the detriment of increased efficiency. There are reasons, however, to expect that the possible improvements based on the this approach, which in principle could be introduced immediately, would be limited, due to the restrictive provisions set by Cohesion policy's regulatory environment. Thus a more significant departure from the present concept of how Cohesion policy is implemented could be conceived, whereby disbursement of funds would be based on agreed outcomes and results instead of on verification of invoices. 
- Lastly, a possibly complementary, and more fundamental approach to reform would be to reduce the number of institutions involved in Cohesion policy, and to address the multi-level governance problem head-on. A 'coordinated full decentralisation' option would conceive Cohesion policy as a bulk transfer of investment-conditioned financial resources, where full responsibility for the legality, regularity, efficiency and effectiveness would be entirely transferred to the Member State/ regional level. The EU perspective would continue to be ensured through a very strategic 'programme', prepared by the recipient areas and agreed with the European Commission. Furthermore, the European Commission would continue to monitor the progress made by the Member States (e.g. on the basis of core indicators and financial indicators), which would allow monitoring and evaluation of the Cohesion policy impact as a whole. Such an approach would preserve Cohesion policy as a genuine European policy, but would, at the same time, radically reduce Cohesion policy administration costs, without any detriment to the effectiveness of the resources used.

In fact, it could be argued both on theoretical grounds, as well as on the answers of the questionnaire respondents, that the impact of Cohesion policy under the coordinated full decentralisation option would actually improve. According to the questionnaire research, the subsidiarity principle is currently not taken into account to a satisfactory degree, and this holds true both for the EU vs. Member States relationship, as well as for the national vs. regional level relationship, the latter only in the EU12, while in the EU15 the present balance is considered to be more or less optimal. In fact, the respondents still attribute $48 \%$ of the decision-making power on operational programmes to the European Commission, while their optimal share is considered to be a much lower $29 \%$ which gives a strong signal for further decentralisation of decision-making power. In a similar vein, there seems to be overwhelming support for additional decentralisation of project-level decision-making in the EU12 to the regional level, where the respondents (on average) considered the optimal relationship between the national and regional level to be 50:50; currently only $35 \%$ of the project decisionmaking is attributed to the regional level.

The analysis also reveals that experience and political context matter. Even though separate coordination could prove to be ineffective for self-standing policies, the newly introduced systems need a strong coordinating institution, with significant decision-making powers for whatever the policy in question. With time, when the system and relationships among institutions become standardised and well established, there seems to be greater scope for a loosening of central coordination. The learning period also seems to be very important for the improved efficiency of the public administration managing the funds, as EU12 Member States see public administrations as a much more pronounced problem than do the EU15 Member States. Countries and regions with longer experience, better know-how, as well as longer democratic traditions and therefore greater trust in politics, seem to accept more subjectivity in the project selection processes, i.e. they are more conducive to open calls, which allow for more innovation and less administratively intensive procedures. Where this is not the case, preference seems to be given to stricter, more quantified approaches, where the political 
sphere has less room for intervention. This is particularly obvious for strategic project selection processes, which should be used only in cases where the project is 'quasi-monopolised' in nature (either because of the nature of the activity or because of the single possible beneficiary) or where successful project implementation requires such a broad scope of partners that the competition would be meaningless or that the administrative costs would be prohibitive. Furthermore, there seems to be a universally low approval rate for decision-making based on direct government decision, while the EU12 Member States generally do not seem to trust single authorities, as they seem to see greater assurance in broader institutional involvement in the appraisal process.

Finally, on average, there seems to be merit in concentration both with regard to the number of operational programmes (less so for their thematic focus) and the number of institutions involved in the implementation systems, horizontally and, especially, vertically. Nevertheless, there seem to be three horizontal guiding principles which contribute to the efficiency of any implementation system: first, the implementation systems need to allow and promote flexibility and adaptability to changed circumstances, as well as new, innovative approaches in particular policy fields, i.e. a managing authority needs to retain the jurisdiction and mechanism to reallocate the money to new instruments or new intermediate bodies; second, an incentive mechanism that promotes competition and thus allocates money to the bestperforming intermediate bodies is clearly conducive to efficiency; and lastly, the intermediate bodies to which the money is allocated need to be accountable and need the proper institutional capacity to implement the activities entrusted to them by the managing authority, which requires careful contracting. 


\section{The Micro-efficiency of EU Cohesion Policy}

\section{INTRODUCTION}

The regional policy of the European Union, commonly termed Cohesion policy, has an overall budget of $€ 347$ billion (in current prices) for the period 2007-2013, representing approximately $35.6 \%$ of the overall budget. Yet, in terms of GDP, the foreseen spending allocations are actually diminishing so that the gap with the peak year of 1999, when almost $0.5 \%$ of GDP was spent on this policy, looks quite large. Considering the 2004 and 2007 enlargement to include the significantly less-developed EU12 Member States, this is a somewhat surprising trend, although improved convergence trends on the level of the Member States could represent an argument that the allocated resources are in fact sufficient to start a virtuous cycle of economic development in the lagging regions and Member States.

Given the severe public finance constraints, increasing attention has been put on the actual effectiveness of Cohesion policy. Admittedly, the European Commission itself has given the evaluation of the policy very high priority, rendering the evaluation principle one of the building blocks of Cohesion policy. This has been the case since the substantial reform in 1989, but further attention is being given to this area in the 2007-2013 period. Due to a strengthened decentralisation of responsibilities from the EU level to the Member States on the basis of the so-called 'strategic approach', which means delegation of daily management issues to the Member States and only strategic issues to be dealt with on the EU level, the importance of evaluation will, almost by definition, increase further still. It is on this basis that the Commission intends to defend its role as the 'caretaker of the EC budget' (Art. 274 of the Treaty) and also be able to report on the policy's results to the European Parliament.

There is a growing body of literature looking at the macro-effectiveness of Cohesion policy; the conclusions, however, are by no means straightforward. The conclusions are, to an important degree, conditioned by the research methodology used, as well as by the time period and Member States under investigation (Ederveen et al, 2006, Bradley, forthcoming). There seems to be consensus, however, that the impact is conditional on good management practices or, more generally, on the institutional or absorption capacity of the recipient regions and Member States. Absorption capacity thus seems to determine the so-called efficiency of the policy on the micro-level, which is also the focus of this paper. Absorption capacity is a broader concept than administrative absorption capacity as put forward by Boot, de Vet and Feekes (2002) and further developed by Mrak and Wostner (2004), as it refers to the quality of the whole development policy cycle (Fitzgerald and Promé, 1996): from planning to project generation and selection, to implementation, monitoring and evaluation of development activities. Administrative absorption capacity by public administration, on the other hand, refers only to handling the EU resources and, on the part of recipients, to their ability to fulfil the administrative requirements for making eligible expenditure and therefore public co-financing. 
There is limited research into what exactly micro-level efficiency refers to and especially what it depends on. On the one hand, there are quite a large number of evaluations which focus on analysis and recommendations of particular circumstances of particular regions. There is a widespread conviction that there is "no single, universally applicable model that holds true for all cases and situations" (ÖIR, 2003: 21). These evaluations are, therefore, looking for efficiency improvements on the basis of particular implementation system problems and possible threats. There has been less insight, however, into the systematic properties of the Cohesion policy implementation systems in general. This is the focus of this paper, whose ambition is to identify systematically those institutional arrangements at every step of the policy cycle, which contribute to an efficient and effective Cohesion policy implementation system.

This paper is structured as follows. After this introduction, the second section presents the relevant studies and evaluations, which address both theoretically and empirically the issue of the micro-efficiency of Cohesion policy. It starts with more general studies, proceeds with the more specific presentation of the absorption capacity concept and then continues with the presentation of more detailed studies. Section three presents the methodology of the paper. A step-by-step, detailed analysis can be found in Section four on 'factors determining micro-efficiency'. This section first presents the framework conditions for the implementation of Cohesion policy, as well as the choices that Member States and regions are faced with as far as general structuring of the implementation systems is concerned. This is followed by the analysis of efficiency factors in each phase of the policy cycle: programming, project generation, appraisal and selection, financial management and controls and monitoring and evaluation. Section five concludes the paper. 


\section{THEORETICAL AND EMPIRICAL CONSIDERATIONS}

One of the most comprehensive analyses in the field is a study prepared in the framework of the Third Report on Economic and Social Cohesion, commissioned by European Commission, DG Regional Policy and performed by ÖIR in association with LRDP and IDOM in 2003. The study's focus was to "explore implementation processes and .... to identify what works well and why and what unnecessary complexities could be simplified" (ÖIR, 2003: 7). It is based on 153 in-depth interviews with people responsible for Structural Funds implementation in 18 case-study regions, all of which were from the EU15. The authors recognised that, in spite of the same set of rules on the European level, the actual delivery mechanisms vary significantly both among different Members States, and even among regions within the same Member States.

For this purpose, a common methodology was used ${ }^{3}$, which focused on three sets of socalled macro-factors that, in the author's opinion, critically determined the efficiency of the implementation systems. These are: (a) actors; (b) context and rules; and (c) procedures and systems. Through a systematic procedure under each of these macrofactors, more specific and particular factors and implementation mechanisms were identified as presented in Table 1.

For each of the factors, a quantitative assessment of the impact was determined on the basis of the interviews. These focused on:

a) identification of the direction of impact on efficiency of the Structural Funds (positive / negative); and

b) identification of the intensity of impact (low / high).

In order to take account of different case study contexts, additional indicators (statements) were identified. For each of these indicators, the evaluator assigned one of the 4 values ( 0 , $0.25,0.5$ or $1.0^{4}$ ), where 0 means that the indicator has not been achieved and 1 means that it was fully achieved.

This comprehensive analysis will serve as an excellent benchmark for our own analysis since the two are complementary. The ÖIR study focuses, first, on the identification of critical factors that influence efficiency of the Structural Funds implementation systems and secondly, it wants to recognise the actual situation in the regions. During the interviews, of course, attention was also given to how the systems should be improved, but this was not systematically quantified. This will serve as an excellent basis for our study since its focus

\footnotetext{
3 This is itself based on a method developed by the Instituto per lo sviluppo della formazione professionale dei lavoratori (ISFOL), ESF Evaluation unit in Italy.

${ }^{4}$ It is not clear or explained why also the value 0.75 was not foreseen.
} 
is particularly on the optimal institutional / administrative arrangements most conductive to efficient implementation of the Structural Funds.

Table 1: Factors and implementation mechanisms as identified in the ÖIR study

\begin{tabular}{|c|c|c|}
\hline Actors & Context & $\begin{array}{c}\text { Rules, Procedures \& Technical } \\
\text { Support }\end{array}$ \\
\hline $\begin{array}{l}\text { 1. The Commission - Policies, } \\
\text { Priorities and Organisation }\end{array}$ & 11. Political Context & $\begin{array}{l}\text { 17. Measures to implement EU } \\
\text { Regulations and Procedures }\end{array}$ \\
\hline $\begin{array}{l}\text { 2. National Government - Policies, } \\
\text { Priorities and Organisation }\end{array}$ & 12. Socio-Economic context & 18. Programming \\
\hline $\begin{array}{l}\text { 3. Regional/ Federal Government - } \\
\text { Policies, Priorities and Organisation }\end{array}$ & 13. Administrative Structures & 19. Management Procedures \\
\hline $\begin{array}{l}\text { 4. Monitoring Committees - Policies, } \\
\text { Priorities and Organisation }\end{array}$ & 14. Institutional Structures & $\begin{array}{l}\text { 20. Control Systems and } \\
\text { Procedures }\end{array}$ \\
\hline $\begin{array}{l}\text { 5. Managing Authorities - } \\
\text { Organisation }\end{array}$ & 15. Forms of Intervention & $\begin{array}{l}\text { 21. Development and use of } \\
\text { monitoring system }\end{array}$ \\
\hline 6. Paying Authorities - Organisation & 16. Future of EU - Enlargement & $\begin{array}{l}\text { 22. Development and use of } \\
\text { evaluation system }\end{array}$ \\
\hline $\begin{array}{l}\text { 7. Implementing Bodies - } \\
\text { Organisation }\end{array}$ & & $\begin{array}{l}\text { 23. Assessment and selection of } \\
\text { Projects }\end{array}$ \\
\hline 8. Beneficiaries - Organisation & & 24. Financial Procedures \\
\hline $\begin{array}{l}\text { 9. Social Partners - Priorities, } \\
\text { organisation }\end{array}$ & & 25. Partnership \\
\hline \multirow[t]{5}{*}{ 10. External Experts - reports } & & 26. Coordination \\
\hline & & $\begin{array}{l}\text { 27. Measures to ensure } \\
\text { Information and Publicity }\end{array}$ \\
\hline & & $\begin{array}{l}\text { 28. Relationships between MA } \\
\text { and Implementing Bodies }\end{array}$ \\
\hline & & 29. Technical Assistance \\
\hline & & $\begin{array}{l}\text { 30. Other monitoring activities of } \\
\text { programme implementation }\end{array}$ \\
\hline
\end{tabular}

Source: ÖIR 2003: 30

The main ÖIR studies findings in terms of positive Structural Funds implementation system features are the following (what has worked well):

i. The programming process is of significant value in the generation of harmonised development strategies between central and regional authorities. 
ii. The management structures that have been put in place to support the implementation process.

iii. The use of specialist intermediary bodies for project implementation. The use of global grants has greatly enhanced the efficiency of Funds utilisation in a manner that is appropriate for local and regional development needs.

iv. The use of ex-ante and mid-term evaluations is seen as greatly enhancing the efficiency and effectiveness of the implementation process. The trend towards the use of 'ongoing evaluations' is seen as a useful approach.

v. Provisions for the disbursement of funds on the basis of payments made rather than commitments is seen as increasing the absorption rates within the programmes.

On the negative side, the following critical elements were recognised (what has not worked).

i. The long approval process for programming documents.

ii. While there is universal agreement about the need for monitoring as an important dimension to accountability, there is little evidence that the outcomes of the monitoring system are being fed back into the management process.

iii. Financial flows are considered to be very long and complex. This is frequently not a result of the regulations themselves but rather to national and regional interpretation of these regulations.

iv. Financial control mechanisms are characterised as being risk averse in the extreme, with no built-in risk management model.

v. The $7 \%$ advance of funds is seen as too little and too slow by project promoters. This reflects more on the transfer of funds within the Member States and regions than from the Commission to the Member State.

vi. There is evidence of the existence of double accounting systems in a number of regions.

vii. There are too many audits of a very exhaustive nature from a variety of different actors.

viii. The application of the $\mathrm{N}+2$ rule in an indiscriminate way is seen as working against innovation and quality. There is a need for flexibility with regard to these. Examples would include transnational and interregional projects, involving partners from a number of different States and regions, requiring significant coordination and adaptation to different political, legal, administrative contexts.

ix. Proportionality is an issue at programme and project level; implementation rules are applied in the same way for large programmes and large projects as for small ones. 
$x$. The completion of the previous programming periods is seen as taking too long, and the ex post evaluation is of no use in preparing for the following period.

xi. There is not enough attention paid to providing project promoters with easily understandable information on the process and educating them to be able to take full advantage.

The analysis by Boot et al, 2001, is the first systematically to put forward the notion of absorption capacity. It has defined it as "the extent to which a member state is able to fully spend in an effective and efficient way the allocated financial resources from the Structural Funds" (Boot et al, 2001: 11). On this basis three more specific factors of absorption capacity have been established.

1. The macroeconomic absorption capacity, which would be defined and measured in terms of GDP;

2. The managerial-administrative absorption capacity which refers to the abilities and skills of central, regional and local authorities to prepare acceptable plans, programmes, and projects in due time, to decide on programmes and projects, to arrange the co-ordination among the principal partners, to cope with the vast amount of administrative and reporting paperwork required by the Commission, and to finance and supervise implementation properly, avoiding fraud as far as possible.

3. The financial absorption capacity, which refers to the ability to co-finance EU supported programmes and projects, to plan and guarantee these national contributions in multi-annual budgets, and to collect these contributions from several partners involved in a programme or project.

Along the same lines Mrak and Wostner (2004) further developed the concept of administrative capacity. In particular, they have specified more precisely the necessary conditions to ensure disbursement of EU funds to the recipient regions / Member States. They put forward the following factors. 


\section{1.) Real absorption capacity}

1.a) Real needs according to the set objectives and international commitments made

1.b) Availability of production factors for identifying, organising and implementing projects and programmes

\section{2.) Financial absorption capacity}

2. a) Co-financing capacity of the recipients of funds

2.b) Capacity of the Member State for public co-financing

\section{3.) Programme / project absorption capacity}

3.a) Relevance of the strategy and programme bases (national and EU) according to real needs - from point 1.

3.b) Adequacy of concrete implementing instruments

3.c) Preparation of project documentation

\section{4.) Administrative absorption capacity}

4. a) Capacity for preparing and implementing administrative work by or for applicants

4.b) Administrative capacity of public administration

Real absorption capacity depends on the real investment needs to reach the objectives set, as well as fulfil international commitments made, where particular account is given to: (i) needs defined in real terms only in part where their fulfilment promotes development, competitiveness and where public intervention is justified; (ii) set objectives, i.e. social, business and individual objectives, which have to be feasible; and (iii) internationally adopted commitments, where it is possible to measure the extent of investment needs with great precision. Further, the availability of production factors for identifying, organising and implementing projects and programmes, where apart from (physical) capital, which in principle is not a limitation in modern society, it is also necessary to include staff, institutional (e.g. regulatory framework and State aid rules) and spatial resources.

Financial absorption capacity can be first divided into co-financing capacity of the recipients of funds. Due to the co-financing requirements of the Cohesion policy regulations as well as rules on state aid, recipients face not just the problem of providing enough cofinancing as such, but can in some systems also face the liquidity problem due to so-called pre-financing of the EU resources by the recipients. The second dimension of financial absorption capacity according to Mrak and Wostner (2004), refers to the capacity of the Member State for public co-financing, i.e. the national public co-finance of EU funds.

Programme / project absorption capacity first refers to the relevance of the strategy and programme bases (national and EU) according to real needs, where it is important that the Member State has a well-defined development strategy, not only on the national level but also on the local/regional level. Second, adequacy of concrete implementing instruments (calls for projects, etc.) will play a major role in determining whether, despite the right purpose and compliance with the programmes, the eventually co-financed operations will have the desired impact, duly taking into account criteria for public intervention and the 
objectives of the programmes. In this regard, the availability and quality of information on instruments or public tenders, extent and adequacy of the required documentation, timely information and suitable deadlines for applications are also of great importance. Lastly, with regard to programme and project absorption capacity, the preparation of project documentation should be given due care. Especially for investment projects, it is necessary to prepare, before the start of the investment and use of funds, extensive documentation and acquire all the necessary permits, which can be a complex and cumbersome process.

With regard to administrative absorption capacity, it is first necessary to take into account the capacity for preparing and implementing administrative work by or for the applicants. They need to be able to cope with a number of more-or-less bureaucratic processes from applications to reporting, storage of documents, providing various supporting documents, etc. Here also, the quality of the consulting services market can be very important as the recipient can outsource a major part of these processes to an external consultant. Second, in order to actually receive EU funds, the administrative capacity of the national administration must be ensured. The Member States need to be able to implement complex procedures, i.e. from the moment when the project/ programme contractors have submitted their invoices to the relevant authority, a system of controls and provision of supporting documents and requests for payment must be introduced, which eventually lead to payment claims submission to the European Commission.

One of a few systematic analysis to be actually verified and quantified on (then yet to become) Member States was prepared by Boeckhout, Boot, Hollanders, Reincke and de Vet (2002, 2003), with the methodology applied to the Candidate Countries by Papadopoulos (2003). The studies identify, for each step of the policy cycle (management, programming, implementation, monitoring $\&$ evaluation and financial management $\&$ control), critical factors in terms of structure, human resources and systems $\&$ tools. Structure relates to the clear assignment of responsibilities and tasks to institutions (including supervisory and ancillary bodies), and more specifically to particular units and departments within those institutions, and this must be done for all the steps of Structural Funds implementation. In terms of human resources, it is not just important to unsure enough properly trained staff, but also to ensure proper detail in specifying the tasks and responsibilities as well as organisational and motivation structures. Lastly, systems and tools relate to the availability of instruments, methods, guidelines, manuals, systems, procedures, forms etc, which do not just improve the quality of implementation in the short run, but make implicit knowledge explicit, making institutional structures less vulnerable to shocks, staff mobility, etc.

All dimensions need to be properly taken care of in order for the implementation system to function, which is summarised in Table 2. 
Table 2: Key indicators for Candidate Countries to effectively manage the Structural Funds

\begin{tabular}{|c|c|c|c|c|}
\hline \multirow[b]{2}{*}{ Indicators } & \multicolumn{3}{|c|}{ DESIGN } & \multirow[b]{2}{*}{ FUNCTIONING } \\
\hline & Structures & $\begin{array}{c}\text { Human } \\
\text { resources }\end{array}$ & Systems \& Tools & \\
\hline Management & $\begin{array}{l}\text { Designation of } \\
\text { MAs }\end{array}$ & Staffing of MAs & $\begin{array}{l}\text { Arrangement on } \\
\text { delegating tasks }\end{array}$ & $\begin{array}{l}\text { Existence of a } \\
\text { modern civil } \\
\text { service }\end{array}$ \\
\hline Programming & $\begin{array}{l}\text { Partnership } \\
\text { already present }\end{array}$ & $\begin{array}{l}\text { Capacity to carry } \\
\text { out programming }\end{array}$ & $\begin{array}{l}\text { Guidelines / } \\
\text { manuals for } \\
\text { programming } \\
\text { exist }\end{array}$ & $\begin{array}{l}\text { Existence and } \\
\text { quality of NDP }\end{array}$ \\
\hline Implementation & $\begin{array}{l}\text { Assignment of } \\
\text { Intermediate } \\
\text { bodies }\end{array}$ & $\begin{array}{l}\text { Staffing of } \\
\text { Intermediate } \\
\text { bodies }\end{array}$ & $\begin{array}{l}\text { Existing } \\
\text { operational } \\
\text { project } \\
\text { development and } \\
\text { management } \\
\text { process }\end{array}$ & $\begin{array}{l}\text { Absorption of and } \\
\text { project pipeline } \\
\text { for pre-accession } \\
\text { funds }\end{array}$ \\
\hline $\begin{array}{l}\text { Monitoring and } \\
\text { evaluation }\end{array}$ & $\begin{array}{l}\text { Designation of } \\
\text { monitoring and } \\
\text { evaluation } \\
\text { responsibilities }\end{array}$ & $\begin{array}{l}\text { Availability of } \\
\text { independent } \\
\text { evaluation } \\
\text { expertise }\end{array}$ & $\begin{array}{l}\text { Existence of a } \\
\text { computerised } \\
\text { monitoring } \\
\text { information } \\
\text { system } \\
\end{array}$ & $\begin{array}{l}\text { Functioning } \\
\text { monitoring system } \\
\text { for pre-accession } \\
\text { funds }\end{array}$ \\
\hline $\begin{array}{l}\text { Financial } \\
\text { Management \& } \\
\text { Control }\end{array}$ & $\begin{array}{l}\text { Designation of } \\
\text { Paying Authorities } \\
\text { and functions }\end{array}$ & $\begin{array}{l}\text { Accounting and } \\
\text { auditing } \\
\text { expertise secures }\end{array}$ & $\begin{array}{l}\text { Existence of } \\
\text { accounting } \\
\text { system and } \\
\text { financial } \\
\text { procedures } \\
\text { secured }\end{array}$ & $\begin{array}{l}\text { Established } \\
\text { practice in dealing } \\
\text { with financial } \\
\text { irregularities }\end{array}$ \\
\hline
\end{tabular}

Source: Boeckhout et al, (2002): 29

More detailed analysis and suggestions were put forward, which will be referred to in later sections. However, the authors have also prepared a short list of key messages for designing efficient and effective implementation systems (Boeckhout et al (2002): 29):

i. Establish the appropriate structures quickly and precisely. They need to reflect the existing administrative structures and traditions.

ii. Overall, simple management structures require less administrative capacity than complicated structures. However, simple management structures can sometimes lead to more complicated implementation structures and extended Monitoring Committees.

iii. Human resources are vital: detail the staff requirements and provide the conditions for recruiting, retaining and training qualified staff, preferably for all administrative staff but at least for the key staff managing the Structural Funds.

iv. Develop systems, procedures, manuals, guidelines and other tools in order to increase productivity, efficiency, consistency and quality of work, while reducing the vulnerability of organisations and their dependence on individuals.

v. Prepare for a head-start by utilising existing experiences that have been gained in the pre-accession stage, wherever applicable and useful. It is crucial that organisations develop a capacity to learn from their previous experiences. 
vi. Divide management attention between all areas of the policy life cycle, notably financial management $\&$ control and implementation, but also programming and monitoring $\&$ evaluation.

Another interesting introduction and overview of the absorption capacity concept and literature can be found in Horvat (2003) and (2005). The author notes the absence of a conceptual framework to comprehensively assess the issue of absorption problems relating to Structural Funds, and so uses more extensively the development economics and public choice literatures. Apart from the theoretical considerations, he makes an empirical investigation in the administrative absorption capacity of the candidate countries, in essence, using the Boeckhout et al (2002) methodology on the basis of newly available documents and making further recommendations as to how Structural Funds can be used in most efficient manner.

Horvat (2005) specifies an interesting 'golden rule', which is about the virtuosity of concentrated implementation systems. It claims that "the smaller the number of institutions (usually sectoral Ministries) involved at the levels of Management and Programmes (Sectoral and Regional) presented at the level of Programming in the Candidate Countries, the clearer the picture and higher the possibility of better administrative absorption of Structural Funds" (ibid., 13). From the more public choice arena, he makes observations as to the relationship between political sphere and absorption, especially from the perspective of staff requirements and institutional structures. The author calls for timely reorganisation and the need to ensure continuity of personnel whatever the organisational changes. He also draws attention to the necessity of having close political relationship between the Managing Authority and the Prime Minister.

At a more detailed level, there is a large range of studies prepared by the European Policies Research Centre (EPRC hereafter), which can be found at www.eprc.strath.ac.uk/eprc/publications.cfm. They have been preparing detailed and regular studies for over 20 years; apart from good analytical work, their particular merit is in the empirical approach, i.e. their method has usually been based on the detailed surveys of the particular situations in the regions and Member States.

As far as implementation systems are concerned the report by Taylor et al (2000), introduces a general typology, which is primarily based on so-called 'administrative additionality', i.e. the extent to which the Structural Funds implementation system is designed alongside national programmes. In such a way the following approaches are identified:

- differentiated systems, whereby Cohesion policy operates outside the usual national policy context (typical countries are B, DK, NL, S, UK); 
- $\quad$ subsumed $^{5}$ systems, where both Structural Funds and national policies are merged (typical countries are D, A, ES);

- composite $^{6}$ systems, where separate system is designed on top of the national system (typical countries are F, FIN, IT).

The authors deem the differentiated systems to be relatively less efficient in that they involve the creation of additional structures and procedures, but this also means that they are more easily made transparent. In the subsumed systems, it is easier to make use of sectoral expert knowledge and existing project pipelines, while the coordinating institution keeps its focus on the strategic issues (programming, monitoring and evaluation). At the same time, this can represent a problem, since it is harder to ensure consistency across different parts of the operational programmes and can also be more demanding and confusing for potential applicants. The report makes a more in-depth analysis of different solutions to which we will make further reference in the relevant section. However, the authors also point out, that in spite of several common features regardless of institutional context, it is difficult to make generalisations as to which approach would be universally better.

An overview of the particular solutions used in the regions and Member States as regards the implementation systems is provided in Ferry_(2005) and Ferry et al (2007). They argue that over the past 15-20 years the implementation systems have become more sophisticated, less centralized and more integrated, with the most noticeable evolution taking place in the project appraisal and selection systems, which have become more proactive and strategic. Recent trends in implementation systems during the transition to the 2007-2013 operational programmes, however, has been compiled by Bachtler et al (2006), which go in three directions.

a) The majority of regions/Member States are largely retaining the previous implementation structures in terms of their centralised or regionalised approach. Thus, one continues to see a centralised approach in EE, LT, LV, MT, CY, L, with the Baltic states and Slovenia making an effort to give sub-national implementing bodies more involvement but not to the extent of regionalising management; $a$ regionalised approach in $A, B$ and non-convergence Italy, while $F I N, F, D, I E$, Convergence Italy, ES use a mixed central-regional approach.

b) There are tendencies, however, of strengthened regionalisation of some aspects of implementation. Especially in countries with increased available resources, i.e. the EU12, there are tendencies to move some of the implementation responsibilities from central to regional level. This is especially the case in $\mathrm{CZ}, \mathrm{HU}, \mathrm{PL}, \mathrm{SK}$ which are introducing regional operational programmes. At the same time, however, due

\footnotetext{
${ }^{5}$ These systems are referred to as integrated systems by Ferry et al (2007).

${ }^{6}$ These systems are referred to as aligned systems by Ferry et al (2007).
} 
to concerns about administrative capacity and expertise at sub-national level, central implementation structures are still expected to continue to play a dominant role. There are also some regionalisation tendencies in other countries based on the motive that in this way more targeted and regionally adapted interventions could be devised.

c) All programmes are looking at ways to rationalise their implementation structures. Rationalisation is an overall phenomenon both in countries with falling as well as increasing financial envelopes. In the former, this can be attributed to efficiency reasons, because it is not feasible to sustain the same institutional structures with smaller programmes, which are consequently more focused on particular issues. The latter Member States are forced into rationalisation because of the restrictions in hiring additional public employees, which prevents them increasing proportionally the staff dealing with Cohesion policy implementation. Thus, we can expect rationalisation at all levels: central, regional as well as effort to improve cooperation and relationships between the two levels.

In terms of what is being financed, i.e. programming, as well financial progress, EPRC has been preparing regular reports based on its secretariat role in the IQ-Net project (e.g. Bachtler et al (2000), Bachtler and Michie (2001), Polverari et al (2005), Bachtler et al (2006) and Gross and Davies (2007). More relevant for our analysis, however, is the question to what extent programming, as a basic characteristic of Cohesion policy implementation systems, in fact brings value added. This issue has been addressed in Bachtler and Taylor (2003), where they argue that programming strengthens the consistency of the operations financed, encourages strategic thinking and planning, promotes an inclusive approach and especially improves the clarity of objectives and targets. Furthermore, programming is supposed to contribute significantly to more evidence-based policy development, with the particular benefit of having a multi-sectoral approach often combined with geographical focus, which due to its multi-annual approach, provides stable policy environment. They also point out some negative properties of programming. First, programming prolongs the implementation cycle, which tends to be under tight pressure anyway due to late regulatory framework approvals; second, that decisions nevertheless remain determined by the overtly political compromise. Furthermore, the programming context is also criticised that it does not provide enough flexibility since adjustment of programmes takes many months.

One of the first systematic insights into project generation, appraisal and selection phases has been put forward by Fitzgerald and Promé (1996). A more in-depth analysis of the processes and their consequences however can be found in Taylor et_al (2000) and Ferry et al (2007). The core objective in project selection is to ensure a system that will be efficient, effective and transparent, since it is the supported projects that will eventually feed through into the foreseen impacts in the operational programmes. According to Ferry et al (2007), project generation, appraisal and selection has been one of the crucial developments in the implementation systems in the last 15 years, with approaches gradually evolving from a 'list of projects' approach to a more sophisticated and coordinated method of allocating resources to projects (ibid., 9). Their work will be used extensively as a reference in our analysis. 
Finally, as far as monitoring and evaluation are concerned, the EPRC has produced a number of studies that give detailed overview on different approaches taken by the Member States and regions, which are also cited later in the text, e.g. Bachtler and Taylor (1999), Taylor, Bachtler and Polverari (2001), Raines and Taylor (2002), Taylor et al (2004) and Polverari et al (2007). The most complete overview can be found in the latter, where it is argued that the long-term trend in the complexity as well as applicability of the monitoring and evaluation systems is encouraging. The first financial perspective after the 1988 reform saw a very modest introduction of the monitoring and evaluation systems, which provided evaluations "of a low quality" and "lacking methodological rigour" (ibid., 5), also due to "widespread lack of monitoring data", which was "particularly acute at the regional level" (ibid., 5). 


\section{METHODOLOGY}

The objective of this paper, as already presented in the introductory section, is to systematically identify those institutional arrangements at every step of the policy cycle, which contribute to an efficient and effective Cohesion policy implementation system. In this regard it has to be recognised that it is usually hard to isolate the contribution of a particular implementation phase or arrangement to the overall efficiency of the system. Furthermore, one has to bear in mind, that, due to very diverse institutional contexts and implementation arrangements, it is extremely hard to make generalised observations. Nevertheless, there is only one underlying set of rules, which underpins the implementation of Cohesion policy, which can be improved only on the basis of generic conclusions. Additionally, for countries with similar implementation arrangements common recommendations can be put forward.

The ÖIR (2003) study has provided extensive insight into what is important and what different solutions Member States and regions came up with. The focus in our analysis however will be on the perception of people directly involved in Cohesion policy implementation, on how systems and processes should be organised in order to make them more efficient and effective as they presently are. Special attention is given to countries that became full EU members in 2004. This is for two reasons: first, because they, apart from the pre-accession period, have not received much systematic analysis and second, because they possess a markedly different historical, administrative and political background, which gives additional insight into possible institutional setups most conductive to efficiency. Furthermore, as new entrants into the system, these countries comparatively exhibit more flexibility and modifications of systems and thus represent a good study group for analysing the micro-efficiency of different systems.

The systematic analysis of the paper makes use of existing evaluations and complements them with the conclusions from an extended EU-wide questionnaire (see Annex 1), which was prepared specifically as a basis for this paper. The questionnaire is structured around the standard phases of the policy cycle (e.g. Fitzgerald and Promé (1996)): (a) programming; (b) project generation, appraisal and selection; (c) implementation (implementing structure, financial management and controls); and (d) monitoring and evaluation. For each phase, a critical assessment has been made of present practices, which often required the preparation of relevant typologies due to different practices in different systems. On this basis, it has been possible to survey respondents' views on how implementation systems could be made more efficient and effective. Since the focus of the paper is on the optimal design (according to Boeckhout et al (2002) of the implementation systems, the framework conditions (or context according to ÖIR (2003) were also addressed. This means that the analysis predominantly looks at the supply side of absorption capacity, i.e. it is primarily interested in the 'programme/project absorption capacity' and 'administrative absorption capacity' according to Mrak and Wostner (2004). That being said however, we have also addressed those demand-side factors that should influence decisionmaking on Cohesion policy implementing provisions (e.g. in project generation or allocation of money to project phases). Structuring of the questionnaire and research has also benefited from the author's first-hand experience of Cohesion policy management, as he 
was directly responsible for the Structural and Cohesion Funds implementation in the Slovenian Managing Authority.

The questionnaire was sent to 449 addresses. Use was made of the existing networks of managing authorities, the Council working group responsible for Cohesion policy (Structural Actions Working Party), while, on the side of the European Commission, the questionnaire was sent to all directors in DG Regional Policy and DG Employment, Social Affairs and Equal Opportunities, including to the evaluation networks. Additionally, the questionnaire was sent to experts involved in Cohesion policy evaluation, for which membership of the European Regional Science Association was used, as was the Interact network. Finally, for every questionnaire sent, a request was also submitted to resend the questionnaire onwards to relevant personnel at Commission, national and particularly regional level. The basic requirement was that the person answering should have direct experience in Cohesion policy management. It was not unusual that the respondents provided answers only in those areas where they felt they had enough experience. Consequently the data set in not entirely balanced.

The characteristics of the questionnaire respondents can be found in Table 3.

Table 3: Characteristics of the questionnaire respondents

\begin{tabular}{|c|c|c|c|c|c|c|c|}
\hline & & \multicolumn{5}{|c|}{ Institution } & \multirow{3}{*}{$\begin{array}{c}\text { Total } \\
11 \\
\end{array}$} \\
\hline \multicolumn{2}{|c|}{ Country } & FC & MA & ID & Impl Reg & Ixnoun & \\
\hline \multirow{3}{*}{ EU15 } & No. & 1 & 1 & 3 & 2 & 4 & \\
\hline & $\%$ & 9.1 & 9.1 & 27.3 & 18.2 & 36.4 & 100.0 \\
\hline & $\%$ & 25.0 & 9.1 & 21.4 & 40.0 & 36.4 & 24.4 \\
\hline \multirow{3}{*}{ EU12 } & No. & 3 & 10 & 11 & 3 & 7 & 34 \\
\hline & $\%$ & 8.8 & 29.4 & 32.4 & 8.8 & 20.6 & 100.0 \\
\hline & $\%$ & 75.0 & 90.9 & 78.6 & 60.0 & 63.6 & 75.6 \\
\hline \multirow{3}{*}{ Total } & No. & 4 & 11 & 14 & 5 & 11 & 45 \\
\hline & $\%$ & 8.9 & 24.4 & 31.1 & 11.1 & 24.4 & 100.0 \\
\hline & $\%$ & 100.0 & 100.0 & 100.0 & 100.0 & 100.0 & 100.0 \\
\hline
\end{tabular}

Note: EC: European Commission; MA: Managing Authority; IB: Intermediate Body; Impl Reg Level: regional level implementation; EU15: Members of the EU before 2004; EU12: Member States that acceded in 2004 or after.

We have received 45 answers, which puts the response rate at exactly $10 \%$ which is not high but still acceptable given the limited number of experienced people in the field and secondly, given the structure of the respondents. Here, one can see that just over $75 \%$ of respondents come from the EU12. This is above their respective share in the available funding for 2007-2013 period, which is $52 \%$ but, as mentioned earlier, we wanted to give these countries more attention. In terms of institutional representation the structure of the sample is also representative. From the European Commission we have received four replies, which put their response rate at a disappointing $6.6 \%$ disappointing especially given its declared focus on the necessity of evaluation in Cohesion policy. Further, $55 \%$ of the respondents come directly from institutions responsible for implementation in the Member States: these are managing authorities (24\%) and intermediate bodies (31\%). The 
former are responsible for all the organisational, management and control systems as well strategic steering of the programmes, while intermediate bodies are institutions to which managing authorities can delegate certain tasks (exact delegation depends on the specific country/regional arrangement). An additional $11 \%$ of replies came from the regional or better sub-national implementation level, which can include both de-concentrated national offices as well as proper regional representations. Lastly, $24 \%$ of respondents came from outside the Cohesion policy implementation system, and are familiar with the Cohesion policy implementation systems usually due to their involvement either as consultants or evaluators.

In order to take account of the institutional contexts of the Member States, we have also classified the Member States in three groups, depending on the extent to which their implementation systems are implemented on the national/regional level and to what extent they are implemented in a concentrated/ de-concentrated manner (the former refers to a situation where there are small, and, in the latter, larger, numbers of institutions involved in the implementation system on a particular level). This typology however needs to be treated with caution, because there is bias in the sample towards national concentrated institutional arrangements (representing $69 \%$ of the answers) due to the bias of such arrangements in the EU12 Member States (CY, SI, EE, LT, LU); 17\% of respondents come from countries with a regionalised but concentrated approach (PL, BU, ES); and 14\% come from countries with a regionalised/de-concentrated approach ( $A, C Z, D$, UK). It should also be recognised that the classification of Member States and regions is somewhat arbitrary so this typology will be used more for illustrative purposes.

The average age of the respondents was 39 years, with an above-average representation of men (62\%). This is probably due to the over-representation of men in strategic management positions, from which $60 \%$ of respondents came. Finally, the respondents from the sample are extremely highly qualified as $53 \%$ have postgraduate education or above and only $2 \%$ high school or lower level of education. Of course this is not surprising given the demanding requirements of Cohesion policy implementation. 


\section{FACTORS DETERMINING MICRO-EFFICIENCY}

\subsection{Framework conditions}

\subsubsection{EU versus national regulation}

The Cohesion policy implementation system must be designed and consistent with the requirements set out in the Council's and Commission's regulations. In the 2007-2013 period, they refer in particular to:

- Council Regulation (EC) No 1083/2006 of 11 July 2006 laying down general provisions on the European Regional Development Fund, the European Social Fund and the Cohesion Fund and repealing Regulation (EC) No 1260/ 1999

- Regulation (EC) No 1080/2006 of the European Parliament and of the Council of 5 July 2006 on the European Regional Development Fund and repealing Regulation (EC) No 1783/ 1999

- Regulation (EC) No 1081/2006 of the European Parliament and of the Council of 5 J uly 2006 on the European Social Fund and repealing Regulation (EC) No 1784/ 1999

- Council Regulation (EC) No 1084/2006 of $11 \mathrm{~J}$ uly 2006 establishing a Cohesion Fund and repealing Regulation (EC) No 1164/94, and

- Commission Regulation (EC) No 1828/ 2006 of 8 December 2006 setting out rules for the implementation of Council Regulation (EC) No 1083/2006 laying down general provisions on the European Regional Development Fund, the European Social Fund and the Cohesion Fund and of Regulation (EC) No 1080/2006 of the European Parliament and of the Council on the European Regional Development Fund.

These regulations give significant scope and flexibility to the Member States and the regions as to how they adapt these provisions to their particular circumstances. The regulations leave considerable room for interpretation, which in such a diverse grouping as the EU is unavoidable and could be considered a strength of the system. The flexibility provided allows more diversity and scope for innovative solutions and adaptations, which can improve the overall efficiency of the system. However, the Council, while discussing the Regulations, can never know ex-ante what kind of attitude the European Commission will take (ex-post) in interpreting the rules. Namely, the interpretations tend not to work in the direction of increased flexibility, but instead tend to be used in a restrictive manner, even though the Council, together with the European Parliament as legislative bodies, might not have had such an interpretation in mind. As a matter of fact, due to the strengthened decentralization of Cohesion policy, the so called 'soft law' at the EU level is gaining in importance. Soft law is predominantly being prepared by the European Commission 
services, often in the framework of the relevant Committees (COCOF ${ }^{7}$ and ESF), which continuously produce interpretations, guidelines and opinions, and these can significantly influence the way Cohesion policy is being implemented. One solution to the problem of different ex-post interpretation of legislation, as foreseen by the legislator, is to be more prescriptive in the regulation, but which has a cost not just with regard to reduced flexibility, but also in increased complexity and bureaucratisation of the legal framework. Thus, in future, it could make more sense that, at the request of the Council working group negotiating the regulations, the Commission's interpretation of a particular article or issue in the regulation during negotiations would be noted for subsequent use. In this way, the legislative bodies, together with the Commission, could better describe the 'spirit and intentions' behind the legal provisions in the regulation. As will be seen later, however, this topic is closely related to the multi-level governance issue, which will be addressed in later sections.

This being said, it would be misleading to point the finger only at the Commission as the main responsible institution for the observation that "the regulatory environment is not conducive to an efficient implementation of the funds", a statement with which $60 \%$ of the ÖIR study respondents agreed (ÖIR, 2003, 64). A lot of complexity and bureaucratisation, namely, is caused by the national and also regional institutional arrangements. Again citing the ÖIR study, "the Commission can simplify some of its procedures" but "it is up to the Member States to streamline the procedures imposed on project promoters" (ÖIR, 2003, 25). The importance of streamlining the procedures cannot be overestimated since the number of beneficiaries all over the EU are actually coming to an almost perverse conclusion that their cost in order to get the EU subsidy is simply too high to be worth the effort. We will come back to this issue, but, in our analysis, we wanted to make a specific investigation into "to what extent are, according to respondents' opinions, the administrative procedures for the absorption of funds related to EU / national legislation"?

The replies confirm the joint responsibility of both EU and national legislations and rules for the complexity of administrative procedures. On average, $55 \%$ of the administrative procedures are estimated to be due to EU legislation, and though the share seems to be lower in the EU15 which ascribes $48 \%$ to the EU level, whereas in the EU12 the corresponding share is actually $58 \%$ This could suggest that, with time, the Member States and regions learn how to make better use of the EU rules' flexibility and play it to their advantage, whereas this is more difficult for the legislation of "national origin". What is also interesting is that there is no major difference of perception among different institutional affiliations. This can be interpreted in two ways: first, that there is significant responsibility and, given the critical perception of beneficiaries, also scope for improvement on the level of EU regulations, but that at the same time almost a corresponding share of responsibility lies on the Member States level. Interestingly though, the least critical score to Member States' bureaucratisation was given by the

\footnotetext{
${ }^{7}$ Coordination Committee of the Funds, as described in article 103 of the Regulation 1083/2006.
} 
countries with a regionalised/de-concentrated approach, having attributed only $28 \%$ of all administrative procedures to the national/ regional level.

\subsubsection{Financial critical mass}

The second issue that needs to be addressed as part the framework conditions analysis is the size of the programmes. Significant attention has been given to the maximum feasible and manageable extent of transfers to particular Member State relative to the GDP. This was explicitly regulated in the 2000-2006 regulation at the level of $4 \%$ of GDP and even lower in the financial negotiations for the 2007-2013 period. At the same time, however, not much attention has been given to the principle of concentration. Even though concentration is one of the Cohesion policy general principles, there was not much debate on the issue. Given the significant administrative and institutional requirements and costs (e.g. programming requirements, control and audit systems, etc.), it is not self-evident that Cohesion policy is justified whatever the level of support. Because people involved in Cohesion policy implementation are usually or rather, not necessarily, well-informed on the average yearly aid intensities for their own and other regions, we have asked the question indirectly, i.e. whether "there exists a critical minimum level of resources per operational programme below which the present Cohesion policy approach is no longer justified"? It turns out that almost two thirds (62.5\%) of the respondents seem to believe this is the case, in other words, that there should be a limited lowest level of resources per operational programme.

The distribution of answers as to what this minimum level of resources per operational programme should be, is however, rather dispersed. On average, $41 \%$ of respondents believe that this figure should be below $€ 20$ million per year (for the seven-year financial perspective this would refer to an operational programme of $€ 140$ million), of which twothirds actually feel that the minimum limit should be half that size. On the other hand, the remaining $60 \%$ believe the operational programme should be financially more significant to justify all the institutions and costs associated with them: at least over $€ 140$ million for the seven year period, with $14 \%$ of respondents claiming that the minimum threshold should be at least around half a billion euros. Thus, there seems to be significant support for the notion that the operational programmes should be financially rather significant: the median respondent estimated the minimum level of resources per OP between $€ 140$ and $€ \mathbf{2 8 0}$ million for a seven-year period. According to the present system, the allocation of resources per operational programme is determined by the Member States, so this proposition to a significant degree affects the Member States. Nevertheless, there might be cases in Objective 2, and especially Objective 3 areas, where this minimum threshold could also be regulated at the EU level.

\subsection{Implementation structure}

Cohesion policy implementation systems are dependent on the broader institutional setup of countries and regions in question. The literature presented in the second section has introduced by now already standardised typology of approaches. 
Firstly, administrative systems can be differentiated according to whether they are centralised or decentralised. We have already introduced such classification in the section on methodology, but will expand on this here. The centralised systems tend to put much more weight on decision-making and implementation by the established national institutions, usually ministries, but also other public bodies. On the other hand, decentralised systems, which predominantly refer to federal countries and systems involving autonomous regions, put greater emphasis on the so-called multilevel governance, with decisions and management taken at different levels, thus giving more attention to decentralisation and partnership. However, there is also a combination, whereby implementation is primarily based on national institutions but in their regional exposures. This is usually classified as a de-concentrated model. In our analysis we are not differentiating between self-governing and de-concentrated regional approaches, because a number of other factors influence the efficiency of either of the systems, which thus goes beyond the scope of this paper. We do recognise that both approaches bring 'implementation closer to the citizen', and this is something that we are interested in.

A second differentiation put forward in the literature (e.g. Taylor et al (2000), Ferry et al (2007)) refers to the degree to which management functions are carried out in the framework of a pre-existing administrative/institutional setup, i.e. the extent of administrative additionality. Systems where Structural Funds rules are interlinked with the general public administrative system are referred to as integrated or subsumed systems, while systems with separate implementation systems specific to Cohesion policy and thus outside of the general administrative framework are referred to as differentiated systems.

The integrated systems try to make best use of the available (sectoral) expert knowledge and know-how in the administration. This also makes them cost effective. These systems can make good use of existing project pipelines, as appraisal and decision-making are usually done through established resource allocation mechanisms. Thus, no special procedures are (in principle) necessary. Some adaptations are admittedly always necessary so as to comply with the minimum standards of Cohesion policy (e.g. publicity requirements). Furthermore, making use of existing economic development administrative channels makes it easier for the potential beneficiaries to have an overview of what is going on in a particular policy field. At the same time, however, an integrated approach makes the system less transparent in terms of public awareness of the purposes that the available EU resources can be used for, and makes it harder for the managing authority to ensure coordination and standardised procedures and forms. This can turn out to be somewhat confusing for potential applicants (e.g. who is responsible for what in Cohesion policy, different approaches and interpretations, etc). Ferry et al (2007) further differentiate between two types of integrated systems depending on whether EU or national resources are dominant. In the former case, the whole national development policy adjusts to the Cohesion policy approach to development policy implementation, which is generally perceived as positive. A major drawback of dominant EU resources might be, however, that development policy could give too much attention to eligible activities only, and that the absorption of EU funds might bias the whole development policy towards those activities were money can be spent more easily. 
Under the differentiated systems, separate institutional structures and channels are put in place, which means that one single system operates across a whole programme. This makes it easier to steer the programme implementation towards set objectives. Differentiated systems also make it easier to ensure consistency in implementation with regard to technical requirements for the applicants whatever the policy area, because there are no pre-established practices in the responsible institutions. Separate systems, however, by definition mean higher costs and potential duplication problems. A particular problem in such an approach is coordination with other national development initiatives. Coming back to Taylor et al (2000), there seems to be a trade-off between, on the one hand, the administrative simplicity offered by using existing domestic systems, and on the other hand, the strategic coherence and visibility of EU funding offered by separate systems.

Taylor et al (2000), have nicely worked out the advantages and disadvantages of both implementation systems in terms of their contribution to efficiency, effectiveness and transparency, which is broadly summarised in Table 4.

Table 4: Advantages and disadvantages of differentiated and subsumed systems

\begin{tabular}{|l|l|l|l|}
\hline & \multicolumn{1}{|c|}{ Efficiency } & \multicolumn{1}{c|}{ Effectiveness } & \multicolumn{1}{c|}{ Transparency } \\
\hline \multirow{5}{*}{ Differentiated systems } & $\begin{array}{l}\text { A single system } \\
\text { operates across a } \\
\text { whole programmes. }\end{array}$ & $\begin{array}{l}\text { Can promote strategic } \\
\text { coherence across a } \\
\text { programme and enables } \\
\text { an overview to be easily } \\
\text { maintained. }\end{array}$ & $\begin{array}{l}\text { Greater visibility of } \\
\text { Funds and easier } \\
\text { overview of how } \\
\text { decisions are made. }\end{array}$ \\
\cline { 2 - 4 } & $\begin{array}{l}\text { BUT has to be } \\
\text { established and } \\
\text { operated. Requires a } \\
\text { marketing effort. }\end{array}$ & $\begin{array}{l}\text { BUT some actors with } \\
\text { limited sectoral } \\
\text { expertise prepare } \\
\text { recommendations. }\end{array}$ & $\begin{array}{l}\text { BUT possible conflicts } \\
\text { of interest in decision- } \\
\text { making. }\end{array}$ \\
\hline \multirow{5}{*}{ Subsumed systems } & $\begin{array}{l}\text { Benefits from pre- } \\
\text { existing channels. }\end{array}$ & $\begin{array}{l}\text { Appraisal \& decision- } \\
\text { making by sectoral } \\
\text { experts. }\end{array}$ & $\begin{array}{l}\text { Systems can be simple } \\
\text { for applicants. }\end{array}$ \\
\cline { 2 - 4 } & $\begin{array}{l}\text { BUT challenging for } \\
\text { the Structural Fund } \\
\text { programmes co- } \\
\text { ordinator to maintain } \\
\text { an overview. }\end{array}$ & $\begin{array}{l}\text { But fragmentation } \\
\text { leading to a potential } \\
\text { lack of overall } \\
\text { coherence. } \\
\text { Hard for Structural } \\
\text { Fund co-ordinator to } \\
\text { influence decision } \\
\text { systems. }\end{array}$ & $\begin{array}{l}\text { BUT overall Fund } \\
\text { visibility can be low. } \\
\text { Overview of decision } \\
\text { and criteria is difficult } \\
\text { to compile. }\end{array}$ \\
\hline
\end{tabular}

Source: Taylor et al (2000): 2

Apart from integrated and differentiated systems, Ferry et al (2007) also refer to aligned systems $^{8}$ in which, there are "separate decision-making systems for the EU and national funding...., but they operate in parallel or in some other coordinated manner" (ibid., vii), so they represent a mix of the two systems presented above. Such an approach promotes coordinated policy-making with the national resources, increases the scope for exchange of

\footnotetext{
${ }^{8}$ Taylor et al (2000), refer to them as "composite systems".
} 
experience and offers better value for money, but at the same time poses a "danger of administrative overload and problems with transparency and complexity".

The decision on the approach to the implementing structure is immensely important since such decisions tend not to change over time. According to Taylor et al (2000), the following factors determine the approach taken by the Member States ( $p 13)$ :

a) The conception of the role of SF in domestic economic development activity, which can be understood 'just' as a financial compensation mechanism or, at the other extreme, Cohesion policy can be taken as an incentive for change not just in terms of policy-making but also institutionally.

b) The influence of legal frameworks governing public sector activities, where it depends to what extent the legal framework allows the introduction or change of responsibilities.

c) The influence of administrative traditions, where decision-making can be traditionally very concentrated in responsible institutions rather than making decisions in the framework of partnership based committees.

d) The demand for SF support can require more complex and transparent decisionmaking structures.

e) J udgements weighting the cost of dedicated structures against the significance of the Funds, thus looking at whether greater costs of the differentiated systems outweigh the benefits.

There is general agreement that every management structure needs clearly defined roles and coordination processes well explained, documented and implemented, for the system to work well. It is furthermore important to realise that the implementation system is capable of operating well within either of the systems described above (see example to ÖIR (2003), Taylor et al (2000), Boeckhout et al (2002). Apart from the above considerations, we will put forward crucial factors as well as guiding principles, which should be taken into account when deciding on structure of the implementation system.

Cohesion policy implementation systems are administratively demanding in all circumstances. This necessitates making the best use of the available resources. With regard to centralised or decentralised approaches this means, at least in the initial stages, that systems should be adapted to the existing institutional set-up of the country (Boeckhout et al, 2002), i.e. towards the level where the greatest institutional capacity lies. Only in the latter stages could they also be used as a means to reform the institutional structures (e.g. strengthened decentralisation). With regard to integrated vs. differentiated systems, the decision should, to an important degree, depend on the quality and efficiency of the existing administrative system. If the existing public administration system is streamlined and efficient, it makes a lot of sense to integrate Cohesion policy into the same framework. This would not just make the implementation easier for applicants, but would also make best use of the existing human capital in the administration. Staffing problems tend to represent one of the most serious challenges in the initial stages of Cohesion policy 
implementation. The decision to adopt the differentiated systems could, however, well be justified if the existing administration system tends to be overly bureaucratic and complex, since it is not very likely that the introduction of Cohesion policy would provide enough incentive to reform the system as a whole. It might only be reasonable to expect this when there is a direct commitment at the highest political level. Furthermore, a differentiated approach might also be relatively more justified where the available financial resources for the Member State in question are rather modest, also indicating that the scope of interventions is rather limited. In such a setting a differentiated system can be advantageous, because the specialised institution can adapt all the procedures to best suit the purpose and requirements of Cohesion policy. As a consequence, however, such systems tend to have more difficulties with project generation (See Section 4.4.1). Finally, in every possible combination or context, we would put forward three horizontal guiding principles that should be addressed when specifying implementation systems. These are (a) the necessity for coordination; (b) number of institutions involved in the implementation system; and (c) the extent to which it is possible/ sensible to outsource the implementation of Cohesion policy.

\subsubsection{Necessity for coordination}

Coordination tends to be associated with the managing authority function, although as we will see later, not necessarily so. Previous studies have already come to the conclusion that the MA's role and importance is strong, that generally there is a predominantly positive attitude towards their performance, and that there is $86 \%$ support for the notion that managing authorities in their respective regions are "organised and structured in an appropriate manner" (ÖIR, 2003: 68). Furthermore, according to Boeckhout et al (2002: 8), it is "vital to locate the MAs of operational programmes in line with the position in the national hierarchy and the existing administrative structures".

To understand the importance of coordination, we must first specify the functions of the managing authorities who, in essence, represent the highest institution in the national hierarchy. With some generalisation, their role could be summarised as:

a) strategic steering of the operational programmes, including the programming/ partnership phases (determining what is being financed); and

b) ensuring legal compliance of the implementation system according to the regulatory framework, and especially compliance with the sound financial management principle.

The first function encompasses programming, decision-making on what is being financed as well as provision of the necessary tools for proper decision-making - i.e. the functions of monitoring and evaluation. As far as the second function is concerned, it primarily refers to the setting up of managing and control systems, and subsequently making sure that the actual implementation abides by those rules. These are standard and also common functions, which managing authorities all over the EU must perform. The difference, however, lies in the extent to which these functions are delegated to the so-called "intermediate bodies". Namely Article 59 of the general regulation (Council Regulation (EC) 
No 1083/2006; general regulation hereafter) stipulates that "The Member State may designate one or more intermediate bodies to carry out some or all of the tasks of the managing or certifying authority under the responsibility of that authority".

The decision on what to delegate primarily lies in the distribution of responsibilities and know-how in the national/ regional institutional system and, as put forward by Boeckhout et al (2002: 9), "no uniform concept regarding the delegation of tasks by MAs has emerged. To the contrary, every country has elaborated the role of MAs in a different way, reflecting the administrative structures, the planning traditions, the balance of power and the size of the country". Based on our analysis, the decision on how to structure the implementation system should, giving due account to the national institutional system, be founded on two criteria:

- To what extent are policy fields that are to be co-financed dependent on other policies? The dependence primarily refers to possible/necessary synergies and complementarities and this can either be with other EU co-financed programmes or with other national policies?

- To what extent is it justified to impose standardised procedures and forms of Cohesion policy on a particular policy area?

Clearly, in the national/regional context the responsibility for a particular function needs to be given to the institutions best capable of pursuing the task, particularly where the benefits of specialisation come to the fore. However, this notion is restricted by the value added of pursuing policies in support of each others' goals (increased efficiency) and the value added of increased transparency for the applicants, if they are required to comply with the same set of rules whatever the particular operation in question. Thus, the more self-standing the policy, the more sense it makes to have all the functions concentrated in the responsible institution (based on national institutional setup). On the other hand, the more the policy in question is intertwined with other policies, and the higher the likelihood that other EU and/or national policies are targeted at the same potential beneficiaries, the more sense it makes to have strong coordinating institution which works closely with the specialised implementing institutions - i.e. intermediate bodies.

Delegation of tasks to intermediate bodies can be organised in different ways, with the crucial distinction being how the negotiating power for policy setting is spread between MA and IBs. We would argue that without the residual rights vested in the managing authority (i.e. the MA having the final approval and decision-making power), the delegation of tasks is inefficient, as it allows game-playing by the intermediate bodies, while forcing the MA into over-regulation, because it is otherwise not able to enforce its position. This generalised suggestion refers to both the national and regional levels, as well as to both differentiated and subsumed systems.

However, it is not necessarily the managing authority which ensures coordination, even though this is usually the case. As shown by the Portuguese or Czech cases, for example, a separate institution can also be foreseen, with power and responsibility to coordinate and/or supervise the managing authorities. The risk with such an approach is that it could 
be interpreted as being, to some extent, inconsistent with the spirit of Cohesion policy regulations which, apart from the monitoring committee, put the managing authority at the top of the hierarchy. This means that final responsibility always rests with the managing authority. The actual ability to coordinate the managing authorities of this separate institution is therefore dependant on its political power; this, however, makes it systematically unstable.

In the questionnaire responses, we found partial support for the above ideas. We asked, not just whether a coordinating institution is needed, but also how much decision-making power it should have. There is universal agreement that Cohesion policy needs a coordinating institution. This seems to suggest that organising implementation systems, or rather operational programmes, "per responsible ministry or institution" is, at least in the initial stages, not an efficient solution. However, there is only limited support for the notion that the final decision-making right should be vested in the coordinating institution. The average score to question 19 namely was 6.4 , suggesting that, on average, the respondents consider that the coordinating institution should have more than just an advice, procedures setting and best practice exchange function, although not as much as to give it the veto right. Interestingly, the greatest support for a strong coordinating institution unexpectedly came from the managing authorities and, even more surprisingly, also from experts outside the system (both scoring 7.3). The intermediate body respondents, whose decision-making power would be restricted, expectedly did not support the notion of a strong coordinating institution (average score 5.4). The most important finding on a more disaggregated level, however, is that the score was significantly lower in the EU15 (5.3) than in the EU12 Member States where the average score was 6.9. This seems to suggest that newly introduced systems need a stronger coordinating institution with significant decision-making powers. With time, however, when the system and relationships among institutions become standardised and well established, there is greater scope for de-concentration.

\subsubsection{How many institutions should be involved?}

After deciding on the role of the coordinating institution, Member States and regions are faced with the next important dilemma, which is about how many institutions (i.e. intermediate bodies), should be involved in the implementation system. In order to analyze this question, we should first point out that we refer to the predominant type of intermediate bodies: institutions which have the authority to propose/ define the detailed provisions as to what kind of operation and how it should be financed; and those directly working with beneficiaries, especially in selecting projects, their monitoring and providing support to the project owners. Of course, such intermediate bodies do not necessarily have to answer directly to the managing authority, as it is common practice that there can be more layers of intermediate bodies, in line with the national/ regional institutional system e.g. public implementing institution (second level IB) answering to the ministry (first level IB) which is answerable to the managing authority. Clearly, the quality of intermediate bodies, given their tasks, is of major importance for the efficiency of the implementation system. This notion received 93\%support in the ÖIR (2003) study. 
Empirical investigations indicate that the number of intermediate bodies can differ markedly. Boeckhout et al (2002: 17), report that the number of IBs per OP can amount to 30 or 40 , but can even go up to 500 . It is hard to assume a priori which approach is more efficient, although some authors have argued in favour of concentration (e.g. Horvat, 2003). It should certainly be recognised however that there are different consequences for the implementation system that need to be taken in account. A greater number of involved institutions allows better institutional adaptability to the demands of the particular policy in question. As a consequence, the involved institutions can reap the benefits of increased specialisation, which can be of significant importance. On the other hand, however, it should be recognised that Cohesion policy implementation, founded on multi-level governance, requires complex and specific know-how. This does not only make the implementation of Cohesion policy more expensive than the implementation of domestic policies, it also involves noticeable learning costs. During the learning period, there is a significantly higher risk of irregularities in the process, resulting in a need to cover the additional costs from other (public) sources. Furthermore, a greater number of involved institutions magnifies the problem of coordination. This is relevant both in terms of policymaking (synergies) and, especially, in terms of legality of implementation (standardisation of procedures and forms).

The responses from our questionnaire seem to give a clear indication as to which dimension dominates. We have asked whether, for a particular OP, a more concentrated approach that involves a smaller number of intermediate bodies and implementing agencies, or a more de-concentrated approach with greater number of institutions involved, was considered more efficient. The average score for this question was 2.7, which means that in more than $\mathbf{7}$ out of $\mathbf{1 0}$ cases respondents would consider a concentrated approach as more efficient (consistent with the findings by Horvat (2003)). This is a common position for the majority of respondents (small variation in the score), with respondents from EU15 having a slightly lower tendency to promote a concentrated approach (average score being 3.1). Interestingly, however, the strongest tendency for a concentrated approach could be found among the experts. Classifying answers on the basis of the organisation of the implementation systems in respondents' countries suggests that being in a concentrated environment makes the virtues of a more de-concentrated approach more apparent and vice versa. Respondents from de-concentrated implementation systems namely consider a concentrated approach more efficient in more than $80 \%$ of cases. That a smaller number of involved institutions is more conducive for an efficient implementation system, was also recognised by the EU12 Member States' representatives during an exchange of experience meeting on 1 March 2007 in Ljubljana, where institutional complexity was identified as one of the commonly-shared weaknesses. There is a very weak tendency that, over time, Member States/regions could "afford" a more de-concentrated approach; the virtues of concentrated approach, however, still seem to dominate strongly.

\subsubsection{Outsourcing}

According to the regulations, primary responsibility for the Cohesion policy implementation lies with the Member States, that is to say, each Member State's elected government needs to determine who is to carry out the implementation tasks. This means that the implementation function originally rests with the public administration. However, some or 
nearly all of the functions could also be outsourced. In this section we will look at this option more closely, making use of a study prepared by Taylor, Rooney and Bachtler (1999), who make very useful typology of outsourcing types (ibid., 28):

- Programme Outsourcing (long-term), which involves contracting a single organisation to undertake most of the management and administration functions.

- Partial Outsourcing (long-term), where either a range of specific programme administration tasks are outsourced (e.g. monitoring and steering evaluation) or all tasks for specific parts of the programme are outsourced (e.g. management and administration of the ESF dimension).

- Mission Outsourcing (short-term), which involves contracting an external organisation to undertake a specific time-limited task (i.e. evaluation study).

- 'Insourcing' brings capacity in terms of manpower and expertise on the basis of seconding staff on a temporary basis.

Our interest primarily lies in the programme and partial outsourcing, since mission outsourcing and insourcing are not relevant with regards to how to design the implementation structure. Programme and partial outsourcing are not very common, though they are not so rare in the implementation of the Community Initiatives. Nevertheless, Taylor, Rooney and Bachtler (1999) list a number of benefits that such arrangements can bring about (ibid., 60):

- A new balance between the partners and programming authority that allows for more equal cooperation.

- Local ownership through accessibility, because the outsourced functions can be physically located closer to the target area.

- Partner 'ownership' encouraged through management style or status due to more independent status with more responsive management style.

- New organisations have more flexibility to innovate, (re)invigorating programming.

- More transparent programme management, since free-standing secretariats are typically more explicit and transparent about their objectives and activities.

- Solution to institutional rivalry: where there are several organisations which could take on a programme management role, outsourcing it to a new organisation provides a solution to potential institutional rivalry.

- Higher profile to the programme: Establishing a dedicated organisation to take on programme management and administration can help to create a higher profile for the programme itself.

- Civil service streamlining. At the same time as outsourcing programme management has benefited programmes themselves, and been welcomed by partnerships, it has 
enabled government units to pursue their own agenda of streamlining and cost cutting.

- Costs may not be reduced, but they can be offset. There is little or no evidence that outsourcing arrangements for programme management and administration cost less than undertaking these functions within government units at whatever level. However, such arrangements have allowed costs to be offset by transferring them to the budgets of other organisations.

We have emphasised the word "can" because outsourcing is beneficial only under certain conditions. It is very hard to generalise on this issue, as solutions again need to be specifically adapted to the particular challenge or situation, taking account of the institutional setting ${ }^{9}$. We could nevertheless say that for outsourcing to work: (1) the rationale for exactly what (and why) would be outsourced must be clearly understood; (2) the institution taking over must have sufficient experience, know-how and organisational capacity and style; ${ }^{10}$ and (3) the institution taking over must be held accountable. All are to a large extent related to the ability for good contracting. The first, in the sense that the subject of outsourcing (and consequently the contract) needs to be spelled out clearly, which also makes the monitoring of its implementation easier. Contractual monitoring has its limits; additional measures could, therefore, be foreseen for ensuring accountability. Taylor et al (1999: 57) for example stress that "a core guarantee of accountability is that the responsibility for outsourced functions can be taken away from the organisations undertaking them, if their performance is unsatisfactory", that the quality of outsourcing must be regularly supervised by the programming authority and that, in some cases, the work of organisations undertaking outsourced functions have often been subject to evaluations.

In our study, we wanted to get our respondents' opinions, not just on to what extent they consider outsourcing useful, but we also wanted to test the proposition put forward by Taylor et al (1999), that there is no noticeable difference in the outsourcing quality dependent on the type of organisation taking over. It is reported that the more substantial types of outsourcing are predominantly given to semi-public/semi-private organisations, while with other types of outsourcing private consultancy firms also get involved. The answers seem to reveal a rather indifferent attitude towards outsourcing in general, which is probably associated with the fact that it was not possible to differentiate the effectiveness of outsourcing under different circumstances or for different functions. Two interesting results appear nonetheless. First, there seems to be greater scepticism towards

\footnotetext{
${ }^{9}$ The report does make a general statement however that "the overall level of satisfaction with the outsourcing arrangements examined appeared to be high" (Taylor, Rooney and Bachtler, 1999: 62).

${ }^{10}$ This is primarily dependent on the extent to which the market for these services is developed, an issue that will be dealt with in greater detail in the section on project appraisal, selection and approval. At this point it is worth mentioning however, that the ÖIR (2003) study found that there was no shortage of expertise in the market, but that it was rather the inability of the responsible institutions to make good use of it that represented the real problem (ibid., 75).
} 
outsourcing to the private firms ( $44 \%$ support relative to $62 \%$ for semi-public organisations) and second, especially among the EU15, there seems to have been bad experiences in this regard, as there is only $25 \%$ support for outsourcing to private firms. This seems to suggest that the Cohesion policy implementation is rather hard to contract, which makes outsourcing of more complex functions to the private sector rather less effective. Nevertheless, this notion needs to be treated with caution as outsourcing efficiency and rationale should be decided on a case-by-case basis.

\subsection{Programming}

\subsubsection{Value added}

Programming is generally considered to be one of the strongest features of Cohesion policy implementation. It has several qualities playing to its advantage. First, it promotes a strategic approach in spending Cohesion policy resources and, at the same time, makes decentralisation of decision-making to the Member States easier. Second, the strategic approach contributes to better coordination in policy design and can, in turn, also translate into improved coordination of policies in the implementation phase. Programme preparation and coordination namely put particular emphasis on the internal and external consistency of the policies, in this way setting the groundwork for the realisation of synergies among different policy fields. Third, the programming approach, by definition, requires Member States to improve the logic, objectives and rationale of their foreseen operations. This makes monitoring and evaluation easier and, in turn, also improves effectiveness. Fourth, programming significantly reduces the uncertainty with regard to the policy-mix particular regions or Member States intend to pursue. This allows better long term budgetary planning on the public side and, even more importantly, provides potential beneficiaries with a stable framework while preparing their own strategies and making their own investment decisions.

The above-mentioned, positive properties of programming are confirmed in the ÖIR (2003) study, where the majority of the respondents assessed programming as having "significant positive impact on the delivery system". There are, however, also a few downsides. First, the whole programming exercise is a demanding and complex procedure, which does not only require skilful administration, but also takes a lot of time. It is not unusual for the whole preparation and negotiation procedure to last for two to three years. Furthermore, negotiations with the European Commission can also involve unwarranted concessions on the side of the Member States, which result out of either generalised policies unjustifiably imposed onto particular region (one size fits all problem) or out of an in-build requirement for general consensus among the Directorates General of the European Commission who might pursue their own "partial interests". Thirdly, programming can have a detrimental effect on experimentation and innovation, an issue to which we will return in the later sections. And finally, the programming requirements are the same whatever the financial size of the programme, which could be unjustified, as illustrated in Section 4.1.2.

In our analysis we did not want to directly weigh advantages against disadvantages. Rather we wanted to focus on the programming contribution to the basic objectives of Cohesion policy, i.e. to what extent does programming actually contribute to the overall impact 
of disbursed resources. As it turns out, the respondents seem to believe that quite a lot. Namely, on average, over half of the impact is attributed to programming and "only" $\mathbf{4 8} \%$ is supposed to be determined by more detailed implementing provisions, like calls for projects. In the EU15 a greater role is attributed to programming (62\% of the impact), while the highest share can, on average, be found in the Member States with regionalised/ de-concentrated systems. Our findings support the generally positive image of programming, since a significant share of Cohesion policy resources' impact seems to be determined by the quality and appropriateness of the operational programmes. This also gives additional leverage to the positive properties listed at the beginning of the section. Furthermore, the importance of programming seems to grow with time and decentralisation, since more and more operations seem to be financed directly on the basis of operational programmes.

\subsubsection{Decision making and allocation of competencies}

Even though programming may be useful, its positive effects in the next step depend on the decision-making relationship between the Member States and the European Commission. The allocation of competencies is clearly presented in European Commission (2004) which ascribes the EC competencies primarily to: (a) ensuring that management and control systems exist and are functioning smoothly; and (b) ensuring efficiency of the assistance on the basis of regular monitoring and evaluation. This approach can be described as a 'shared management' model (as defined in Article 14 of the general regulation), as well as partnership principle (as defined in Article 11 of the same regulation). Furthermore, Article 28 of the general regulation stipulates that "the Member State shall prepare the National Strategic Reference Framework in dialogue with the Commission, with a view to ensuring a common approach". This means that the European Commission has de jure authority to codecide on what should be financed out of Cohesion policy resources, and on how.

This could be questioned on the theoretical grounds of fiscal federalism (Tiebout 1956, Oates, 1968 and 1972, Musgrave 1959) and the more commonly quoted subsidiarity principle. Namely, if there is sound theoretical backing for the redistribution function to be implemented at the central level, this is not the case with the allocative function, where decentralization has definite advantages. As long as Cohesion policy is not seen as a fiscal transfer mechanism, i.e. that its objective is not to compensate for income differentials but is instead devised to strengthen long term competitive capacity of the recipient areas (productivity oriented investment-transfer mechanism), then Cohesion policy has the properties of a policy with allocative objective. This view is confirmed, for example, by Bailey and De Propris (2002), who argue that Cohesion policy "not only had to redistribute resources from the rich to the poor regions/countries, but more importantly ... had to trigger or accelerate a process of economic development in the poorest regions/ countries in order to enable them to compete in the new competitive environment" (ibid., 419). This means, in turn, that decentralization brings added value as it "fosters greater responsiveness of policy-makers to the tastes of individual jurisdictions" as "the distance between citizens (demand) and politicians (supply) on one side, and between citizens and the bureaucracy (management and production) on the other, remains as short as possible", which makes "signalling and control ... effective, resulting in a better congruence between 
public preferences and public policies", while "political clientelism and bureaucratic rentseeking behaviours should be minimized" (Dafflon, 2006: 287). The subsidiarity principle, i.e. that decisions should be taken at the higher level only when that same decision cannot be taken at the lower level, is in fact already enshrined in the Treaty on the EU (Art. 5) and thus also represents one of the basic principles for Cohesion policy (as also specified in the preamble of the Cohesion policy regulations).

Generally speaking, the long-term trend in terms of the allocation of competencies has been towards strengthened decentralisation (Bache, 1998; Peterson and Bomberg, 1999; Allen, 2000; Pollack 2003). This usually means that the European Commission has remained primarily involved only in the decision-making on strategic choices (i.e. structure and financial weight of priority axes) and major projects. On the basis of principal agent theory Bloom-Hansen, (2005) in fact claims, that it is Member States who "appear to be in full control" (ibid., 644). From our own experience, this does sound like an exaggerated proposition, as also exemplified, for example, in criticisms that the Commission's comments and influence in the programming process have been of limited added value. In fact, the ÖIR (2003) study established that only $36 \%$ of respondents support the notion that comments from the Commission are seen as useful (ibid., 80).

This is an important question for the efficiency of Cohesion policy and, in order to check the position of our respondents, we firstly wanted to see whether or not the regulation itself, in their opinion, gives enough flexibility in terms of what can be financed. As it turns out, there seems to be general support for the current scope of operations allowed in the regulations, as the average score to question 9 was 4.9, indicating almost perfect support for the notion that "there is enough flexibility" in this regard.

More surprising, however, are the results to the question as to whether the Commission or the Member States actually have the decision-making power in determining the policy mix, as defined in the operational programmes. The respondents attributed a very high $48 \%$ of decision-making power to the European Commission, with virtually no variation between the EU15 and EU12 Member States. This seems to refute the notion that the major part of decision-making power has been transferred to the Member States' level and is consistent with the findings of Bachtler and Mendez (2007), who argue that "the Commission's role has not been weakened, but the way it has exerted its influence has changed over time" (ibid., 557). What is more, there seems to be general agreement that the balance of decision-making power should shift significantly in favour of the Member States. The optimal decision-making share in determining the policy mix was estimated by the respondents to be $71 \%$ This gives a strong signal that significant additional effort should be put into further strengthening the decentralisation process.

\subsubsection{Structure of operational programmes}

In terms of the structure of the operational programmes, most attention has been given to the dilemma of what the relationship should be between sectoral and regional operational programmes. According to Boeckhout et al (2002), there is no uniform answer to this problem since the solution needs to reflect "the administrative structure and the policy culture in the Member States" (ibid., 12). They point out that, as a guiding rule, sectoral 
programmes should deal with those issues that are priorities from a national development perspective, whilst those that are sub-national in nature (e.g. those that are a priority only for certain regions) should be dealt with in regional programmes (ROPs). The decision in this regard should pay particular attention to who has the responsibility and jurisdiction over the operations in question (national or regional level), and also where the co-financing comes from.

Since we clearly cannot make any generalisations as to the a priori efficiency of either of these arrangements, we wanted to investigate a related issue, i.e. the question of whether or not the relative number of operational programmes (ceteris paribus) has any systematic influence on Cohesion policy efficiency. This can be checked at both the general, as well as regional, levels. As it turns, out the respondents, on average, believe that a smaller number of operational programmes are more efficient (5.8 out of 10 cases), giving reasonable support to the notion that multiplying the number of operational programmes is detrimental to their efficiency.

This, however, does not necessarily apply to the regional level, where, on the basis of the conclusions in the previous sub-section, one could recommend introducing integrated regional operational programmes. These are common operational programmes for more regions, each of which, however, has a separate financial envelope specified in the OP. Regions thus need to find agreement on the more-or-less common set of priorities and activities. In the replies, we found no indication on the basis of which one could generalise about superior efficiency of regional vs. integrated regional operational programmes. We realised, though, that respondents from the national-centralised Member States have found a significantly greater appeal in integrated regional operational programmes. On average, they found them more efficient in almost $60 \%$ of cases. On this basis, it is reasonable to conclude that, in the countries with long established and strong regions, there is no sense in introducing integrated regional operational programmes, but that this might be an interesting option for Member States with weak regions, both administratively and financially.

\subsubsection{Criteria for strategy setting}

The final issue that needs to be addressed in the programming section is about the choices Member States and regions face when deciding on the strategy for the use of Cohesion policy resources. In the context of strengthened decentralization, this is a particularly relevant question, which also touches on the extent to which, or the strictness with which, the subsidiarity principle should be implemented - namely, to what extent should European priorities be considered in the strategy development for a particular region or Member State.

First, two approaches to the operational programme's setup need to be differentiated: a concentrated one; and one with a broad coverage of those policy areas the operational programme is trying to address. There are number of factors that influence such a decision, especially the extent of available resources, the administrative capacity of the region as well as the socio-economic situation (e.g. one major weakness of a region can make a concentrated approach much more obvious). Furthermore, the critical mass consideration 
for a notice-worthy impact of co-financed activities, ceteris paribus, justifies a concentrated approach, even though this can often go against the political preferences. We tested the extent to which the decision on an operational programme's policy area coverage influences the efficiency of supported operations. There is some support in favour of the concentrated approach (average response score 4.3), which seems to be stronger in the EU15 Member States (average response score 3.7). This result probably reflects two effects: (1) EU15 countries are now in the context of reduced aid intensities, so more concentration naturally follows from this trend; and (2) in times of extensive support, a majority of policy areas have benefited, so there is a better awareness of the administrative complexity of EU Cohesion policy, justifying only the best performing activities being supported with EU resources. In our replies, it is furthermore interesting to see that there is significantly greater support for the concentration principle at the higher levels (EU and managing authorities have average score of 3.5) than among the intermediate bodies and regional level (average score 5.3 and 4.6). This might result from the fact that intermediate bodies and the regions have better information on the investment possibilities, which tend not to be concentrated.

The second crucial question in the specification of the operational programmes is the criteria that should be taken into account in the strategy setting, as well as in the negotiation process. Obviously, we wanted to ask the respondents what criteria were taken into account in practice. However, we considered that we would very likely get biased results because at least some of the respondents would be unwilling to detail the actual process (in particular where political and other negatively perceived interventions etc. were applied). For this reason, we focused on the 'ideal' situation and asked instead what criteria should be used in the specification of strategy and operations in particular. This is a widely debated area, not just in terms of the necessary strength of the European vs. national priorities, but also in regard to the importance of synergies, geographical concentration, consideration of administrative costs etc. In fact Ferry et al (2007), point to three broad trends for the 2007-2013 period: (1) a trend to larger and fewer projects, which implies greater selectivity; (2) strengthened thematic targeting especially towards the Lisbon agenda, but also, for example, in the urban dimension; and (3) a trend towards geographical targeting.

In the questionnaire, we listed 11 possible criteria for strategy setting and asked respondents to attach the relative weight on a scale from 0 to 10 (strongest impact) to each one of them. The highest score (8.3) was given to the 'expected impact' according to the 'nationally/regionally defined priority fields'. This was significantly higher than the one for "priorities as defined at the EU level" which had a 6.1 average score. This confirms the general support for decision-making at the level of the Member States and regions. Nevertheless, there also seems to be rather strong preparedness and agreement that EU priorities should be taken into account as well. This conclusion somewhat contradicts both our finding in Section 4.3.2, and the theoretical considerations of fiscal federalism theory and subsidiarity principle, although only partly so, since respondents could suggest that EU priorities should be taken into account by the regions and Member States themselves and that they do not necessarily need EU level to instruct them for doing so. 
The second group, according to their relative weight given by the respondents, are the following criteria: "Operations should have measurable and visible results" (average score 7.2), "complementarity among operations - synergies" (6.9) and "catalytic effect", with an average score of 6.6. The message seems to be that, in the framework of the national priority actions, those should be selected for co-financing who have: (1) measurable and visible results, which is also a preference of the European institutions; (2) who reinforce each other's effects in order to achieve synergies; and (3) actions that would not have happened without the EU support - the catalytic effect. In this regard, it should be pointed out that synergies seem to be very hard to implement in practice. The ÖIR (2003) study points out that "while programming is based on an assumption that the use of the different Funds will be integrated in the implementation process, there is little evidence that this is in fact the case" (ibid., 126). On the one hand, this is the result of different types of operations, especially investment dominated expenditure by ERDF vs. softer, human resources related investments by ESF, which tend to have different "resources project allocation mechanisms". On the other hand, this could not, in practice, explain the separate implementation of either of the programmes. Important factors in this regard are thus institutional considerations on both the national and EU levels. On the latter level, anecdotal evidence suggests that there seems to be reservation by the ESF authorities to draw ESF monies closer to the ERDF programmes, due to a fear that, with time, this might strengthen the argument for joining the two funds together. At the national level, however, the implementation of isolated policies seems primarily to be the result of ineffective coordination and policy-making.

The third group of criteria, in terms of their strength, for strategy and operations selection in the operational programmes refer to "positive externalities of operations" (average score of 6.0), "operations should have quick and predictable absorption capacity" (6.0) and "deadweight/displacement/substitution effects of operations" (5.6) criteria. It might be argued that giving "visible results" criteria more weight than externalities, deadweight, displacement and substitution effects is somewhat surprising. In reality, however, the score for these effects is in fact not so much lower. This might also reflect the perception, especially on the implementing level, that deadweight, displacement and substitution effects are hard to recognise ex ante (the average score for the regional level representatives was a very low 3.4), which, in turn, could only disproportionally complicate implementation. On the other hand, administrative burdens and problems were given a rather high priority. What is interesting to see though is that it is not so much the costs that seem to matter (the "Administrative costs of operations" criteria score was only 4.9), but rather the influence of administrative considerations on delays and uncertainty in implementation. Finally, the lowest scores were given to the two financial criteria - the "EU co-financing rates" and "Other available sources of funding, especially EU" - which on average were given 4.6 and 4.8 respectively. This seems to suggest that Cohesion policy is not about maximising the receipts from the EU, but is instead understood as a means to the set objectives, i.e. about the genuine impact operational programmes have been devised to achieve. 


\subsection{Project generation, appraisal and selection}

All the decisions and steps presented thus far are immensely important for the efficiency of Cohesion policy. Nevertheless, "project generation, appraisal and selection" is the phase which determines the projects that will ultimately receive financial support. And it is the projects that, at the end of the day, are responsible for the impact Cohesion policy resources deliver. The fact that more detailed implementing provisions are responsible for almost half of the impact has already been established in Section 4.3.1. It should be taken into account, however, that, as also indicated in the ÖIR (2003) study, there is limited awareness among beneficiaries of the advantages of the Structural Funds. Even worse, among those that do try to participate in Cohesion policy, there is a feeling that "Structural Funds subsidies are not worth the effort" (ibid., 25).

One of the reasons for such a negative perception is that application and approval processes are overly bureaucratic and complex, inflicting disproportionately high costs on the applicants and, consequently, driving them away. On the other hand, there are strong arguments for introducing more sophisticated appraisal and selection processes, because they do not only increase transparency but can directly contribute to the quality of the selected projects. Thus, as pointed out by Ferry et al (2007), one of the most crucial developments in the implementation systems in the last 15 year has been in the area of project appraisal and selection systems. They report that "approaches have gradually evolved from a "list of projects" approach to a more sophisticated and co-ordinated method of allocating resources to projects" (ibid., 9). Taylor, Bachtler and Rooney (2000), go into somewhat more detail and explain that, prior to 1989, the funding decisions were in fact taken by the European Commission. This was followed by a period in which priority has been put on maximisation of control over Structural Funds and the retrieval of the monies from Brussels. Between 1989 and 1994 there was little systematic project appraisal, and the operational programmes tended to give preference to a limited number of rather few, but large, projects. It was only in the following programming period, which also broadened the scope of interventions towards softer measures, that more systematic and co-ordinated methods of allocating resources started to be introduced. Ferry et al (2007) expanded on this, arguing that more systematic and co-ordinated methods also increased complexity, which in 2000-2006 already spurred calls for more streamlined, but also more competitive systems. The ultimate objective thus remains to ensure efficient, transparent and flexible allocation mechanisms.

In order to better understand the resource allocation problem, one needs to go deeper into the relationship between the public sector in the function of "transfer-distributing authority" and the applicants. The core of the problem lies in the information asymmetry and consequent adverse incentive mechanisms. As pointed out by Horvat (2005: 103), "economic agents proposing projects have the incentive to reap rents and have better information about the returns on these projects than the principals allocating the transfers". The public authority is compelled to make decisions on the basis of information provided by the agents and is, at the same time, also under pressure to act as quickly as possible in order to satisfy both the absorption dynamics (as required by the $\mathrm{N}+2$ rule), as well as to "satisfy their constituencies which may be highly influenced by the lobbying efforts of rent-seekers (e.g. a firm claiming to create or preserve a number of jobs, but 
only if it gets public support)". The presented moral hazard and asymmetric information problem is compounded by the public sector's vulnerability to public choice considerations, i.e. to making sub-optimal decisions due to the election cycle, rent-seeking behaviour by the public sector and median voter problem (ibid.).

There are, however, additional, objective reasons for the intrinsic conflict relationship between the "transfer-distributing authority" and the recipients. First, the public sector needs to ensure accountability and transparency, which represents one of the reasons for red tape. Processes need to be documented since the audit institutions require proof for years back, i.e. they ask the public authority to reconstruct the arguments for their decisions, thus inducing even more paperwork. Second, due to the multi-level governance structure, the regional and national levels respectively need to report to the higher levels, which again puts an administrative burden on the applicant. Finally, the "transferdistributing authority" is usually faced with greater demand than the available resources so it must, as much as possible, ensure objectivity in decision-making, an issue whose consequences we shall turn to later.

On the other hand, these circumstances tend not to be apparent to the applicant, who is usually focused only on his or her project and is, therefore, not knowledgeable about the regulatory environment and circumstances of the public sector. Furthermore, applicants are used to private sector practices, which, to a certain extent, can be applied also in the public sector, but certainly not predominantly so. The basic reason for such a constraint in the framework of project appraisal and selection is the illegitimacy of the decision, which would be based on subjective considerations. Thus, the applicants, based on anecdotal evidence, tend to consider any administration as redundant, which makes the relationship between the applicant and the administration a notoriously conflicting one. Nevertheless, every effort needs to be made to keep this conflict to the minimum possible, as this directly influences the efficiency of Cohesion policy resources. What choices Member States and regions have in this regard is the topic of the following sub-sections.

\subsubsection{Project generation}

Project generation seems to receive different attention in different systems, even though the quality of project proposals is what, in fact, determines the final impact of the operational programmes. The reasons lie predominantly in the extent of the demand for public resources relative to supply (the larger the demand, the lower the incentive for the implementing bodies to get involved in project generation). Also, Member States and regions with the differentiated systems seem to place more attention on project generation. The reason for this is basically that "projects are generated by the existence of the programmes" (Taylor et al (2000: 30) to a much greater extent than in the integrated systems, which forces the implementing bodies to be much more active in making sure there are enough projects available. In the integrated systems, the extent of project generation activity rests much more on the attitude of the particular implementing body.

The project generation phase can, in principle, be divided into two separate dimensions: (1) the generation of the project idea; and (2) the administrative work in order to get the project approved and then also to receive the funding from the implementing body. With 
regard to the former, the generation of the project ideas depends, to a great extent, on real as well as administrative absorption capacity as defined by Mrak and Wostner (2004). If the former cannot be influenced by the public sector, because the extent of the real needs that can be justified for the public support is more-or-less given, the latter certainly can. The extent to which real needs will actually be addressed by the operational programmes depends, firstly, on the capacity of the potential applicants to get involved in the project implementation. In order to increase the number of, or extent to which, potential applicants actually get involved, some administrations and secretariats will facilitate and support involvement of potential project-holders. This can either be in the form of information campaigns, training, workshops etc. Secondly, of all the potential applicants, only those actually aware that there is available funding will get involved. This is especially relevant in the systems that use calls for projects, where timing is also very important. Finally, of those that got involved, only those that can successfully manage all the administrative work required for the application, as well as the required administration work during implementation, will actually receive funding.

Project facilitation and advice can be done internally by the administrations, or can be outsourced. Ferry et al (2007) differentiate among: (a) support given at the programme level; (b) sub-regional support and "multiplier structures"; and (c) external support. The first refers to those cases where support and advice is provided directly by the managing authorities and secretariats, or in their name established one-stop-shops. The second refers to broader and more extensive support, whose objective is to be as close to the applicant as possible (especially important with softer measures), which require larger network of support institutions. In all circumstances, including the one with external support, it is crucial that there is full conformity of interpretation and understanding of framework conditions between the managing authority (or the body granting support) and the support structures. Namely, in the preparatory phase it is never possible to foresee all the possible eventualities. This means that new, unforeseen circumstances can arise in the project preparation phase. The support systems, therefore, must take the need for common interpretation into account, so that the same programme will enable the same framework conditions for all the potential applicants, whoever they get support from.

Advice and support given directly by the managing authorities, intermediate bodies or secretariats is, in principle, the most desirable form, since these institutions are the ones who make the decisions and have the best information and overview. Taylor et al (2000), argue that "pro-active approaches to project operation, involving face-to-face contact between programme managers and applicants, are more likely to be successful than passive methods" (ibid., 61). At the same time, it should be realised that the capacity of programme managers to provide such services tends to be limited, not least due to staffing and remuneration limitations of the public sector. The external, outsourced support can thus represent an efficient bridge between the applicant and the public sector, but only provided that the market for the provision of these services is developed enough. In this case, the competition and specialisation ensure quality service for an acceptable price, which is, of course, crucial for the applicant. It has to be borne in mind that, even though Cohesion policy is a European policy, the market for these services is still differentiated because EU regulations are always integrated in the national administrative systems in a 
context-specific way. This means that there is always local know-how that needs to be ensured. In our questionnaire, we asked to what extent the respondents perceived the market for providing services in project generation and administration to be seriously underdeveloped (zero points) to well developed (10 points). The average score was 4.8, which seems to suggest that there are some support services which can be outsourced, but that a lot still needs to be done directly by the responsible institutions. It is interesting to note that there is no difference between the situation in the EU15 and the EU12 Member States. There is, however, a lower score from the group of "intermediate bodies" that are actually the ones that implement the majority of projects and calls for projects (average score of 3.9). This suggests that the institutions responsible for the implementation of Cohesion policy should either strengthen their own efforts in giving advice and support to the applicants and/or should get involved in market making activities so that the quality of the market provided services would increase.

A special case in project generation is public investments. Responsibility for their implementation usually lies directly with national and regional public authorities. These projects tend to be larger and take a long time to prepare. Due to specialised institutions with clear responsibility there usually is no significant problems with the ability to prepare projects per se. Rather, these institutions might be faced, firstly, with a problem with the quality of their planning which is, among other things, conditioned by the decision-making quality and speed that is often outside of their (full) control and, secondly, with the problem of costs associated with the preparation of the project documentation, which can represent a noticeable share of total project costs (e.g. extensive set of permits and plans, as well as comprehensive cost-benefit analyses, environmental impact assessments, etc.). The whole process gets even more complicated where there are possibilities for publicprivate-partnerships, which in terms of timing additionally prolong the project preparation phase and make it even more complex. All these elements need to be taken into account by the managing authorities, in order to ensure smooth and efficient implementation of the operational programmes.

\subsubsection{Allocating money to intermediaries}

The legal basis for allocating resources in Cohesion policy is the approved operational programmes, while, institutionally, the overall responsibility rests with the managing authority. We have seen numerous institutional setups in the previous sections and how implementing structures can be organised. This clearly also has repercussions for the allocation of money. Ferry et al (2007: 49), broadly differentiate among three approaches:

- programmes which divide the funding envelope at the start of the programme and channel the funding through domestic budget lines or through intermediate bodies, which are then responsible for organising allocations to projects;

- programmes where resources are directly allocated to projects by the managing authority; and

- programmes which operate a combination of allocations to intermediate bodies, and allocations directly to projects. 
We will be looking at the ways of allocating money to projects in the next sub-section, but here the focus lies on the relationship between the managing authority and the intermediate bodies, i.e. on the question of how these relationships can be organised. We have already established in Section 4.2.1. that, especially in the initial stages of introducing new implementation structures, a strong coordinating institution is generally welcomed. In the framework of its overall responsibility however, the following principles need to be taken into account when determining relationships with the intermediate bodies:

First, the system needs to allow and promote flexibility and adaptability to the changed circumstances, as well as new, innovative approaches in particular policy fields. This is especially relevant for the first group of programmes above, which divide the available envelope at the start of the programme. Even though this is done, the managing authority needs to retain the jurisdiction as well as mechanism to reallocate the money to either new instruments (that still comply with the operational programmes) or new intermediate bodies.

Such a system needs to have an incentive mechanism that promotes competition and, thus, allocates money to the best performing intermediate bodies. The competition principle represents the second guiding principle. In this regard it is particularly important to avoid monopolisation of particular activities by one institution. This can often be the case for public or quasi-public institutions, which might get exclusive responsibility for a particular activity. In such a system, it is very hard for the managing authority to monitor the efficiency and effectiveness of the supported operations.

Second, the intermediate bodies to which the money is allocated need to be accountable and need the proper institutional capacity to implement the activities entrusted to them by the managing authority. This again requires careful contracting, an issue which we have already addressed in Section 4.2.3.

In terms of practical aspects, Ferry et al (2007) list four arrangements for allocating money to intermediate bodies, i.e. on the basis of the following:

a) single stream budgets combine Structural Funds and domestic funding, which can be rather efficient for administering but can also pose coordination problems and complexities if not properly managed;

b) allocation of funding "blocks" where only EU money is allocated to a predetermined or selected organisations on the basis of competitive call, which need to find their own co-financing from their own or other sources. An example of such an approach are global grants;

c) strategic thematic or geographical partnerships are dedicated groups of partners who take over the responsibility for the delivery of particular parts of programmes. Such an approach has the advantage of strong motivational element, which promotes inclusive approach to development, however, can be rather problematic in terms of accountability and institutional capacity. 
d) new financial instruments where management is allocated to a special fund, which operates as financial intermediary (e.g. risk capital funds).

\subsubsection{Allocating money to projects}

We described the evolution of project selection mechanisms in the introduction to Section 4.4, where it was established that these mechanisms have become increasingly sophisticated and complex. According to ÖIR (2003), there is general consensus that "project selection processes contributes to the quality, transparency, accountability and credibility of the system" (ibid., 133). They also list number of advantages and disadvantages of the project selection mechanisms:

\section{Table 5: Advantages and disadvantages of project selection}

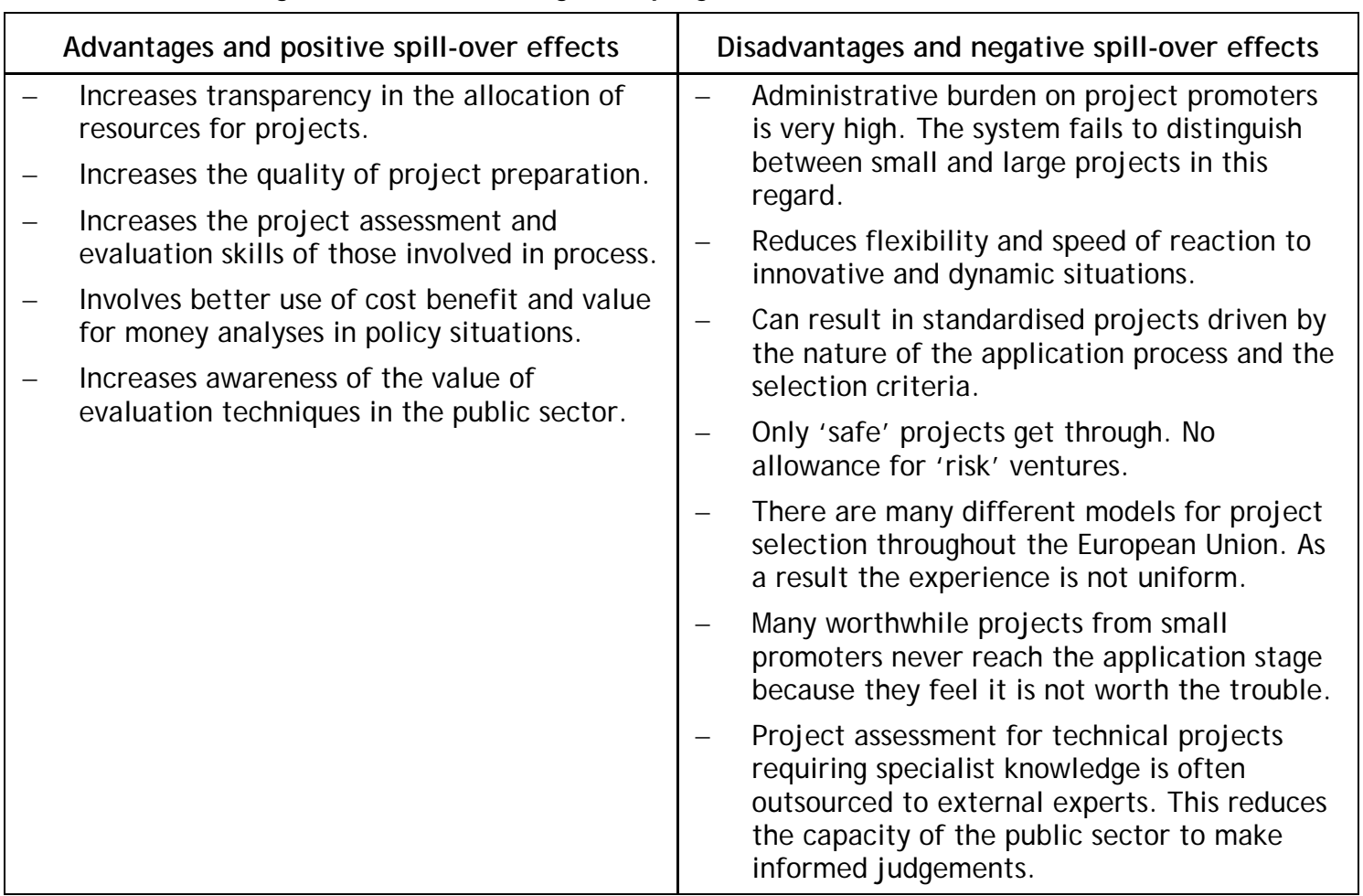

Source: ÖIR (2003: 133)

Before taking a closer look at different mechanisms for project selection, we want to address the question of what level is, ceteris paribus, best suited for decision making. In this regard the ÖIR (2003) study suggests that "project selection seems to be tackled more pro-actively in decentralised contexts and in smaller programmes, whereas centrally managed programmes and bigger ones still often struggle for getting reasonable procedures in place" (ibid., 90). This can be especially problematic in already bureaucratic administrative systems where Structural Funds additional requirements tend to make matters worse.

At the same time, it has to be recognised that the issue of project selection is a predominantly national/regional matter. The European Commission has retained its 
decision-making powers only for projects whose total cost is greater than $€ 50$ million (€25 million in the field of environment) ${ }^{11}$. We have already presented the theoretical arguments as to why decision-making should be made as close to the people as possible in Section 4.3.2. However, we also wanted to inquire about the experience of our respondents. We thus asked "to what extent does European Commission's project approval (major projects) contribute to selected-project quality on a scale between 0 - not at all and 10 - significantly". It turns out that there seems to be reasonable acceptance of the Commission's role in project-level decision-making as the average score was 5.6, with no significant variation between the Member States and the types of institutions the respondents came from. This could be explained in a number of ways: first, that the Member States and the regions consider major projects as highly risky because of the monies involved and therefore welcome the shared responsibility (reduction of uncertainty in the latter stages); second, that they accept that major projects should also have a European dimension, thus that apart from the contribution to the convergence of the region/Member State in question, major projects should also posses straightforward "European value-added"; third, it has already been argued in ÖIR (2003), that the obligatory cost-benefit analyses and the separate approval by the European Commission increase the rationality in decision-making, among others, due to the reduced possibilities of decision-making based on political pressure (ibid., 93).

The second issue we wanted to investigate was the decision-making relationship between the national and the regional level. Firstly, we wanted to inquire to what extent the decision-making is presently (actually) performed at each level. The replies suggest that on average $35 \%$ of the decision-making is done at the regional level, with this share being significantly higher in the EU15 (67\%) and significantly lower in the EU12 Member States (26\%). This is an expected result and is not such an important conclusion, since there are also marked differences among the Member States themselves. There is, however, a very strong message for the EU12 in terms of the optimal decision-making relationship. Namely, there is overwhelming support for additional decentralisation of decision-making in the EU12 Member States to the regional level. The respondents, on average, considered that the optimal relationship between the national and regional level would be 50:50. The regional representatives in both EU15 and EU12 would naturally want to go even further, as their average optimal allocation of decision making would be $75 \%$ for the EU15 and 70\% for the EU12 in favour of the regions. This might be somewhat overdone but additional decentralisation of decision making in the EU12 does seem to have strong and uniform support, in spite of all the reservations put forward by Bachtler and McMaster (2007).

Mechanisms for project appraisal and selection

The best way to illustrate the complexity of the project generation, appraisal and selection processes is to look at the average time needed to get from a project idea to the actual start of the project implementation. We have asked this question in our questionnaire for

\footnotetext{
${ }^{11}$ Article 39 of the general regulation.
} 
four types of projects: major infrastructure projects; smaller infrastructure projects; productive investment projects; and human resources related projects. The longest time to get a project started is obviously needed for maj or infrastructure projects (on average 26.8 months according to our respondents). This is followed by smaller infrastructure projects where 15.2 months is needed on average. For productive investment and human resources related projects, 12.2 and 9.9 months is needed respectively. Thus, in planning an operational programme, it should be born in mind that there are, on average, around $\mathbf{1 . 5}$ to 2.5 years delay for the implementation of infrastructure projects, and around half to one and a half years delay for productive investment and human resources related programmes. Of course, the time needed can vary significantly depending on a particular project and also on the exact modalities of the implementation systems. We can observe, for example, that the EU12 countries seem to be less time-efficient in all project types apart from small infrastructure projects - the time difference is two months on average, while for small infrastructure projects EU12 seem to require 1.5 months less than the EU15 Member States. An even bigger variation is seen among the different implementation systems. We can confirm the findings of ÖIR (2003), as well as our conclusions from Section 4.2.2, that a de-concentrated approach, especially if it involves several levels of decision making, is less time-efficient. The time required for project approval in deconcentrated systems seems to be significantly longer, even up to $60 \%$ in case of major infrastructure projects. This time efficiency needs to play a very prominent role in deciding on the project allocation mechanisms.

According to Ferry et al (2007), there are basically two approaches to allocating funding to projects: on the basis of so called "call systems", which rely on some kind of invitation to potential beneficiaries to submit projects applications; or on the basis of so called "strategic projects", which are chosen and approved directly by the responsible institution.

Call systems have the advantage of being transparent - they improve public awareness of the given policy objective, which in turn provides an additional incentive for economic actors to change their behaviour in the desired direction (e.g. stimulating a general investment cycle in a sector even though only some of the potential beneficiaries will actually receive the funding). Due to their competition-based approach, call systems also contribute to the quality of the generated projects. On the other hand, due to their pre-set standards they can become overly bureaucratic and unfriendly for the project promoters, because they can make the relationship between the applicant and funding institution more distant and formal and, also, they might give false impression of the more objective selection procedures, which, it is sometimes argued, are misused for "political purposes". As far as the administrative dimension is concerned, Mrak and Wostner (2004), have argued that the extent of administrative burden for the applicant needs to be proportionate to the anticipated benefits for the applicant (taking into account the likelihood of receiving the funding). Such a principle generally means that, for more sophisticated and financiallyheavy projects, more extensive documentation should clearly be required but, at the same time, that the whole appraisal need not necessarily be done in one step. Namely, it can be much friendlier for applicants to get the first feedback on a shortened requirement list, which gives them the framework conditions for the project's structure. Only at the second 
stage should they be asked to submit the whole, required documentation. Such an approach can save both money and time for applicants, rendering the selection process more efficient.

According to Ferry et al (2007), call systems can generally be differentiated in a number of ways. First, one can differentiate between "continuous calls" and "calls with fixed deadlines". Continuous calls invite projects without any time limitations on submissions, until the available funding is exhausted. Their advantage according to Taylor et al (2000), is that projects can be fully developed and project promoters are not then rushed into premature submission. A problem might appear in such cases, however, as time pressure can have detrimental effects on the project's quality, especially in terms of its strategic orientation. It is inherent in continuous call systems that projects are appraised as they arrive (i.e. on a first-come-first-served basis). At the end of the day, this can result in the best projects not being selected because the funding has dried up. On the other hand, calls with fixed deadlines face a problem of immature project proposals being submitted, as well as the problem of concentrated workloads for the administration. However, they may be better equipped to introduce more sophisticated quality selection criteria which will promote the strategic dimension of projects. Increasingly, a mixed type of calls system is being used, i.e. a fixed deadline call, which allows more than one deadline for project submission. This can combine some of the positive qualities of both approaches; however, in such cases, attention needs to be put into the time-management of such calls. It is important to ensure that the results of one call opening are known early enough for the unsuccessful applicants to update their bids for the new call opening.

Second, calls can be differentiated in terms of their openness and selectivity. Some Member States invite projects on a broad, rather unrestricted basis, i.e. requiring project proposals to comply only with the eligibility criteria which, apart from the usual "compliance with the strategic objective of the programming document" or priority axis, tend to be of a rather formal nature. Such an approach might be relevant for small projects or cases where demand significantly falls behind the available funding; however it is much less likely in cases where only projects with genuine added value would be selected, and/ or those projects where public support is actually needed. On the other hand, selective calls are much more restrictive in terms of their appeal to potential project promoters. However, their selection criteria are exactly the means through which the public interest can be encouraged, because project promoters would adapt their activities towards the desired direction. This positive feature of restrictive selection criteria does, however, increase the workload for the selection committees, thus prolonging selection processes. It might also be discouraging or biased against more innovative and risky projects, resulting sometimes in the criticism that such an approach is stimulating the production of standardised projects ${ }^{12}$. The ÖIR (2003) study argues that even standardised projects can be innovative, provided that "innovation has been build into strategy" (ibid., 135). On the

\footnotetext{
12 According to the ÖIR (2003), study, it is decentralised systems in particular that are especially vulnerable to project standardisation.
} 
basis of our experience and anecdotal evidence, we see the problem of innovation more in the light of the jurisdiction of selection committees to make their decisions on the basis of a more quality (instead of quantified) criteria which, of course, also allows for more subjectivity. The more there is quality assessment in the process, the more conducive it is to innovation, although also more susceptible for "in-transparent decision-making". Taylor et al (2000) in fact differentiate between the "automatic yes/no systems" which leave no room for discretion, but are, at the same time, insensitive to variation in quality and between "scoring systems" which give an enhanced role to appraised judgement (which however is subjective in its nature).

The issue of transparency will be addressed in a later sub-section. We did, however, enquire about the qualities of open or selective calls in our questionnaire. In the replies, there is some preference given to more open calls (average score was 4.3), but it is instructive to see that, in the EU15 Member States, support for such an approach seems to be much greater (average score 3.4). This seems to indicate that longer experience and better know-how, as well as longer democratic tradition, and therefore greater trust in politics, are conducive to more open calls, which allow for more innovation, as well as more subjectivity. Where this is not the case, preference seems to be given to stricter, more quantified approaches, where the political sphere has less room for intervention. Interestingly, however, the greatest support for open calls comes from the regional level (average score 2.4), where, due to their "closeness to the people", there seems to be a closer relationship and mutual recognition between project promoters and funding institutions.

\section{Strategic projects}

The second approach to allocating money to projects is on the basis of a "strategic projects" selection process, which is, by definition, non-competitive. Instead projects are selected on the basis of some kind of consensus, the modalities of which depend on the type of the strategic projects. In all cases, the projects can be identified during the programming process ${ }^{13}$ or during the implementation phase. According to Ferry et al (2007), there are four type of strategic projects.

a) Major projects are large, complex projects, which also require separate approval procedure by the European Commission if their total cost is over $€ 50$ million or $€ 25$ million in the field of environment (refer to Section 4.4.3(i)). Such projects tend to be "flagship", distinctly visible projects, which consequently focus only on a limited number of issues as well as beneficiaries. They tend to be dominated by managing authorities or/ and national ministries.

b) Negotiated projects are similar to the major projects in terms of their importance and size however there is a difference in their generation and selection. Namely

\footnotetext{
${ }^{13}$ Ferry et al (2007) conclude that "the use of pre-selection appears to be decreasing in most of the EU15 Member States" (ibid., 58).
} 
for such an approach it is typical that projects are generated and/ or selected on the basis of the partnership principle, often on the sub-national level. Such an approach is still a top-down approach in its nature however it gives more attention also to the bottom-up initiatives and consensus building. The extent to which this is the case, of course, depends on the coordinator and the extent to which an inclusive approach is used.

c) Complex projects are projects that are composed of more parts financed from different operational programmes and generated jointly by a number of managing authorities (e.g. combining hard investment with human resources development), usually on a specific issue or topic.

d) Groups of projects are similar to complex projects but are predominantly prepared by the project applicants. This can be in the interests of the managing authority because in this way some of the administrative workload can be transferred to the project management.

The main weakness of the strategic project selection approach is certainly the noncompetitive nature of project selection, which also has a tendency to result in less transparency ${ }^{14}$ (decision-making is to a much greater extent top-down based). On the other hand, strategic project, if managed properly, can have as a consequence reduced and more streamlined administrative processes. Taking all of the above into account, it seems reasonable to argue that a strategic project selection process should be used in those cases where the project in question is "quasi-monopolised" in nature (either because of the nature of the activity or because of the single possible beneficiary) or where successful project implementation requires such a broad scope of partners that the competition would be meaningless or that the administrative costs would be prohibitive. Cases, for example, include waste management systems (where economic costs pre-determine the minimum level of users and thus the projects), risk prevention measures (where there clearly needs to be top-down coordination of activities taken by a large number of actors) or even national/regional business zones (where geography and initial conditions might pre-determine who would be the beneficiary).

\section{Transparency and selection process}

The quality of selected projects crucially depends on the transparency of the decisionmaking process. In turn, this is dependent on the governance quality. This is usually closely related to the advancement of the political sphere and the level of trust vested in it. We have already put forward the public sector constraints in terms of public choice considerations in the introduction to Section 4.4. This cannot be totally eliminated, even in the most advanced administrations and democracies. Thus both call as well as strategic

\footnotetext{
${ }^{14}$ Cleary this can only be argued on average, since selection committees making use of the call systems are also questioned on their neutrality or might be constrained by lack of expertise, resources and adequate data (Taylor et. al, 2000: 38).
} 
projects selection systems should aim to produce transparent, replicable and objective results. This can be achieved to a greater or lesser extent in a number of ways.

We enquired in our questionnaire as to what type of selection process and, in particular, selection committee "come closest to selecting best available projects", ranging from government decision or managing authority/ intermediate body decision only or a selection process involving multi-departmental selection committees, perhaps also including external independent experts or even the foreign ones. Taking into account the results from the open calls question, we would also expect that results would significantly differ between the EU15 and EU12 Member States. This is fully confirmed in the results as the only universal conclusion for the two groups is a low approval rate for the direct governmental decision-making (average score 5.6 for the EU12 and 5.2 for the EU15 Member States). The EU15 Member States then have significantly greater trust in the managing authorities/intermediate bodies' internal appraisal procedures, since the average score increases to 6.0, while for the EU12 Member States the trust level falls, relative to the direct governmental decision-making, to 5.5. The EU15 Member States have highest trust (average score 7.0) in the multi-departmental decision-making by the MA/IB, but are wary of the involvement of independent experts (score of 6.0), and even more wary of foreign experts (score of 5.6). EU12 Member States do not seem to trust single authorities and seem to feel greater assurance in broader institutional involvement in the appraisal process. Thus, the EU12 Member States certainly approve of involvement of independent experts, including foreign ones (average scores 7.6 and 7.7 respectively), but are somewhat less fond of MA/IB decision-making based on multi-departmental selection committees (average score 6.6). This again confirms that political tradition and trust in political systems significantly determines the optimal selection process in the framework of strategic project selection systems.

Small vs. large projects

Bachtler et al (2006) report that a number of countries have put more and more emphasis on larger, key projects, or at least on integrated groups of smaller projects, with the intention to "strengthen the strategic impact of projects" (ibid., 68). The debate on the value added of larger and smaller projects is as long as Cohesion policy itself and is clearly dependent on the particular socio-economic situation, as well as the quality of project generation, selection and implementation systems as a whole. It is for this reason that we have not asked about this issue in the questionnaire. We wanted, however, to identify the advantages and disadvantages of both kinds of projects.

Larger projects, by definition, mean a smaller number of co-financed projects, which makes monitoring of the co-financed projects easier. Large projects are, ceteris paribus, also associated with less administration per monetary unit and are easier to control. Large projects tend to be infrastructure related projects, which might also require introduction of complementary activities (e.g. human resources development). On the one hand, it is easier to introduce such complementarities where there are a limited number of large projects; on the other hand, however, the increased project complexity can reduce some of the savings in administration. More importantly, larger projects are associated with 
significantly higher risk for the managing authorities of "not spending money in time" if something goes wrong with the project, or even if there are just simple delays associated with, e.g. acquiring legal permits etc. Such delays are common with larger projects, as reported by Gross and Davies (2007). Due to their size, large projects also significantly reduce the flexibility of the manager in the implementation phase, should there be a change, for example, in the socio-economic situation of the recipient region. Finally, as already indicated in the previous sub-section, larger projects are far more susceptible to political pressure, which can have detrimental consequences on the impact of Cohesion policy resources.

Smaller projects, on the other hand, tend to be more demanding in terms of management requirements and are thus associated with a greater administrative burden per monetary unit spent. For example, human resources related projects need to keep track of each individual who has benefited from the programme, even though the amount of money spent might be minimal. A larger number of supported projects require more advanced project generation and selection mechanisms, as well as good monitoring systems. Together, these can ensure transparent project selection and management. It is crucial that administrative and implementation system requirements, both for the beneficiary as well as administration, are kept to the minimum necessary taking into account the principle from section 4.4.3(iii): the extent of the administrative burden needs to be proportionate to the anticipated benefits for the applicant. Admittedly, this can sometimes be difficult to ensure, due to formal requirements. For this reason, it is even more important that smaller projects get EU co-financing only for those parts of their activities that are easier to control, and not necessarily for all of the costs associated with the project, as long as this does not disproportionately increase the administrative burden.

Thus, both large and small projects have advantages and disadvantages. Larger projects are more visible in themselves; however, a larger number of smaller projects also mean a significantly greater coverage of potential beneficiaries, areas and possibly also opportunities and challenges. As already indicated, it is not possible to come to a general conclusion about what kind of projects have greater impact. On the basis of the abovementioned arguments, however, it is clear that, in countries and regions with efficient implementation systems, smaller projects can have comparatively at least as great an impact as larger projects.

\subsection{Financial management and controls}

According to Boeckhout et al (2002), financial management and controls are one of the most important phases in the framework of systems and procedures. They have been receiving increasing attention with every reform of Cohesion policy, making them now a top priority for the Member States (ÖIR, 2003). Financial management and controls are immensely important, not just due to the "sound financial management" requirement, but also because all the required processes designed to ensure compliance, both within the administration and with the beneficiaries, can be made prohibitively high.

The overall objective of financial management and control systems is thus to ensure legality and regularity of transactions, as well as compliance with the principles of 
economy, efficiency and effectiveness (sound financial management requirement). This can be split down into more specific tasks. First, in terms of financial management, Member States need to ensure that "the beneficiaries receive the total amount of the public contribution as quickly as possible and in full" (Art. 80 of the general regulation). Obviously public contributions can be made only against expenditures declared that are: (1) real; (2) for the products or services that have been delivered in accordance with the approval decision; (3) the applications for reimbursement by the beneficiary must be correct; and (4) the operations and expenditure must comply with Community and national rules, without any possibility of double-financing with any other Community or national schemes and with other programming periods (Art. 13 of Commission Regulation 1828/2006).

In order to comply with these standards, Member States are required to set up complex management and control systems, where particular attention has been given to the division and description of responsibilities, taking due account of the principle of separation of functions (Art. 58 of the general regulation), establishment of financial flows, together with the required documentation flow from the European Commission to the beneficiary and backwards in case of recoveries (audit trails) and crucially the control provisions, which need to be specified in detail (specification of responsibilities, control lists, risk analyses where sample checks are used, etc).

Even though the number of checks and controls has all but reached prohibitive levels, the Court of Auditors still found that "the Commission does not maintain effective supervision to mitigate the risk that the controls delegated to the Member States fail to prevent reimbursement of overstated or ineligible expenditure" (European Court of Auditors, 2006: 128) since "control failures were found in all of the audited programmes" (ibid., 120). Furthermore, the European Court of Auditors is reasonably confident that, for the budgetary year 2006, "at least $12 \%$ of the total amount reimbursed to Structural Policies projects should not have been reimbursed" (European Court of Auditors, 2007: 152). On the other hand the ÖIR (2003) study found that only $38 \%$ of respondents agreed with the proposition that "financial procedures are seen as necessary and work well" (ÖIR, 2003: 103). The same study also found that only $55 \%$ of respondents believe financial procedures have a positive impact, while the corresponding figure for control mechanisms is an even lower $50 \%$ It is true that we have found that $45 \%$ of the administrative procedures are due to the national legislation. Nevertheless, the financial management and especially control provisions are in fact very closely regulated on the side of the Commission, so national authorities cannot be predominantly "blamed" for perceived ineffectiveness of management and control systems. The following table lists some of the major concerns as expressed in the ÖIR (2003) study. 
Table 6: Advantages and disadvantages of financial management and control systems

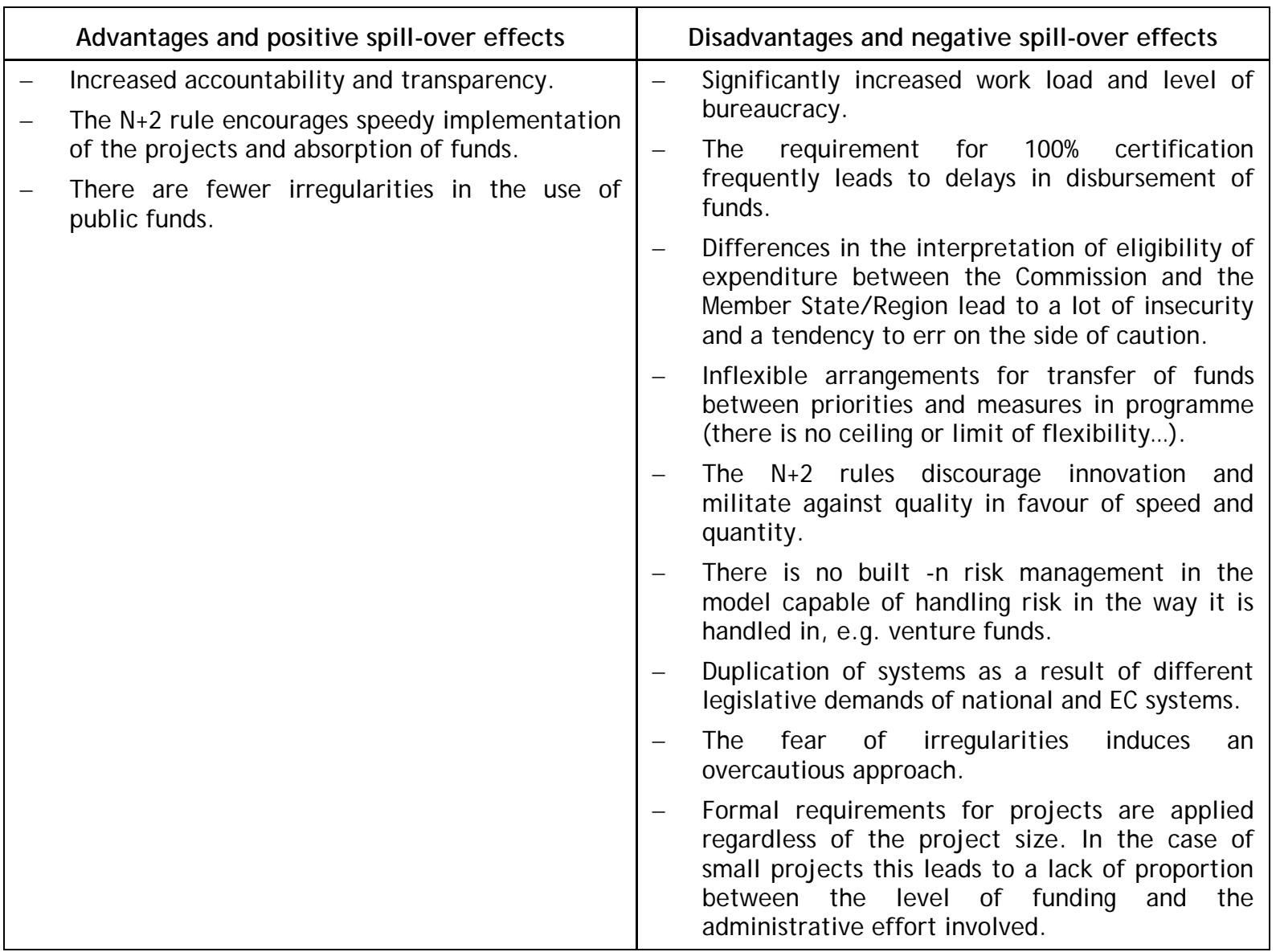

Source: ÖIR (2003: 144); slightly generalised by the author

Clearly, the concerns raised above refer to the legal requirements and practices that applied to the 2000-2006 period, and some of the shortcomings were partly eliminated or at least reduced for the 2007-2013 period. Among such reforms, we could mention: decentralisation of eligibility rules to the Member State level (Art. 56 of the general regulation); a more strategic approach in programming with the elimination of Programme Complements and measures; payments to be calculated on the priority axis level. All of this should give greater flexibility to the Member States. The new requirements still need to be tested in practice. There are already concerns, however, that, for example, the description of management and controls systems is already "more detailed and complex than in 20002006" (Gross and Davies 2007: 35). Furthermore, due to the multilevel governance model with "the Commission remaining ultimately responsible for the regularity of structural operations expenditure" (Court of Auditors, 2006: 118), it is doubtful whether the abovementioned reforms would bring about noticeable simplifications. There might be a potential positive impact, however, from the new Lisbon Treaty, which changes previous article 274 of the Treaty in that "The Commission shall implement the budget in cooperation with the Member States" (the text in italics is new).

Our approach in tackling the issue of financial management and control, is based on a horizontal logic, since Member State's practices differ significantly in line with their institutional practice and tradition. In other words, we will break down the problem of inefficient financial management and controls into two dimensions. 
1. The time- and cost-efficiency of the system. The sound financial management principle is a prerequisite for the use of Cohesion policy resources; however, the framework condition is that "the extent and intensity of checking should make an appropriate balance between the overall cost of operating those checks and the overall benefits they bring" (European Court of Auditors, 2004: 7). In other words, the costs and time required to comply with the principle of sound financial management must not eliminate or overly diminish the benefits of the very operation it is providing finance for. In order to better understand this relationship, we will check where the inefficiencies in terms of timing and costs come from.

2. The issue of the relationship between the implementing and supervisory bodies involved in Cohesion policy implementation. In a multilevel governance context, the complexity of the systems and processes can increase dramatically if their jurisdictions, daily activities and understanding of the policy objectives are not fully in line and coordinated.

\subsubsection{Timing problem}

There seems to be general agreement that timing is a serious problem in Cohesion policy. The ÖIR (2003) study publishes a number of statements to support such a conclusion: e.g. only $29 \%$ of respondents agree that the decision on approval of programmes, programme complements and transfer of payments is taken promptly; that only $35 \%$ of respondents find the Structural Funds implementation system to be efficient; and that only $43 \%$ of respondents believe that "the time taken from application to approval is not excessive" (ibid., 73). We have asked a similar question in our questionnaire, namely "to what extent do time management problems in project approval and implementation phases represent a problem" on a scale between 0 and 10. The average response was 7.5 without a significant variation, which confirms that time management is indeed a problem and this conclusion holds both for EU12 as well as EU15 Member States.

Our interest, however, lies more in identifying what phases are, to the greatest extent, responsible for such a situation. The most significant reason in the EU12 Member States seems to be hidden in the inefficiency of the public administration, especially their inexperience (average score 7.4), while their inefficient operation ${ }^{15}$ is deemed as somewhat less problematic, although still rather severe (average score 6.5). Public administration in the EU15 Member States is not considered to be so problematic (average scores 5.6 and 4.8 respectively), which again confirms that there is a learning period needed for efficient implementation on the side of administration. Apart from the administration the most significant factor for delays in the implementation seems to come from "long internal administrative procedures due to national requirements" (average score 7.2), which is noticeably higher than for the "long administrative procedures due to EU requirements" (average score 6.1). Contrary to the conclusion from Section 4.1.1 (that on

\footnotetext{
15 The question asked was whether the reason for time management problems lies in: "Public administration has the experience, but is inefficient in itself (low motivation,...)".
} 
average $55 \%$ of the administrative procedures are estimated to be due to EU legislation), it seems that, in terms of timing, it is particularly national administrative procedures that are problematic. In this framework, most criticism is attributed to "overly complex interdepartmental/inter-institutional coordination requirements" (average score 6.9) and, especially in the EU15 Member States, also to the "unclear procedures and rules" (average score of 7.1 for the EU15 and 6.3 for the EU12 Member States). This seems to confirm the findings from the previous studies that time inefficiency is closely related to the involvement of too many institutions in the implementation and controls, giving rise to problems of different interpretations and, in certain cases, also different administrative/reporting requirements, as commented by one of the respondents. Finally, it was also the "inability of decision makers to decide" which fitted in the first group of time inefficiency factors, with an average score of 6.4 , and with no significant variation between the EU12 and EU15 Member States. It is also interesting to note that, in terms of the institutional approach to implementation, it seems that regionalised systems (both concentrated and de-concentrated) are particularly susceptible to the problem of unclear rules and procedures (average scores 7.5 and 7.4 respectively). Regionalised, deconcentrated systems, however, seem to exhibit more efficient decision-making (average score 5.4 vs. 6.4 on average) and, interestingly, seem to have fewer problems with coordination (average score 5.0 vs. 6.9 on average).

First in the second group of time inefficiency factors was "budgetary procedures and provisions" (average score 5.7), followed by "legal complaints" (average score 4.9) and "lobbying of the pressure groups" (average score 4.1). The only note-worthy difference between the EU12 and EU15 Member States could be found in difficulties due to legal complaints with the EU12 countries having an average score much higher than the average (5.4), whereas, in terms of institutional approach to implementation, it was especially respondents from regionalised de-concentrated systems who did not find legal complaints as problematic (average score 1.6).

Without having analysed the problems related to controls, we can nevertheless draw some conclusions. The problem of timing does not seem to be as much related to the decisionmaking process per se, but rather with the procedures and requirements that need to be dealt with by the administrations: financial management and controls clearly being of central importance. The roots for this can be found in inexperienced administration where systems are being newly introduced. Universally, however, their time-inefficiency seems to be predominantly caused by the rules set by the Member States themselves. The procedures should be as straightforward, short and adapted to the needs of the beneficiaries as possible; results seem to indicate however, that standardisation and low number of involved institutions is more conducive for such an implementing structure.

\subsubsection{Management and administration costs}

In terms of administration costs it is very hard to make generalised observations since there are notorious difficulties in getting comparable data. The study by ÖIR (2003) has come to the conclusion that there are significant differences in costs from one programme to another. These do not seem to be correlated with the type of administrative system, type 
of programme or relative size of the programmes and therefore other factors seem to be at work (ÖIR 2003: 119). Boeckhout et al (2002: 16) have found that "staffing requirements are relatively modest in the fields of infrastructure (roughly $€ 15$ million per staff member), moderate in the case of business support (about €3 to €5 million per staff member), and high in human resource development or small-scale farm support (up to €0.1 million per staff member for the latter). More important than looking at the exact number of how much one administrator can manage per year (data namely differ enormously with different authors, e.g. Horvat, 2005), it is worth highlighting their eventual conclusion, that it is not the funding level that seems to be decisive for staffing requirements, but the number of projects. The reason for this is that every project, irrespective of size and type, needs to be processed through more-or-less the same procedures and requirements.

The same conclusion can be made on the basis of the data, which were collected by the informal group of the EU12 Member States that met in March 2007 in Bled, Slovenia. This again reveals large variations among the individual Member States. What is instructive, however, is that there seems to be a consistent pattern in terms of staffing requirements by Fund. If operations financed under European Social Fund are taken as a benchmark, then the data suggests that the European Agricultural (EAGGF) and the Fisheries Fund (FIFG) required almost twice as many personnel for their management - exactly $90 \%$ more. The European Regional Development Fund, on the other hand, requires, on average, 22\%less, and the Cohesion Fund a massive $88 \%$ less. Taking into account the types of operations these Funds finance, it can be said that these results fully comply with the findings of the ÖIR (2003) study.

In our questionnaire, we additionally asked what respondents believed was the maximum still-acceptable level of management costs for the administrative body implementing Cohesion policy, and what is the maximum acceptable level of administration costs for the project holder. The results reveal that the still-acceptable level of management costs for the administration were, on average, estimated to be $6.9 \%$ of the programme value ${ }^{16}$, while the administration costs for the project-holder should, on average, not exceed $8.8 \%$ Thus, even though the two bases of calculating costs are not fully comparable (programme costs vs. project costs), we could say that on average respondents believe that total administration costs of Cohesion policy should not surpass roughly $15 \%$ of total costs. In quantitative terms for the 2007-2013 period, assuming the minimum possible co-financing rate of $15 \%$ which indeed is unrealistically low due to revenue-generating projects provisions, PPPs, etc., these costs amount to $€ 61$ billion and every percentage point reduction in administration costs would save more than $€ 4$ billion. This represents a significant amount which, if it could be brought down, would noticeably improve the overall efficiency of Cohesion policy.

In determining the consequences for implementation systems, we first need to realise that Cohesion policy resources form only part of a broader development policy which regions

\footnotetext{
${ }^{16}$ It should be added that a few respondents have differentiated the maximum administration costs by the operational programme size.
} 
and Member States pursue. According to the Fourth Cohesion Report, "between 2000 and 2006, transfers from the Funds amounted, on average, to an estimated $60 \%$ or so of total public capital expenditure in Portugal, 48\% in Greece and 24\% in Spain", while "transfers to Italy, Germany and Ireland are estimated at around 9.0\% of public investment" (European Commission 2007: 143). Secondly, the administration costs are, on average, lower for the implementation of national policies only, which is due to the multilevel governance framework, additional administrative requirements, additional controls, etc.

In such a setup, regions and Member States have two non-exclusive strategies for how to optimise the impact of available resources. First, as already argued in section 4.4.3(vi), in order to support the kind of operations that are predominantly characterised by smaller projects, it is of paramount importance that the implementation systems are made as lean and efficient as possible. Taking into account the findings from that section we could add, not just that only parts of small projects which are easy to implement and control should actually be financed by EU resources, but also that the principle of proportionality should be widely used in order to bring down costs. This principle has been introduced in the Regulations (Art. 13 of the general regulation), however it is still rather unclear how extensively it will be used, or rather how extensively the control and audit institutions will allow it to be implemented.

Should proportionality not be used so extensively, the regions and Member States would increase the overall impact of their public incentives, if they would use Cohesion policy predominantly to finance operations, which are cheaper to implement while the rest would be financed through national policies only. This would significantly change the intervention structure of the EU resources (towards larger investment predominantly financed through ERDF and Cohesion Fund). The overall strategy would, however, remain unaffected since the part left out of the Cohesion policy would be taken over by the national policies. Such a commitment could be contract-based or established on the basis of the open method of coordination approach. Although there would be clear and measurable benefits in terms of overall impact, the political acceptability of such an approach would be highly questionable on the part of the European Commission.

\subsubsection{Legality \& regularity vs. efficiency \& effectiveness: the right balance}

On the one hand, ÖIR (2003) points out that "there is universal acceptance of the need for a strong system of financial control" and also that "overall, there are no fundamental objections to the methods that are used" (ibid., 142). Thus, taking into account the multilevel governance context and the given division of responsibilities, a proper system of checks and balances must be ensured. There seem to be significant doubts, on the other hand, as to what extent the principle of the European Court of Auditors - that "the overall cost of controls should be in proportion to the overall benefits they bring in both monetary and political terms" (European Court of Auditors, 2004: 2) - is in fact complied with.

In the questionnaire, we investigated whether or not respondents believed that Cohesion policy implementation systems were over or under-controlled. There was universal agreement that the systems are over-controlled (average score 6.9). There was no 
significant variation between where the respondents come from, geographically or institutionally. We furthermore wanted to get an insight into what level is responsible for such a conclusion. As it turns out, it is both the EU and the national level that seems to be responsible for over-controlling: almost two-thirds and three-quarters of all respondents believe there is over-control at the EU and national level respectively. This result is not surprising, taking into account the number of levels and institutions involved in controls.

Each item of expenditure is initially inspected by the responsible person, and subsequently controlled by another person, whose functions are separated by regulations (controls are both administrative as well as on-the-spot, Commission Regulation No. 1828/2006). If there are more layers in the management systems, higher-level institutions must exert additional sample controls of the lower-level intermediate bodies, in order to make sure that their management and control systems function properly. After being verified by at least two 'pairs of eyes' and by an additional sample-based control in multilevel management systems, declared expenditures are again checked (also on a sample basis) by the certifying authority. On top of the above-mentioned controls, public institutions are usually subject to internal control requirements, which represent an additional level of control. At the third stage, the correctness of expenditures is verified by the European Commission officials, on the basis of which the money is actually disbursed. This also marks the end of the internal control mechanisms and the start of the following round of verification - external auditing. There are again numerous institutions responsible for doing audits. First, the national audit authority, then the national Courts of Auditors, while on the European level there are audits of the European Commission, the European Court of Auditors and, additionally, there is OLAF, the European Anti-Fraud Office who can conduct their own investigations. Thus, overall, there are more-or-less ten steps of verifications and controls that each expenditure is, or at least can be (due to sampling) subjected to. To make the whole system worse, "there is no formal requirement for control bodies to coordinate the planning of these checks or to take into account the checks made by the others" (European Court of Auditors 2004: 7). However, the new 2007-2013 regulations do give more attention to providing tools that could be used to improve coordination (e.g. the audit strategy as foreseen in Art. 61 of the general regulation).

In spite of these massive (and increasingly extended) control system requirements, however, the European Court of Auditors still found control failures in all of the audited programmes (European Court of Auditors 2006: 128), thus indicating that, since no obvious improvement seems to be established during the years, other problems must be involved. A study by the European Court of Auditors (2004), found the biggest weaknesses of the system in: (1) unclear and inconsistent objectives of the policies; (2) lack of coordination of the involved institutions; (3) absence of information on costs and benefits of control and audit operations; and (4) inconsistent application of the approach taken, extent, timing, coverage, margins and follow-up. The ÖIR (2003) study, on the other hand, identifies as the biggest problem the duplication of systems, (especially the problem of reinterpretation of the national decisions on the European level) which creates uncertainties, an assessment that our analysis fully supports. They also find it to be a regular practice that "the same institutions are controlled several times, each time from different institutions, with each 
applying slightly different rationales" (ibid., 106). An, at least partial, answer to this problem in the 2007-2013 regulations might lie in the decentralisation of eligibility rules to the national level, as stipulated in Article 56 of the general regulation. As already mentioned, it remains to be seen how this provision will be reconciled with the provision that the European Commission remains ultimately responsible for the regularity of structural operations expenditure. Apart from the duplication problem, there are reports that "controls are very time consuming", that they "are considered to keep the implementing bodies and MAs from doing their actual work", and that "the cost-benefit ratio from control procedures ... does not make sense" (ÖIR, 2003: 106).

Different assessment of the problem requires different remedies. In order to reduce the complexity of the control systems, two approaches could be conceived. First, there could be a modification of the way controls are being performed and/ or second, the number of institutions involved in this process could be reduced, resulting in a considerable reduction in the complexity of the system, as well as in a reduced uncertainty problem due to multilevel governance problem.

As far as the former approach is concerned, there is certainly significant scope for optimisation in the manner controls and audits are performed. The starting point in this regard should be the proposition that "there is no overall vision or coordination of the many and varied systems" (European Court of Auditors, 2004: 6). In such a context, it is clearly all but impossible consistently to determine the reasonable assurance on the legality and regularity of transactions, because every control institution has an inbuilt incentive to 'play it safe', i.e. to interpret the regulatory environment in a rigid and formalistic manner. Through time this gives rise to working practices that put "more focus on procedures rather then on content" (Wostner 2007: 10), a common observation made by all the EU12 Member States at their informal meeting in Slovenia. The same problem was also recognised by the EU15 Member States, i.e. that due to fear of irregularities Cohesion policy uses an overcautious approach (ÖIR, 2003). It was also voiced at the Santander, Spain, seminar of $9 \mathrm{~J}$ uly 2007 on "Present and future of regional policies", namely that it is the risk-averse practices that represent the biggest challenge for more efficient implementation systems. Such an approach can ultimately lead to verification practices, whereby the impact of the disbursed resources becomes irrelevant as long as Member States have abided by the rules, while the implementation system would remain very complex and costly. Clearly, although this is an exaggeration, it does point to the danger the system could end up in if appropriate measures to reverse the present trend were not introduced. These include, amongst others, measures that would strengthen the mutual trust of the institutions involved. It needs to be recognised that a system such as Cohesion policy is "only tenable in a polity with high levels of mutual trust ...." (Hooghe, 1996:117). Thus, taking all of the above-mentioned into account, the new approach for the 2007-2013 period, together with the European Commission's initiative of the so called "contracts of confidence", seems to be a step in the right direction. The new system requires the national audit authorities to prepare an audit strategy, which will specify the bodies to be audited, methods to be used, sampling methods, indicative planning of what shall be done when, etc. Should this ex-ante coordination work also be used to address the abovementioned problems, if necessary also in the contract of confidence, then this could 
represent the basis for (in time) more streamlined management and control systems. The Commission already made clear in 2002 that "where [the Commission] has confidence in the effectiveness of the management and audit system in a Member State or region, the level of auditing which it needs to undertake can be reduced" (European Commission, 2003: 10). One possible snag of this approach, of course, is that contracts of confidence could, in practice, also make national control and audit institutions more, and not less, rigid than they are at present.

There are, however, reasons to expect that the possible improvements based on the contracts of confidence approach, which in principle could be introduced immediately, would be limited, due to the restrictive provisions set by Cohesion policy's regulatory environment. Thus, a more significant departure from the present concept of how Cohesion policy is implemented was proposed by the Estonian delegation at the Maribor conference on the future of Cohesion policy, organised by the Slovenian Presidency in April $2008^{17}$. The proposal rests on the idea that disbursement of funds should be based on agreed outcomes and results instead of verification of invoices. Such an approach has merit, in particular with regard to reorientation of focus from legality and regularity to efficiency and effectiveness, while at the same time also significantly reducing the administrative burden (since there would be no need any more to verify each and every single invoice). The challenge remaining to be solved is whether such an approach could be applied to all types of operations financed under Cohesion policy (e.g. infrastructure) and, secondly, how could uncertainty due to ex-post 'reinterpretation and questioning' of the ex-ante agreed outcomes by the auditors (potentially also resulting in money recoveries) be avoided.

Hence, additionally or complementary to the possible improvements presented thus far, the use of the second approach also seems necessary - i.e. improvement of the implementation and control systems based on a reduced number of involved institutions, in particular in the relationship between the Member States and the European level. Within this framework, the first option would be in institutional merging of the national and European Courts of Auditors, on the one hand, and of European Commission and national audit authorities on the other. This would not just reduce the number of involved institutions but would, consequently, also reduce the problem of reinterpreting the rules due to the multilevel governance structure. That being said, this scenario could prove hard to put into practice, especially due to legal considerations, the independence requirements, etc. Therefore, a better solution might be found in the way that Cohesion policy is being conceived. There are two fundamental principles of public policy and fiscal federalism theories that underpin the functioning of Cohesion policy. First, there is the generally accepted notion that one of the functions that should be performed at the central level is (financial) redistribution. Thus, this principle, by definition, supports Cohesion policy's positioning at the EU level. At the same time, however, the principle of subsidiarity argues

\footnotetext{
${ }^{17}$ For more details refer to the presentation ' 13 Estonian contribution to the debate CFCP Slovenia April 2008' accessible at http:/ / www.svlr.gov.si/en/ eu_presidency/ events/ conference_on_the_future_of_cohesion_policy/
} 
in favour of decision-making at the levels where costs and benefits accrue (see Section 4.3.2), i.e. at the Member State or regional level. In areas with high aid intensities, where Cohesion policy resources, therefore, represent a large share of public resources, there could be an accountability reservation to full application of the subsidiarity principle, since, in these areas, costs would be covered by taxpayers outside of the benefit area. This could be mitigated with lower co-financing rates. In such a setting, however, Cohesion policy could be conceived as a bulk transfer of investment-conditioned financial resources, where full responsibility for the legality, regularity, efficiency and effectiveness would be entirely transferred to the Member State/regional level. An EU perspective would continue to be ensured through very strategic "programme(s)" ${ }^{18}$, which would be prepared by the recipient areas and agreed with the European Commission. Furthermore, the Commission would continue to monitor the progress made by the Member States (e.g. on the basis of core indicators and financial indicators), which would allow monitoring and evaluation of Cohesion policy impact as a whole. Such an approach to Cohesion policy implementation could be termed as "coordinated full decentralisation", which would preserve Cohesion policy as a genuine European policy, but would, at the same time, radically reduce Cohesion policy administration costs, without any detriment to the effectiveness of the used resources. In fact, it could be argued, both on the basis of theory and the answers of our respondents from practice (overwhelming support for further decentralisation) that the impact of Cohesion policy would actually improve.

\subsection{Monitoring and evaluation}

\subsubsection{Efficiency principles}

The importance of monitoring and evaluation is presented as one of the basic principles and value added of Cohesion policy. Empirical studies show, however, that there is a rather limited translation of findings into policy-making. For example, the ÖIR (2003) study found limited support (57\%) for the notion that "evaluation system is seen to be necessary and to work well", and even less (43\%) for the notion that "the interaction/integration between management and monitoring is seen as efficient". On the other hand, Polverari et al (2007) report that the long-term trend in the complexity, as well as applicability, of the monitoring and evaluation systems is encouraging. According to them, the first financial perspective after the 1988 reform saw a very modest introduction of the monitoring and evaluation systems, which provided evaluations "of a low quality" and "lacking methodological rigour" (ibid., 5), also due to "widespread lack of monitoring data", which was "particularly acute at the regional level" (ibid., 5). Through time, the monitoring and evaluation systems became more complex, computerised and, by the 2000-2006 period, also increasingly starting to use internet-based platforms. In this period, however, the legislation was rather prescriptive (ex-ante, mid-term, ex-post framework), which was later considered as a weakness. Thus, for the 2007-2013 period, more focus was given to

\footnotetext{
${ }^{18}$ The specificity of such a programme should be lower than the current National Strategic Reference Frameworks, which often already specify rather concretely the foreseen operations.
} 
"strategic, results oriented approach based on flexible and needs based evaluations" (ibid., vii).

Such an approach gives Member States a lot of flexibility. As a result, they need to give due attention to a number of efficiency principles. The monitoring and evaluation systems should be integrated in the policy cycle, which means that the monitoring and evaluation systems need to be designed in line with the prevailing institutional setup for Cohesion policy. In terms of evaluation design, three approaches have been defined (Polverari et al, 2007: 1) a national approach used in centralised systems; (2) a guided approach with weak central coordination function but decentralised implementation; and (3) a regional approach, characterised by total decentralisation of monitoring and evaluation. Even though the monitoring and evaluation design is, of course, subordinate to the general implementation systems structure, there seems to be a trend towards (at least) a strengthened central coordination function and greater standardisation. Whatever the implementation system, Member States themselves can decide on the design of the monitoring system. This can be integrated (one system for multiple programmes and regions), or fragmented (one system per region and/or programme). The advantage of the latter is that it allows for needs-based, tailor-made solutions, which also make it more adaptable. The former, however, sets minimum standards, which can contribute to a system's quality, allow aggregation of data, and savings due to economies of scale, and, finally, integrated frameworks promoting exchange of information, all of which can contribute to greater quality of monitoring systems. Looking at the trends, it seems that, if properly managed, the benefits of the former tend to outweigh the benefits of the latter (ibid.). Finally, in order to ensure accountability and legitimacy of the interventions, a monitoring system needs to comply with the transparency criterion, so that the data collected are methodologically sound, correct, timely and, thus, ultimately also trustworthy.

The second important efficiency dimension in monitoring and evaluation is the "pragmatic approach", used because over-ambitious approaches tend to have negative consequences (ÖIR, 2003). Monitoring and evaluation systems, in order to make sense, need to bring "value-for-money". Collecting and analysing data namely creates costs both for the beneficiaries and the administration As a result, processes need to be streamlined and data collected only for exactly defined purposes. In order to achieve this, it is necessary to establish a clear vision and focus for monitoring and evaluation, as it is only on this basis that practical information and results without administrative overload will be collected and fed into the policy cycle. That being said, it is increasingly recognised (Polverari et al, 2007) that the crucial quality-determining factor for monitoring and evaluation is the quality of the data collected at the project level. This also institutionally needs to be fed into the monitoring system as close to the project itself as possible, otherwise it is increasingly hard to ensure the correctness of the data. Of course, monitoring systems should have in-built quality control systems. These can, however, never replace first-hand knowledge of the project. In the framework of the pragmatic approach, it is also necessary to point out the principle of proportionality, since smaller projects clearly are much more sensitive to the administrative burdens associated with monitoring than larger projects, where greater monitoring requirements are not just feasible, but also justified. 


\subsubsection{Partnership}

Partnership was also one of the fundamental principles introduced following the reform of the Structural Funds in 1988 and its scope has been broadened ever since. The first 19891993 programming period saw the introduction of monitoring committees, which "came to play a key role in reprogramming of CSFs and OPs ... as well as providing an input into some of the evaluations carried..." (Polverari et al, 2007: 4). In the subsequent programming periods, their jurisdiction was extended as far as approval of selection criteria and modifications of implementing provisions. This is not surprising from the perspective that the partnership principle has always been intended to cover all stages, from programme preparation to implementation to monitoring and evaluation. It is remarkable, however, that monitoring committees managed to acquire such power even though they were increasingly set up from economic, social, regional and other representatives, which was, in effect, only possible to the detriment of the decision-making powers of the official authorities.

There seems to be an undisputed value added in strong partnership. The ÖIR (2003) study, for example, found $73 \%$ support for the idea that a "monitoring committee is necessary for the efficient implementation of the Structural Funds" (ibid., 67). There is, however, significantly greater scepticism as to the effectiveness of the present arrangement, since just over half $(55 \%)$ of questionnaire respondents believe, not just that a monitoring committee is necessary, but also that it works well. This can, to a great extent, be explained by "the lack of total real involvement of the social partners in genuine decision making and implementation" (ibid., 75).

Optimal arrangements for cooperation between administrative bodies and partners are clearly dependent on the institutional and historical practices of different regions and Member States. There are common lessons, however, with regard to identification of those phases of the policy cycle where the partnership principle brings the highest added value. This is important to be aware of, because it gives guidance to the administrations as to where additional effort in cooperation with the partners is necessary. This, in turn, would improve partners' ownership of the programme and thus also the effectiveness of monitoring committees' functioning. According to our respondents, the three most important phases, with the greatest value added for partners' involvement, are programming (average score 8.2), strategic monitoring (average score 6.8) and evaluation (average score 6.3). There is less support for partners involvement in the definition of implementing provisions - for example calls for projects - (average score 5.8), as well as for the definition of administrative procedures and regular, operational monitoring (both with an average score of 5.6). Thus, according to our findings, administrations and managing authorities should attach most attention to developing close relationships with the partners in programming, strategic monitoring and evaluation. This, in turn, suggests that monitoring committees should primarily be involved in strategic issues and not get involved in operational matters. This casts some doubt on the present requirement that monitoring committees "shall consider and approve the criteria for selecting the operations" (Art. 65 of the general regulation). On average, it seems to be difficult to expect enough specialised know-how among the committee members on operational issues; furthermore, partners could also potentially be faced with a conflict of interest. Under the 
conditions stated above, and with an attitude of genuine cooperation from the managing authorities, the partnership principle rightly represents one of the building blocks of Cohesion policy implementation. This is also demonstrated by high approval rates among the respondents with regards to strategic issues. 


\section{CONCLUSIONS}

This paper has addressed the issue of micro-efficiency in Cohesion policy, a factor determined by the institutional or absorption capacity of recipient regions and Member States which, in turn, co-determine the macro-economic impact of Cohesion policy. The paper set out systematically to analyse the choices recipient Member States and regions face when deciding on the implementation system. In doing this, they are restricted by the regulatory framework agreed at the EU level, which, according to our findings, is responsible for $55 \%$ of the administrative procedures. The EU regulatory framework, therefore, plays a prominent role with regard to possible improvements of the system. On the other hand, the remaining $45 \%$ of the administrative procedures are due to national/ regional requirements. The challenge in making generalised observations about them is that the institutional and legal setup of recipient Member States is immensely diverse, necessitating the use of either the relevant typologies of approaches or horizontal guiding principles.

The paper presents a systematic analysis of the properties of different implementation systems, with regard to their contribution to the micro-efficiency of Cohesion policy. In doing so, a strong conclusion emerges: the implementation systems, together with the regulatory framework, not only need simplification, but proper change. This conclusion is not based solely on the finding of the European Court of Auditors, who have reported control failures in all of the audited programmes, but also on the fact that: (a) time needed from the project idea to the project start in a modern, globalized world is unacceptably long; in fact, time management in general represents a fundamental weakness of the Cohesion policy implementation systems; (b) there is a universal agreement that the system is over-controlled, which holds true both at the national and EU levels; and (c) the management costs on the side of administration and project-holders were estimated to be as high as $15 \%$ of total costs, which would translate to a soaring €61 billion over the financial perspective, and potential savings of $€ 4$ billion for every percentage point reduction in administration costs.

Four proposals for improvements have been put forward. The most radical of them, the "coordinated full de-centralisation", conceives Cohesion policy as a bulk transfer of investment-conditioned financial resources, where full responsibility for the legality, regularity, efficiency and effectiveness would be entirely transferred to the Member State/regional level while, at the same time, preserving Cohesion policy as a genuine European policy. The analysis furthermore reveals that: the subsidiarity principle is still not taken into account to a satisfactory degree; that experience and political context have significant influence on the (optimal) design of implementation systems; and, finally, that, on average, there seems to be merit in concentration, both with regards to the number of operational programmes (less so for their thematic focus), as well as the number of institutions involved in the implementation systems, horizontally and especially vertically. 


\section{REFERENCES}

1. Allen D, 2000, "Cohesion and Structural Funds: Transfers and Trade-Offs" in Wallace, $\mathrm{H}$ and Wallace W (eds) "Policy-Making in the European Union", Oxford University Press, Oxford.

2. Bache I, 1998, "The Politics of European Union Regional Policy: Multi-level Governance or Flexible Gatekeeping", Sheffield Academic Press, Sheffield.

3. Bachtler J and McMaster I, 2007, »EU Cohesion policy and the role of regions: investigating the influence of Structural Funds in the new Member States", Environment and Planning C: Government and Policy, advance online publication.

4. Bachtler J and Mendez Carlos, 2007, »Who Governs EU Cohesion Policy? Deconstructing the Reforms of the Structural Funds«, Journal of Common Market Studies, Vol. 45, No. 3, pp. 535-564

5. Bachtler J and Taylor S, 1999, "Objective 2: Experiences, lessons and policy implications", European Policies Research Centre, University of Strathclyde, Glasgow

6. Bachtler J and Taylor S, 2003, "The Added Value of the Structural Funds: A Regional Perspective", IQ-Net Report on the Reform of the Structural Funds, European Policies Research Centre, University of Strathclyde, Glasgow

7. Bachtler J, Downes R, Michie R, Ronney M L, Taylor S, 2000, "New Structural Fund Programming: Laying the Foundations", IQ- Net, European Policies Research Centre, University of Strathclyde, Glasgow

8. Bachtler J, Ferry M, Mendez C, McMaster I, 2006, "The 2007-2013 Operational Programmes: A Preliminary Assessment", IQ-Net Thematic Paper No. 19(2), European Policies Research Centre, Glasgow

9. Bachtler J, Michie R, 2001, "Programme Review: November 2000-May 2001", IQ- Net, European Policies Research Centre, University of Strathclyde, Glasgow

10. Bailey D and De Propris L, 2002, 》The 1998 reform of the European Structural Funds: Entitlement or Empowerment «, J ournal of European Public Policy, 9:3, J une, 408-428

11. Bloom-Hansen J, 2005 »Principals, agents and the implementation of the EU cohesion policy«, J ournal of European Public Policy, 12:4, August

12. Boeckhout S, Boot L, Hollanders M, Reincke K-J, de Vet J-M, 2002, "Key indicators for Candidate Countries to Effectively Manage the Structural Funds", Final Report, Sectoral and Country Reports, NEI, Ecorys, Rotterdam

13. Boot L, de Vet J-M, Feekes F, 2001, "Absorption capacity for Structural Funds in the regions of Slovenia", Final Report, NEl, Rotterdam

14. Bradley J, forthcoming, "EU cohesion policy: the debate on Structural Funds", International J ournal of Public Policy

15. Dafflon B, 2006, "The assignment of functions to decentralized government: from theory to practice" in Ahman E and Brosio G (eds.) "Handbook of Fiscal Federalism", Edward Elgar, Cheltenham, UK and Northampton, MA, USA

16. Ederveen S, de Groot LF H, Nahius R, 2006, "Fertile Soil for Structural Funds? A Panel Data Analysis of the Conditional Effectiveness of European Cohesion Policy", Kyklos, Vol. 59 - 2006 - No. 1, pp. 17-42

17. European Commission 2003 "Communication of the Commission on the simplification, clarification, coordination and flexible management of the structural policies 20006", C(2003)1255, Brussels, 25 April 2003.

18. European Commission, 2004, "The respective responsibilities of the Member States and the Commission in the shared management of the Structural Funds and the 
Cohesion Fund Current situation and outlook for the new programming period after 2006"

19. European Court of Auditors 2004 "Opinion No 2/2004 of the Court of Auditors of the European Communities on the 'single audit' model (and a proposal for a Community internal control framework), (2004/ C 107/ 01) 30.4.2004

20. European Court of Auditors 2006 "Annual Report on the implementation of the budget concerning the financial year 2005"

21. European Court of Auditors 2007 "Annual Report on the implementation of the budget concerning the concerning the financial year 2006"

22. Ferry M, 2005, "Regional Governance in the EU: A Comparative Assessment", EoRPA Paper 03/05, European Policies Research Centre, University of Strathclyde, Glasgow

23. Ferry M, Gross F, Bachtler J, McMaster I, 2007, "Turning strategies into projects: The implementation of 2007-2013 Structural Funds programmes", IQ-Net Thematic Paper No. 20(2), European Policies Research Centre, Glasgow

24. Fitzgerald R, and Promé C, 1996, "Generating Good Projects", IQ-Net Thematic Paper 1(3), European Policies Reseach Centre, University of Strathclyde, Glasgow

25. Gross T, Davies S, 2007, „Programmes in transition - between closure and start; Review of Programme Developments: Winter-Summer 2007“, IQ-Net Review Paper No. 20(1), European Policies Research Centre, University of Strathclyde, Glasgow

26. Hooghe L, 1996, "Building a Europe with the Regions: The Changing Role of the European Commission" in Hooghe L (eds.) "Cohesion Policy and European Integration: Building of Multi-level Governance", Oxford University Press.

27. Horvat A, 2003, "Absorption Problems in the European Union's Structural Funds Focussing on Administrative Absorption Capacities in the Candidate Countries"; Vienna University of Economics and Business Administration; dissertation, December 2003

28. Horvat A, 2005, "Why does Nobody Care About the Absorption?", Working Paper No. 258/2005, WIFO, Wien

29. Musgrave R, 1959, "The Theory of Public Finance", McGraw-Hill, New York.

30. Oates W, 1968, "The theory of public finance in a federal system", Canadian J ournal of Economics, 1, 37-54.

31. Oates W, 1972, "Fiscal Federalism", Harcourt Brace J ovanovich, New York.

32. ÖIR, 2003 "A Study of the Efficiency of the Implementation Methods for Structural Funds", Commissioned by European Commission, DG Regional Policy

33. Peterson J and Bomberg E, 1999, "Decision-Making in the European Union", Macmillan Press Ltd, London.

34. Pollack M, 2003, "The Engines of European Integration: Delegation, Agency and Agenda Setting in the EU", Oxford University Press, Oxford.

35. Polverari L, McMaster I, Gross F, Bachtler J, Ferry M, Yuill D, 2005, "Strategic Planning for Structural Funds in 2007-2013. A Review of Strategies and Programmes", IQ-Net Thematic Paper No. 18(2), European Policies Research Centre, University of Strathclyde, Glasgow

36. Polverari L, Mendez C, Gross F, Bachtler J, 2007, "Making sense of European Cohesion policy: 2007-2013 on-going evaluation and monitoring arrangements", IQ-Net Thematic Paper No. 21(2), European Policies Research Centre, University of Strathclyde, Glasgow

37. Raines P and Taylor S, 2004, "Mid-term Evaluation of the 2000-2006 Structural Funds Programmes", IQ-Net Thematic Paper No. 11(2), European Policies Research Centre, University of Strathclyde, Glasgow 
38. Taylor S, Bachtler J and Polverari L, 2001, "Information into Intelligence: Monitoring for Effective Structural Fund Programming", European Policies Research Centre, University of Strathclyde, Glasgow

39. Taylor S, Bachtler J, J osserand F and Polverari L, 2004, "Achieving the aspirations of the 2000-2006 period", IQ-Net Thematic Paper No. 14(2), European Policies Research Centre, University of Strathclyde, Glasgow

40. Taylor S, Bachtler J, Rooney MS, 2000, "Implementing the New Generation of Programmes: Project Development, Appraisal and Selection", IQ Net Thematic Paper, European Policies Research Centre, University of Strathclyde, Glasgow

41. Taylor S, Rooney M L, Bachtler J, 1999, "Out-sourcing programme management: a comparative assessment", Final Report to the Ministry of Economics and SMEs, Technology and Transport of the Land of Nordrhein-Westfalen, European Policies Research Centre, University of Strathclyde, Glasgow

42. Tiebout CM, 1956, "A pure theory of local expenditures", Journal of Political Economy, 64, 416-24

43. Wostner P., 2007, "NMS Meeting on Cohesion Policy; Implementation 04-06", powerpoint presentation, Bled, Slovenia, 1-2 March 2007 


\section{ANNEX - QUESTIONNAIRE}

Remark: Questions one to six and eight are not addressed in this paper as they will be dealt with in a separate paper.

\section{COHESION POLICY RATIONALE}

1. Is EU Cohesion policy, in your opinion, needed (please, place " $\mathbf{X}$ " in the appropriate box)?

\begin{tabular}{|c|c|c|c|c|c|c|c|c|c|c|}
\hline $\begin{array}{c}\text { Cohesion } \\
\text { policy is not } \\
\text { needed }\end{array}$ & \multicolumn{9}{|c|}{$\begin{array}{c}\text { Is needed, } \\
\text { but with } \\
\text { limited } \\
\text { resources }\end{array}$} & \multicolumn{2}{|c|}{$\begin{array}{c}\text { Should be } \\
\text { one of } \\
\text { crucial EU } \\
\text { policies }\end{array}$} \\
\hline 0 & 1 & 2 & 3 & 4 & 5 & 6 & 7 & 8 & 9 & 10 \\
\hline & & & & & & & & & & \\
\hline
\end{tabular}

2. Should Cohesion policy provide income transfers or should it provide resources for productive investment (please, place " $X$ " in the appropriate box)?

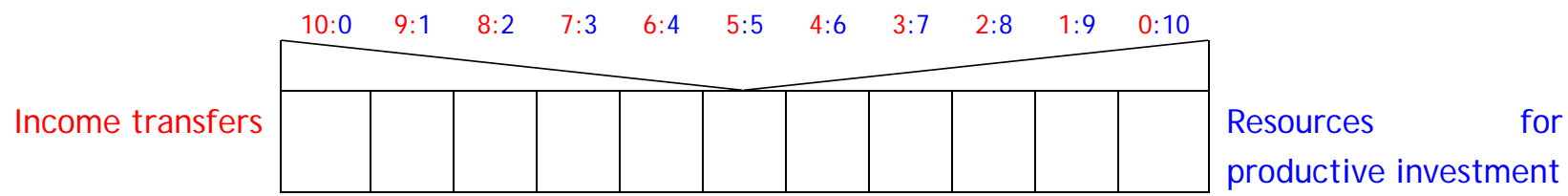

Example: the mix of $7: 3$ would indicate that Cohesion policy should provide $70 \%$ of resources for income transfers and $30 \%$ for productive investment.

3. What do you feel should be the focus / objective of Cohesion policy (please divide 100 points between the following objectives):

Economic growth and economic competitiveness

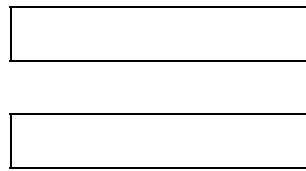

J ob creation

Balanced regional development

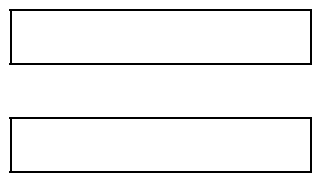

Environmental sustainability

Social sustainability

Support for overcoming temporary shocks

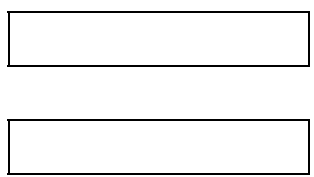

Support for structural adjustment

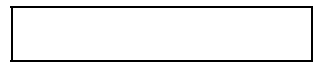


Urban development

Rural development

Preventing depopulation of peripheral areas

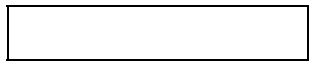

Other (please specify):

TOTAL $=100$

4. What should be the eligible area (you can "X"s more then one box)?

Country level

Macro-regions level (East-Germany, South Italy,...)

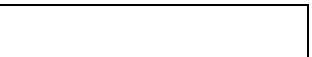

NUTS II regions

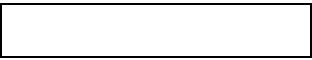

NUTS III regions

Other (please specify):

5. What criteria should be taken into account for the allocation of Cohesion policy resources (please divide 100 points between the following criteria)? 
GDP / GNI per capita

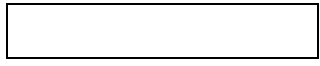

Employment level

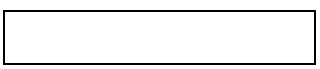

Unemployment level

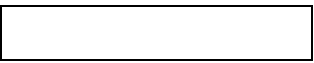

Population density

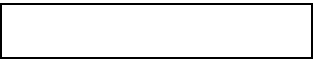

Innovation criteria $(R \& D$, patents, ...)

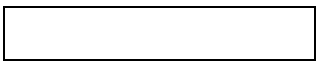

Education criteria

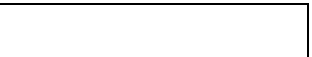

Social criteria (poverty levels, ...)

Territorial criteria (island, rural, mountainous areas,...)
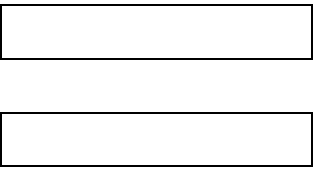

Prosperity of the neighbouring regions

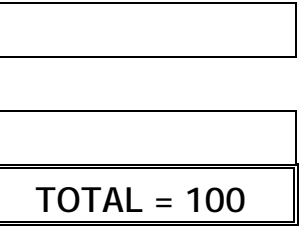

Other (please specify):

TOTAL = 100

6. Would you say there exists a maximum level of transfers from funds supporting cohesion to a Member State/Region (as \% of GDP) beyond which Cohesion policy can no longer be efficient?

No

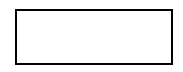

Yes

If so, what would this limit be in \% of GDP:

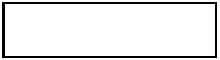

7. Would you say there exists a critical minimum level of resources per operational programme (in million $€$ per year) below which present Cohesion policy approach is no longer justified?

No

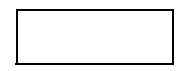

Yes

If so, what would this limit be in million $€$ per year:

Below 10 million $€$ per year

Between 10 and 20 million $€$ per year

Between $€ 20$ and $€ 40$ million per year 
Between $€ 40$ and $€ 70$ million per year

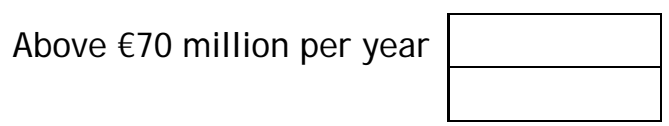

8. To what extent do you support the logic and rationale of (on a scale between $\mathbf{0}$ not at all - and $\mathbf{1 0}$ - totally):

Convergence objective

Regional competitiveness and employment objective
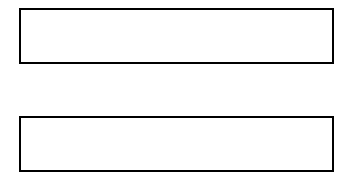

Territorial coop. : cross-border cooperation

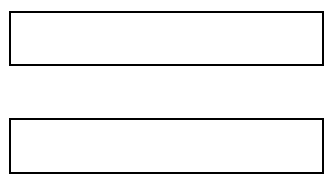

Territorial coop. : trans-national cooperation

Territorial coop.: inter-regional cooperation

\section{PROGRAMMING}

9. How do you feel about Cohesion policy regulations and the Community Strategic Guidelines in terms of Member States' flexibility for deciding the scope of assistance and eligibility rules (place " $\mathbf{X}$ " in the appropriate box)?

\begin{tabular}{|c|c|c|c|c|c|c|c|c|c|c|}
\hline $\begin{array}{c}\text { The } \\
\text { framework } \\
\text { is too } \\
\text { narrow }\end{array}$ & & & & & $\begin{array}{l}\text { There is } \\
\text { enough } \\
\text { flexibility }\end{array}$ & & & & & $\begin{array}{l}\text { There is } \\
\text { too much } \\
\text { flexibility }\end{array}$ \\
\hline 0 & 1 & 2 & 3 & 4 & 5 & 6 & 7 & 8 & 9 & 10 \\
\hline
\end{tabular}

What areas of intervention (or eligibility) are you $\quad$ What areas of intervention (or eligibility) missing:

o 10

$0 \quad 0$ 
10. For a given Member States, would you render as more efficient a more centralised approach with smaller number of operational programmes or more decentralised approach with greater number of OPs?

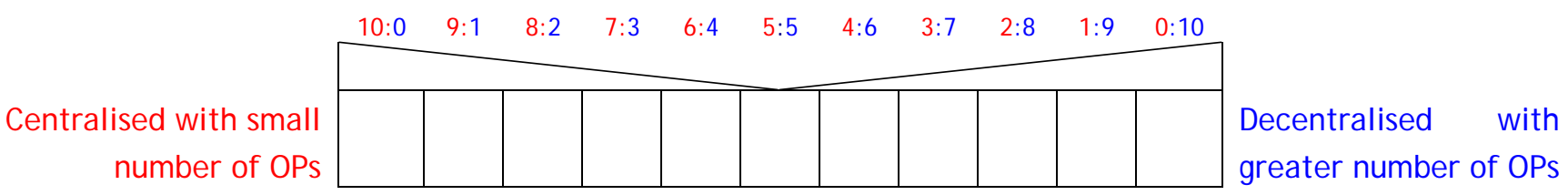

Example: the mix of 7:3 would indicate that in your opinion centralised approach tends to be more efficient in 7 out of 10 cases. The same logic applies to the next question.

11. Regional operational programmes (separate OPs for each region) vs. integrated regional programmes (one OP for more regions prepared on the basis of regional input, but managed at the national (evel): in terms of absorption and impact, which works better?

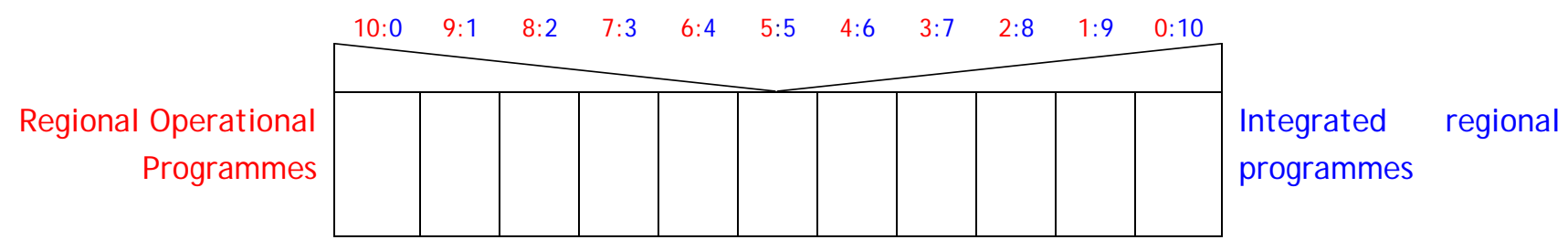

12. To what extent, in your estimation, is operational programmes planning (policymix), determined by the Member States/regions, and how much by the Commission? And what is, in your opinion, the optimal balance?

\begin{tabular}{|c|c|c|c|c|c|c|c|c|c|c|}
\hline $10: 0$ & $9: 1$ & $8: 2$ & $7: 3$ & $6: 4$ & $5: 5$ & $4: 6$ & $3: 7$ & $2: 8$ & $1:$ & $0: 10$ \\
\hline
\end{tabular}

ACTUAL

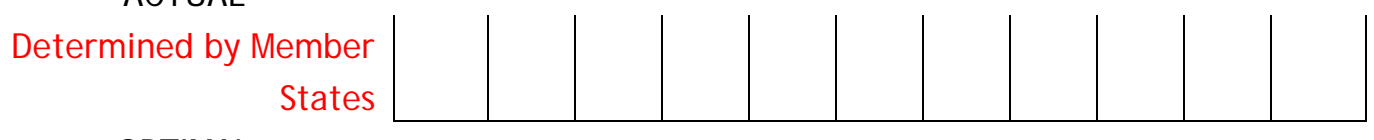

OPTIMAL

States
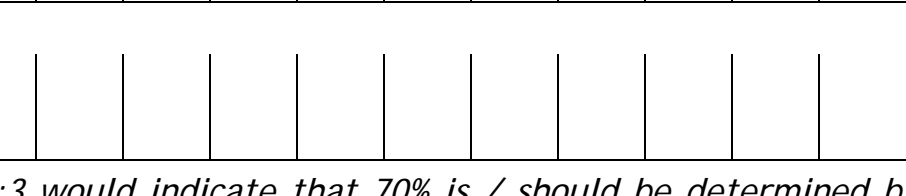

\section{Determined by the European Commission \\ OPTIMAL}

Determined by the European Commission

(Example: the mix of $7: 3$ would indicate that $70 \%$ is / should be determined by Member

States and $30 \%$ by the EC) 
13. In the planning of operational programmes should operations be concentrated on a limited number of areas or should they ensure broad coverage of policy areas?

\begin{tabular}{|c|c|c|c|c|c|c|c|c|c|c|}
\hline Concentrated & & & & & $\begin{array}{c}\text { Neither } \\
\text { concentrated } \\
\text { nor broad }\end{array}$ & & & & & $\begin{array}{c}\text { Broad } \\
\text { coverage }\end{array}$ \\
\hline 0 & 1 & 2 & 3 & 4 & 5 & 6 & 7 & 8 & 9 & 10 \\
\hline
\end{tabular}

On the basis of which criteria, in your opinion, should operations be selected (on a scale between $\mathbf{0}$ - not relevant - and $\mathbf{1 0}$ - criteria should have a major)?

Priority fields as defined at the national / regional level: greatest expected impact

Priority fields as defined at the EU level

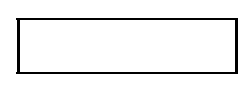

Catalytic effect (operations which would not have happened without the support of the EU funds)

Complementarity among operations (synergies)

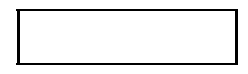

Other available sources of funding, especially EU

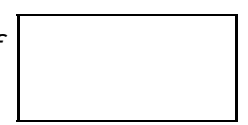

EU co-financing rates

Operations should have quick and predictable absorption capacity

Administrative costs of operations

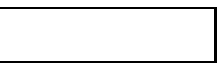

Operations should have measurable and visible results

Deadweight / displacement / substitution effects of operations
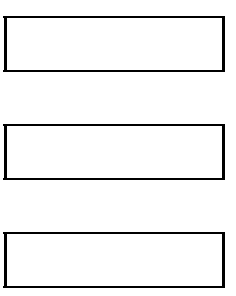

Positive externalities of operations

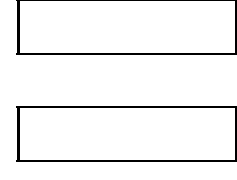

Other (please specify): 


\section{PROJ ECT GENERATION, APPRAISAL AND SELECTION}

14. To what extent is project selection performed on the national and how much on the regional / local level? And what is, in your opinion, the optimal balance?

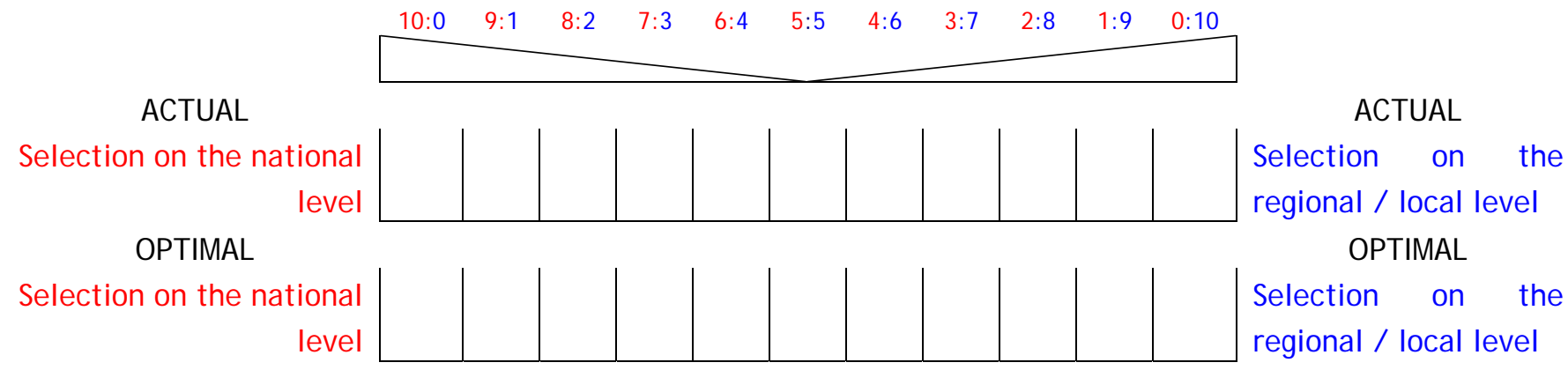

(Example: the mix of $7: 3$ would indicate that $70 \%$ is / should be selected on the national level and $30 \%$ by the regional / local level)

15. In your opinion, what kind of a call for projects delivers better results:

- open ones, which enable more innovative approaches by the applicants and give more flexibility to those appraising the projects or

- restricted ones, which define more precisely what exactly the administration wants and allow for a more formal appraisal?

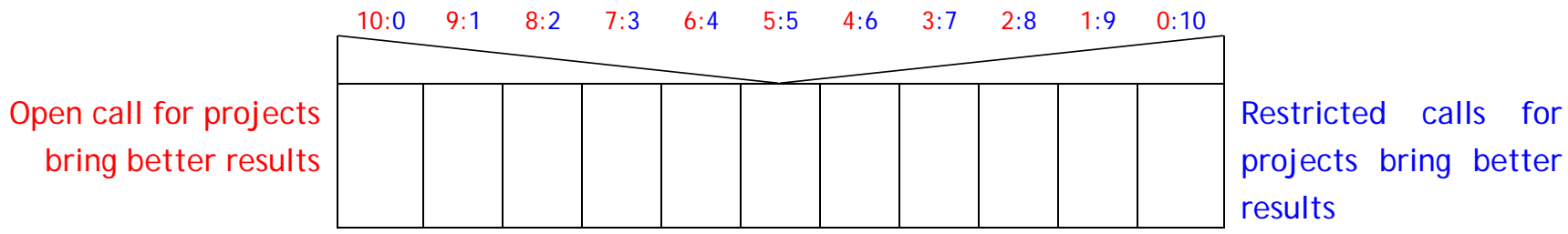

(Example: the mix of 7:3 would indicate that open calls tend to deliver better results in 7 out of 10 cases.)

16. What kind of project appraisal and selection, in your opinion, comes closest to selecting the best available projects (on a scale between $\mathbf{0}$ - "project quality is predominantly neglected" - and $\mathbf{1 0}$ - "project quality plays a decisive role"):

Government (national, regional) decision

Decision by the managing authority/intermediate body (MA/IB) based on internal appraisal

Decision by the MA/IB based on recommendation from a multi-departmental selection committee

Decision by the MA/IB based on recommendation from a multi-departmental selection committee, which also includes external independent experts 
Decision by the MA/IB based on recommendation from a multi-departmental selection committee, which also includes external independent experts, including foreign ones

To what extent does European Commission's project approval (major projects) contribute to selected projects' quality (on a scale between $\mathbf{0}$ - "not at all" - and 10 - "significantly")

17. In your experience, what is the time scale for getting from a project idea to the start of the project implementation in case of (in months):

Major infrastructure project

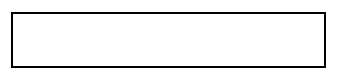

Smaller infrastructure project

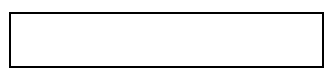

Productive investment project

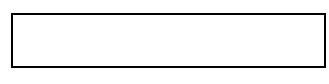

Human resources project

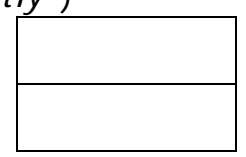

18. Is there enough qualified firms in the market providing services for the preparation of project applications, project management and project documentation (on a scale between $\mathbf{0}$ - "the market is seriously underdeveloped" and $\mathbf{1 0}$ - "the market is able to provide all the services")?

\section{IMPLEMENTING STRUCTURE, FINANCIAL MANAGEMENT AND CONTROLS}

19. Would you support the notion that above the responsible line-ministries (either in the function of managing authorities or intermediate bodies) there should be an overall coordinating institution, which could block the line ministries' decisions?

\begin{tabular}{|c|c|c|c|c|c|c|c|c|c|c|}
\hline $\begin{array}{l}\text { No coordinating } \\
\text { institutution } \\
\text { needed: } \\
\text { Ministries } \\
\text { should have } \\
\text { total } \\
\text { responsibility }\end{array}$ & & & & & $\begin{array}{c}\text { Some } \\
\text { coordinating } \\
\text { institutution is } \\
\text { needed: for } \\
\text { advice, } \\
\text { procedures, } \\
\text { best practice }\end{array}$ & & & & & $\begin{array}{c}\text { Strong } \\
\text { coordination. } \\
\text { institutution } \\
\text { with veto } \\
\text { right is } \\
\text { needed }\end{array}$ \\
\hline 0 & 1 & 2 & 3 & 4 & 5 & 6 & 7 & 8 & 9 & 10 \\
\hline
\end{tabular}


20. In the framework of a particular operational programme, what type of approach would you consider as more efficient:

- concentrated with a smaller number of intermediate bodies and implementing agencies or

- d-econcentrated with a larger number of intermediate bodies and implementing agencies

Concentrated

\begin{tabular}{|c|c|c|c|c|c|c|c|c|c|c|}
\hline $10: 0$ & $9: 1$ & $8: 2$ & $7: 3$ & $6: 4$ & $5: 5$ & $4: 6$ & $3: 7$ & $2: 8$ & $1: 9$ & $0: 10$ \\
\hline & & & & & & & & & & \\
\hline & & & & & & & & & & \\
\hline
\end{tabular}

De-concentrated

(Example: the mix of $7: 3$ would indicate that in your opinion concentrated OP implementation tends to be more efficient in 7 out of 10 cases.)

21. Do you support the notion that public authorities should outsource the implementation to (on a scale between $\mathbf{0}$ - not at all - and $\mathbf{1 0}$ - totally):

Specialised public bodies

Private sector

22. How would you describe the Cohesion policy management systems in terms of controls required on different levels?

\begin{tabular}{|c|c|c|c|c|c|c|c|c|c|c|}
\hline $\begin{array}{c}\text { System is } \\
\text { under- } \\
\text { controlled }\end{array}$ & \multicolumn{9}{|c|}{$\begin{array}{c}\text { System is } \\
\text { Sppropriately } \\
\text { controlled }\end{array}$} & \multicolumn{9}{|c|}{$\begin{array}{c}\text { System is } \\
\text { over- } \\
\text { controlled }\end{array}$} \\
\hline 0 & 1 & 2 & 3 & 4 & 5 & 6 & 7 & 8 & 9 & 10 \\
\hline & & & & & & & & & & \\
\hline
\end{tabular}

On what level is it under-controlled (you can " $X$ " more then one):

EU

National

Regional / Local
On what level is it over-controlled (you can "X" more then one)::

EU

National

Regional / Local

\begin{tabular}{|l|}
\hline \\
\hline
\end{tabular}

23. To what extent do "time management problems" in project approval and implementation phases represent a problem (on a scale between $\mathbf{0}$ - "not at all" and $\mathbf{1 0}$ - "very serious problems"):

What would you say are the main reasons for this (mark each criterion on a scale between $\mathbf{0}$ - not at all - and $\mathbf{1 0}$ - major importance):

Inexperienced public administration

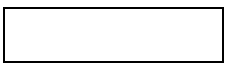

Public administration has the experience, but is inefficient in itself (low motivation) 
Unclear procedures and rules

Inability of decision makers to decide

Long administrative procedures due to EU requirements

Long internal administrative procedures due to national requirements (permits)

Overly complex interdepartmental / inter-institutional coordination requirements

Lobbying of the pressure groups

Budgetary procedures and provisions

Legal complaints

Other (please specify):

24. To what extent are, in your opinion, the administrative procedures for the absorption of funds related to EU / national legislation?

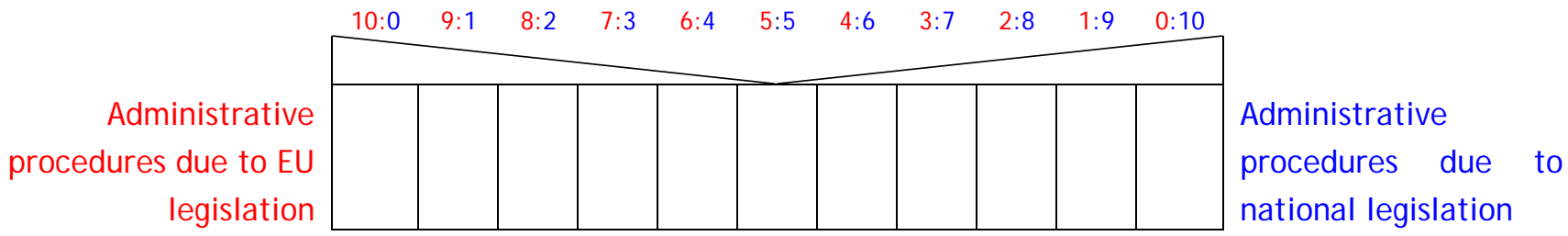

(Example: the mix of 7:3 would indicate that administrative procedures are $70 \%$ due to EU and $30 \%$ due to national legislation)

25. What is, in your opinion, still an acceptable level of (expressed as $\%$ of available resources):

Management costs in the public administration implementing the Cohesion policy? (as \% of programme resources)

Administration costs for the project holder (admin. costs at the project level for the recipient - as \% of project value)
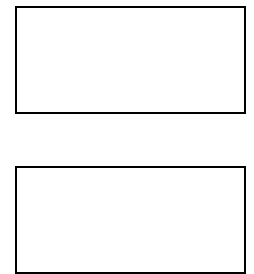


\section{MONITORING AND EVALUATION}

26. In which phases does involvement of partners bring the highest value added partnership principle (mark each phase on a scale of $\mathbf{0}$ - no value added - to $\mathbf{1 0}$ greatest value added)?

Planning of operational programmes

Definition of administrative procedures

Strategic monitoring

Definition of implementing provisions (calls for projects)

Regular, operational monitoring

Evaluation

27. In your opinion, how much of the Cohesion policy impact is determined by the quality/ appropriateness of the operational programmes and how much by the more detailed provisions defined in the implementing provisions and structures (call for projects, administrative procedures...)?

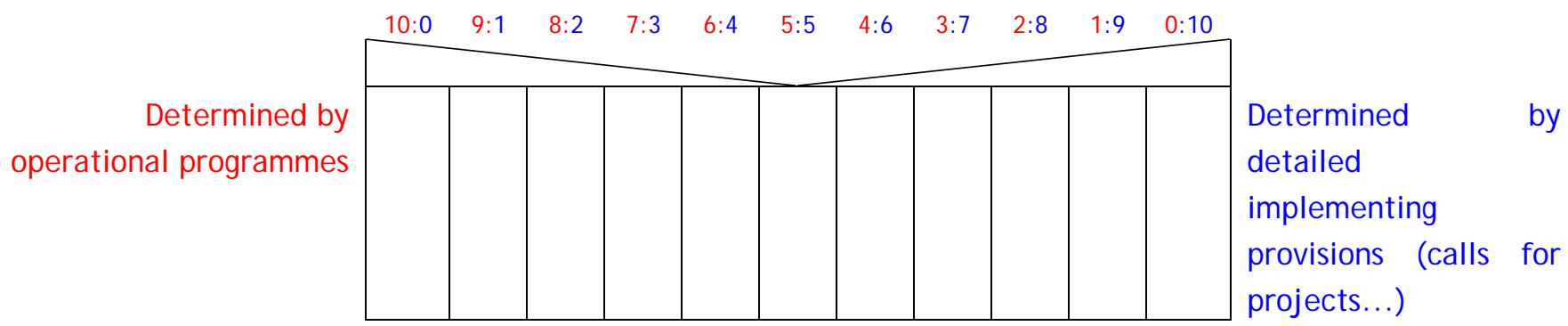

(Example: the mix of $7: 3$ would indicate that $70 \%$ of the impact is due to the quality/ appropriateness of the OPs and $30 \%$ due to detailed implementing provision) 


\section{RESPONDENT PROFILE}

\section{Country:}

\section{Type of institution you are working in:}

European Commission

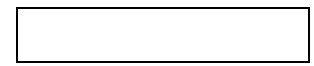

Managing / Paying / Certifying / Audit Authority

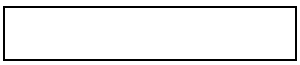

Ministry / intermediate body

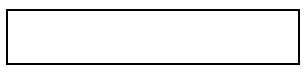

Implementing body / agency at national level

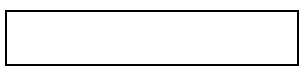

Implementing body / agency at regional/local level including regional branch of national institutions

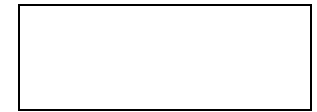

Other (experts, private service providers, research...)

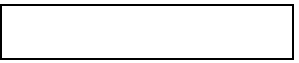

\section{Work experience in Cohesion policy (years): :}

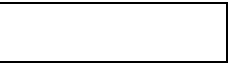

\section{Position:}

Majority of my work is of strategic and / or management type (senior level)

Majority of my work is focused on operational issues
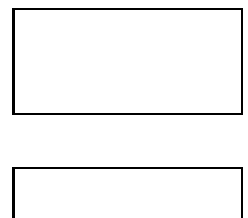

Age:

\section{Gender:}

Male

Female

\section{Education:}

Less than 12 years

High school

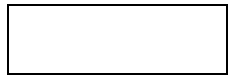

University/ College 
Postgraduate degree

Doctorate

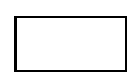

Name (optional):

Institution (optional):

Function (optional):

\section{Thank you very much for your contribution.}

